\title{
Knowledge and Diplomacy
}

Ed. Jovan Kurbalija

Prepared by

Academic Training Institute 


\section{About this Publication}

Knowledge and Diplomacy is a collection of papers addressing the topic of knowledge and diplomacy from a variety of perspectives. Most of the papers were presented at the

Conference on Knowledge and Diplomacy which took place in Malta in January, 1999.

The publication is available in two formats: online, and print. In order to access the online version you need to register with us (diplo@diplomacy.edu). We will provide you with a username and password, and then you can access the website at http://www.diplomacy.edu/Books/knowledge

To order the print volume, please fill in the web-based order form available at http://www.diplomacy.edu/Books/Order Forms

Or contact:

\section{DiploProjects}

Mediterranean Academy of Diplomatic Studies

University of Malta

Msida, Malta

Tel: $+356-3290-2820$

Fax: + 356-21-483091

E-mail: diplobooks@diplomacy.edu 


\section{Contributors}

JOVAN KURBALIJA is Director of DiploProjects, and lectures on diplomacy at the Mediterranean Academy of Diplomatic Studies, Malta. He has academic and professional background in diplomacy, international law and computer science. Along with academic research, Kurbalija has developed many applications in the field of diplomacy (knowledge management systems, databases, online learning courses, etc.). His major research interests focus on a multidisciplinary study of the influence of information technology on diplomacy and international relations.

Ambassador WALTER FUST is Head of the Swiss Agency for Development and Cooperation (SDC), a branch of the Swiss Ministry of Foreign Affairs. The Swiss Agency for Development and Cooperation is responsible for humanitarian aid and relief, the Swiss Corps of Disaster Relief, and bilateral and multilateral development cooperation programs. Fust has widely varied experience in international relations, having served both in the Swiss diplomatic service and in private industry.

Professor RICHARD FALK is the Albert B. Milbank Professor of International Law and Practice at Princeton University. He has lectured as a guest at a number of universities, including the University of Stockholm, the Mediterranean Academy of Diplomatic Studies in Malta and the Institute of International Relations in Vietnam. Falk is the author of numerous books and articles on globalisation, international relations, international law, conflict, and human rights, among other topics. His most recent book, Predatory Globalization: A Critique, has just been published by Polity Press in the UK. Falk currently serves as an advisory member for a great variety of American and international committees and organisations.

COLIN JENNINGS has served as Director of Wilton Park, an academically independent agency of the British Foreign and Commonwealth Office (FCO), since 1996. He worked for the UK Ministry of Defence from 1976 to 1983, primarily on NATO conventional and nuclear weapons defence policy. Jennings transferred to the Foreign and Commonwealth Office in 1983, working in Policy Planning Staff on security policy issues and the Americas, and eventually serving in Lagos and Cyprus.

Dr. KEITH HAMILTON is Historian in the Foreign and Commonwealth Office and Senior Editor of Documents on British Policy Overseas. His publications include Bertie Thame: Edwardian Ambassador (Royal Historical Society: Woodbridge, 1990) and (with Richard Langhorne) The Practice of Diplomacy: Its Evolution, Theory and Administration (London: Routledge, 1994). He is currently Honorary Visiting Fellow in the University of Leicester's Centre for the Study of Diplomacy.

J. THOMAS CONVERSE has served as the Chief of the Records Management Section of the Inter-American Development Bank since 1993. His experience as an archivist began with his work, from 1979 to 1985, at the State Archives of Kentucky, following completion of an M.A. in Library Sciences at the University of Kentucky. In 1985 Converse joined the Foreign Service of the U. S. Department of State, serving in Guatemala, Spain and Nicaragua. In 1991 he resigned his commission in the Foreign Service to return to the United States as Head of the Library of the U.S. National Archives.

Professor ROBIN ALSTON served as the Chair of Library Studies at London University from 1990 to 1998, teaching and guiding research in librarianship at University College, and since 1994 at the Centre for English Studies in the School of Advanced Study, where he started the first postgraduate MA degree in book history. Before this, Alston was involved in a British Library undertaking of cataloguing all of the books printed in Britain and her dependant territories during the $18^{\text {th }}$ century. Alston has also taught English Literature at Leeds University, and has initiated innovative projects in the printing of classic texts for the study of English literature and history, and art lithography. 
Dr. JOHN PACE is an international civil servant of long standing in the United Nations. He served as Secretary to the Commission on Human Rights from 1978 to 1994, and was the Coordinator of the World Conference on Human Rights (Vienna 1993). He has headed Special Procedures and Technical Cooperation programmes and has led fact-finding missions for the Commission in several countries. He is currently the head of the Research and Right to Development Branch in the United Nations Office of the High Commissioner for Human Rights.

Dr. JOHN HARPER is a consultant in manpower planning and human resource development with worldwide experience in both developed and developing economies. A Visiting Professor in International Management at the American University in Cairo, he has worked in both public and private sectors, dealing with the variety of HR situations arising in each of these environments. He is currently Director of Studies at the Malta Chamber of Commerce.

JENNIFER CASSINGENA HARPER is the International Relations Officer of the Malta Council for Science and Technology, responsible for coordinating international relations in science and technology. She read international relations at Keele University and carried out her postgraduate studies at the London School for Economic and Political Sciences. She is currently completing her doctoral research at the University of Malta on the theme "The Internationalisation of S\&T Policy: Malta Case Study 1988-1996."

Professor DIETRICH KAPPELER served as Director of the Diplomatic Studies Program of the Graduate Institute of International Studies in Geneva from 1993 to 1998. He was the founding Director of the Mediterranean Academy of Diplomatic Studies at the University of Malta, 1990-1993. Kappeler has extensive experience in diplomacy and international relations, and lectures and writes on International Law, Diplomatic and Consular Law, Law of International Institutions, Human Rights and Humanitarian Law, Diplomacy, and Constitutional and Administrative Law of Switzerland.

Dr. ALEX SCEBERRAS TRIGONA has been organizing courses simulating international negotiations-bilateral and multilateral—at the Mediterranean Academy of Diplomatic Studies, University of Malta, since 1991. Dr. Trigona served as Malta's Minister of Foreign Affairs from 1981-1987. He negotiated Malta's Neutrality Agreements. He lobbied for, won and managed Malta's first ever seat on the United Nations Security Council for 1983-1984. His Law Doctorate was awarded on the basis of a seminal thesis "Constitutional Change and the Maltese Constitution." Fundamental constitutional changes in 1974 followed this thesis in both manner and substance. His thesis as a Rhodes Scholar at the University of Oxford on "The Anglo-Maltese Crisis 1971-1972" innovatively used a rigorous multi-disciplinary approach to international relations employing legal, political, strategic, and economic analyses of international disputes.

GAETAN NAUDI was appointed Malta's Ambassador to Egypt in April 1999. Naudi entered Malta's civil service in 1964 and progressed through a variety of administrative and managerial roles, assuming responsibility for activities mainly in the fields of financial management, human resource administration and internal audit. From 1990 to 1993 Naudi served as Manager of the Finance and Administration Division in the Management Systems Unit (now MITTS), and was the Secretary of the Board of Directors. In 1993 Naudi became Director of Corporate Services in the Maltese Ministry of Foreign Affairs, and has promoted and actively participated in the computerisation and ICT projects of the ministry.

DRAZAN PEHAR currently works in Sarajevo at the Office of the High Representative to Bosnia and Herzegovina as media analyst. He served as Chief of Staff to the President of the Federation of Bosnia and Herzegovina in 1996, and took part in the final series of 1996 negotiations on establishment of the Federation institutions. Pehar acquired a Masters of Diplomacy from the Mediterranean Academy of Diplomatic Studies in Malta in 1997 with summa cum laude. His theoretical interest is primarily in creative uses of language (metaphors, ambiguities, politeness figures, historical analogies) focusing on international politics, diplomacy, and conflict research. 


\section{PREFACE}

\section{Jovan Kurbalija}

Knowledge management is a new concept in the business sector. Recognising the importance of knowledge as a key resource, many companies have started implementing knowledge management policies. Knowledge is even more central in diplomacy than in the business sector. Diplomats operate in a highly fluctuating and flexible environment both on the international and local scene. Lacking clearly definable structures and a predictable operational context, diplomats rely on knowledge in all its variety as their ultimate resource.

While the importance of knowledge can easily be observed, it is difficult to describe let alone analyse the influence of knowledge in diplomacy. Through the activities associated with our DiploKnowledge project, we have investigated the role of knowledge in diplomacy in several ways: through research, publications, software development and training courses. The following have been our main areas of focus in the last few years:

a. Academic research initiated several years ago led to the first International Conference on Knowledge and Diplomacy, held in Malta (29 - 31 January, 1999). The conference gathered leading scholars and practitioners from various areas who contributed expertise from their particular fields towards building the initial mosaic of the concept of knowledge management in diplomacy. Most of the papers in this publication were presented at the conference.

b. Software development complements our academic research. By developing and testing practical tools we are in the optimal position to verify our research: an effective way to merge theory and practice, keeping in mind that practice should determine the validity of theory. The latest application developed in this process is the knowledge and information management system "DiploWizard".

c. As important aspect of our project is training. In this field we have tried to introduce knowledge management through extending our training to the transfer not only of the explicit (formalized) knowledge contained in books but also tacit knowledge based on experience and intuition. Tacit knowledge is often crucial for the success of diplomatic activities. Some of our online learning applications such as DiploAnayltica, a module for the dissection of diplomatic documents, are designed to facilitate the transfer of tacit knowledge.

The innovative contributions presented in this book should provide impetus for the continuous development of knowledge management in all three of the above mentioned directions. The variety of backgrounds, academic interests and orientations represented by the authors of the various papers in this book accurately reflects the multidisciplinary character of knowledge management.

The book covers a wide range of topics, beginning with a general introduction to the concept of knowledge management by Jovan Kurbalija. Ambassador Walter Fust focuses on the support knowledge management offers to development programs, and the interplay between development and diplomacy. Professor Richard Falk provides a general approach to the influence of IT, including knowledge, on international relations.

After this general introduction, Colin Jennings, Director of Wilton Park, contributes with a description of how the knowledge management institution Wilton Park provides a framework for the exchange of knowledge on international relations and diplomacy. Dr. Keith Hamilton's paper highlights the importance of institutional memory of diplomatic services for diplomatic activities. Along the same lines of discussion, J. Thomas Converse addresses the question of archives in the modern age. The part of our book dealing with organisational memory concludes with Professor Robin Alston's paper on libraries and preserving memory of institutions. 
The next section of the volume is dedicated to practical examples of knowledge management in international organisations. Dr. John Pace provides an interesting case study of knowledge management in the UN High Commission for Human Rights. This is followed by a paper by Dr. John Harper and Jennifer Cassingena Harper on knowledge management in international organisations.

The educational section starts with Professor Dietrich Kappeler's paper on diplomatic training and knowledge management. Next is Dr. Alex Sceberras Trigona's contribution on a practical method of diplomatic training: the dissection of diplomatic documents.

Ambassador Gaetan Naudi describes the experiences of the Maltese Ministry of Foreign Affairs in the field of development of information systems, with special emphasis on knowledge management.

The final contribution is a paper written by Drazen Pehar on language use in international relations. We feel that language is one of the key elements for future research in knowledge management and diplomacy; our upcoming activities will therefore focus on the language of diplomacy and diplomatic documents.

The volume ends with a short note by Ivo Andric, which we came across during our research activities. It is a refreshing, although realistic and at time cynical, reflection on diplomacy and the role of diplomats provided by an author who spent part of his life in diplomatic services. We hope that this paper will encourage further research on writers in diplomacy and their reflections about diplomatic work. Special appreciation goes to the Andric Foundation for giving us permission to translate and publish Andric's note on diplomacy.

This volume would not have been possible without the team work and dedication of the members of the DiploTeam. In particular, Hannah Slavik contributed throughout the production, helping with organising the conference, transcribing several articles, taking care of linguistic preparation, and finally, supervising production of the book. Dalibor Milenkovic contributed through transcribing and preparing two articles; those of Professor Alston and Ambassador Naudi. Special thanks go to the Swiss Agency for Development and Cooperation for their support of DiploProjects in general and the publication of this book in particular. 


\title{
KNOWLEDGE MANAGEMENT AND DIPLOMACY
}

\author{
Jovan Kurbalija
}

Diplomats need to know a certain amount, but there should be no trace of erudition or pedantry in what they know, and their knowledge should agreeably surprise and perhaps impress those with whom they are speaking, but never embarrass, offend or shame them.

Ivo Andric, Nobel Prize Laureate for Literature (1961)

With the end of the cold war, the high level of certainty and predictability in international and national decision-making environments has been replaced with dynamic international relations and constant fluctuation. Multipolarity, combined with globalisation and increased radical national and religious movements, has made the international world very unstable. As a result, the "diplomatic kaleidoscope" has been changing very fast. Diplomats are often called upon to deal with situations for which they cannot prepare in advance, for which they cannot find instructions in diplomatic manuals.

Knowledge - a combination of information, training, experience and intuition-is what enables a diplomat to act appropriately in unpredictable situations. The knowledge used in diplomacy appears in a variety of forms, starting from the general knowledge gathered in the course of regular education, knowledge of particular subjects such as international relations and international law gathered through specialised diplomatic training, and ranging to knowledge gained through experience, such as knowledge of regions, tacit knowledge of how to react in particular situations, and knowledge of procedures.

A diplomat's use and need of knowledge seems in many ways obvious, but proves difficult to explain and define. In this paper we aim to provide a comprehensive introduction to the topic of knowledge management in diplomacy. First we provide working definitions of knowledge and knowledge management, and examine the evolution of the concepts. Next, we consider specific features of diplomacy that affect and limit the way knowledge management can be implemented. Then we look at specific techniques which diplomacy can adapt from the business sector in the field of knowledge management. Finally, we consider some important questions related to human resources and knowledge management.

\section{KNOWLEDGE MANAGEMENT—CONCEPT AND BASIC TERMINOLOGY}

Every new discipline develops specific terminology both by introducing new terms and assigning new uses to existing terms. Early phases are usually characterised by terminological confusion, especially in fields which are multidisciplinary. Knowledge management is such a discipline, drawing from a variety of sources: management theory, economics, psychology, information technology, etc. While everybody recognises the importance of knowledge and knowledge management, few can define them even in vague terms. 


\section{What is knowledge?}

Philosophers throughout history have addressed this question, arriving at a variety of answers. Our modest attempt will not claim philosophical pretensions, however, we will try to provide elements for a definition of knowledge as it is used in the framework of knowledge management.

First, we must define two relevant terms from the field of information technology: data and information. ${ }^{1}$ Data is a record of a particular event. Information is data which has acquired additional meaning: a message beyond simple semantic meaning. ${ }^{2}$

An example from diplomatic practice may make this distinction more clear. We can consider the fact that "Ambassador A met Ambassador B" to be data. It is a fact-a diplomatic event. As salesmen sell things and waiters serve food to people, diplomats meet and discuss. If we add to this the statement that "Ambassador $A$ and $B$ met agreed to conclude a visa agreement" we have information. Information carries some additional meaning and message beyond the simple statement of fact presented in data.

If we interpret this information and consider it from various perspectives (e.g. Ambassador A's country needs to improve relations with the other country; country B is under pressure from regional institutions to conclude this agreement, etc.) we are creating knowledge. Davenport and Prusak provide the most comprehensive definition of knowledge in the field of knowledge management: "Knowledge is a fluid mix of framed experience, values, contextual information, and expert insight that provides framework for evaluating and incorporating new experiences and information. It originates and is applied in the minds of knowers. In organzations, it often becomes embedded not only in documents or repositories but also in organizational routines, processes, practices, and norms. ${ }^{3}$ In diplomacy probably more than in business sector knowledge is both a basis and a product of the thinking process. In order to analyse we need knowledge and through analysis we produce knowledge.

\section{What is knowledge management?}

Knowledge management is not about the automation of the thinking process but about the use of technology to assist the normal thinking process. ${ }^{4}$ Peter Murray and Andrew Myers from of the Cranfield School of Management define knowledge management as "the collection of processes that govern the creation, dissemination, and utilization of knowledge to fulfil organizational objectives."

An important first element of knowledge management is the introduction of intelligent access to information. Information is increasingly available and the key question is becoming how to use it in order to gain value-added elements. For example, today you can find much information about international conventions including texts, information about signature and ratification, etc. The general availability of this information is a necessary but not sufficient condition for it to be fully utilized. The data that a convention was signed by Malta is useful and may serve a specific, limited purpose. But often one needs to approach information in a broader context. For example, one may need to know all conventions ratified by Malta but not by member states of the European Union. Such information can provide useful input for further diplomatic and political activities. New techniques such as data-mining allow this type of advanced access to information.

A second element of knowledge management is automation of procedures through the use of workflow. Workflow can be defined as the series of tasks or steps used by an organization in order to produce a final result. The increased capacities of IT have provided an opportunity to shift some business and administrative processes from traditional methods to IT-based procedures. Workflow is usually based on following the movement of documents in the decision-making process. Besides improvements based on automation, workflow 
activities allow us to re-examine the question of organisation of activities. The introduction of automation usually provides an opportunity to discuss the question of preservation of institutional memory stored in working procedures and activities. Although workflow is ITbased and IT-related, it may have some side-effects not directly linked to IT, such as demonstrating the need for restructuring of diplomatic services.

Another aspect of knowledge management is the automation of routine activities. While it is not possible to replace human intelligence, it is possible to automate many activities if they can be logically described. A major division in cognitive science is between those who think that all human problems can be reduced to logical algorithms and thus simulated by machines and those who think that human intelligence is too complex to be reduced to a description of the way humans solve particular problems. However, both sides agree that it is possible to automate routine activities. In diplomatic services routine activities are those related to consular and administrative activities. For example, the process of issuing visas, passports and other documents can be automated to a large extent through IT.

A final element of knowledge management is the recognition and appreciation of knowledge as an institutional resource. Knowledge can be identified both as the knowledge employees bring with them to their work, and the knowledge generated through the activities of an institution. Diplomatic services have to recognise data, information and knowledge as their primary resources. Often these are rhetorically acknowledged as a primary resource of diplomatic services, but when it comes to day-to-day and organisational issues, this is not the case. Sometimes, paradoxically, a piece of furniture has a higher declared financial value than top expertise in internal organisation and accounting. Such a situation can lead to enormous institutional and political losses. Once data, information and knowledge are recognised as the key resources of diplomatic services, most knowledge management improvements will be obvious and they will come as common sense solutions.

\section{Evolution of knowledge management}

Although knowledge management has been recently "re-discovered" by the business community, the attempt to understand knowledge is as old as civilisation and has always been a central theme of philosophy. Epistemology and logic are the two key knowledgerelated disciplines that developed in ancient philosophy. Epistemology discusses the nature, structure and origins of knowledge, while logic analyses the validity of reasoning.

Plato and Aristotle laid the foundations of epistemology. The fundaments were further developed after the reformation within the framework of rationalism. Cogito, ergo sum became the key slogan of the rationalist approach. The approach centred around knowledge, human thinking and a supposedly rational reflection on society. The line of inquiry into epistemology was continued through the work of Kant and Hegel, and towards modern times, by the German philosopher Edmund Husserl, founder of phenomenology, Martin Heidegger, Jean-Paul Sartre and others. Cognitive science developed through a combination of traditional epistemology with linguistics, computer science and neuroscience. The key focus of cognitive science is on the human mind and thinking processes, including knowledge as a result of these processes. ${ }^{6}$

As the power and potential of tools and techniques for information management grew, the idea of managing not only information but also knowledge emerged. Stronger computational power led towards an attempt to create artificial intelligence. Attempts to develop computer programmes to simulate human thinking processes failed in the 1970s, as a result of unrealistic expectations. The failure discouraged further research in the area. Only recently, with the increased popularity of the idea of knowledge management, have researchers begun developing IT to assist with some mental processes and activities. Now, although the concept of knowledge management was introduced as a pragmatic tool, it has become one of the hype business concepts, similar to re-engineering, outsourcing, etc. 
Another area where knowledge management has been adopted is economic and management theory. Interest in knowledge as an economic factor has grown with the structural changes in modern economy characterised by the increasing importance of the service sector. However, traditional economics has had difficulties integrating knowledge into its models. Penrose, who developed the economic theory of the firm, describes the reluctance of economists in the following way: "Economists have, of course, always recognized the dominant role that increasing knowledge plays in economic processes but have, for the most part, found that the whole subject of knowledge too slippery to handle." ${ }^{7}$ American economist Alfred Marshall highlighted the importance of knowledge as an economic factor. ${ }^{8}$ In modern economics, one of the key proponents of the importance of knowledge as an economic factor is Paul Romer of Stanford University, who demonstrated that ideas and knowledge are key factors in economic growth. ${ }^{9}$

The importance of knowledge has been examined in more detail in business and management circles. Paul Drucker is considered the founding father of knowledge management. He introduced the basic terms that are used in this field, such as "knowledge work", "knowledge society", etc. Drucker argues that we are moving from an economy based on traditional resources (land, natural resources, land and capital) towards a new economy based on knowledge as a key economic resource. ${ }^{10}$ In the field of management, knowledge has acquired a central position in a variety of ways. Senge focuses on organisational learning; he sees learning as a key component of a company's success. Learning should be built in to the company structure in order to facilitate permanent growth. ${ }^{11}$ Prahalad and Hamel focus on the concept of "core competence". ${ }^{12}$ Schein focuses on the need to develop an organisational culture; the need to develop shared views in companies through shared experience. ${ }^{13}$

\section{IMPORTANT ASPECTS OF THE USE OF KNOWLEDGE MANAGEMENT IN DIPLOMACY}

\section{Business sector and diplomacy—similarities and differences}

Applying business logic to various areas of human life is a general tendency, usually aimed at increasing efficiency and reducing expenses - the mantras of the modern world. Government and academic sectors aim to increase their efficiency through borrowing techniques and methodologies from the business sector. Use of IT, downsizing, and re-engineering are some of the concepts that have been transferred from the business sector and with varying levels of success implemented in non-business areas.

Diplomatic services have been included in this process to some degree, but remain close to the end of the list of government sectors to embrace business logic. Diplomatic services were shielded by their special status, especially during the cold war. The priority of protection of national interests characterised by secrecy was a strong safeguard against discussion about efficiency and organisation of diplomatic services. In the last ten years the situation has changed dramatically. Diplomatic services have become more open to the public. This allowed the public to look behind the walls of diplomatic services and to discuss not only the question of foreign policy but also the process of conducting this policy. Diplomacy, like many other professions, has been faced with the question of what is "value for money". The most intensive debate has taken place in the UK, Canada, Australia and recently, in the United States. Various reform attempts inspired by experience and expertise from the business sector were introduced. Apart from their success, most of those reforms introduced the need for diplomatic services to be more business-like. The pendulum could even swing to the other extreme, making diplomatic services completely business-like.

For several reasons, however, there are limits to the application of expertise from the business sector in the diplomatic field. 
First, there is a difference in function. While companies are established in order to generate profit, diplomatic services promote national interests in particular, and maintain international order in general.

Second, companies have a strong feedback loop in the form of market and profit. This makes them constantly strive to increase efficiency. Diplomatic services usually lack this feedback loop. Not only the fact that diplomatic services have exclusivity in official representation of the country, but also the specificity of diplomatic work, makes diplomacy difficult to effectively evaluate. Moreover, the complex environment in which diplomatic services operate renders any attempt to measure efficiency almost impossible. ${ }^{12}$

Third, processes in the business sector are organised in order to achieve some quantifiable result at the end (profit). Processes in diplomacy are not simple instruments to an end, but have importance in themselves. Sometimes the diplomatic solution to a problem lies in the process. Currently, in international affairs we have three on-going processes (North Ireland, Dayton and Middle East) and at least one in the making (Kosovo Peace Process).

Fourth, time has a different meaning in business and in diplomacy. While in the business sector the guiding principle is to do more in less time, in diplomatic services the equation is more complex. Often it is necessary to have some delay between message and response. Sometimes the time factor is an important element of diplomatic signalling. Delays in response, the channels through which a response is sent, etc., are all part of diplomatic signalling.

These major differences between the business sector and diplomacy influence the application of knowledge management in diplomacy. In the business sector knowledge has instrumental value which is directly applied to particular circumstances (management campaigns, interaction with customers, etc.). In diplomacy, knowledge has a more general importance. It is the basis of organisation and is more often used indirectly, for reacting to new situations, than directly, to deal with expected situations.

\section{Specific features of diplomacy that could influence knowledge management projects}

The nature of diplomacy and diplomatic processes naturally influences the type and degree of IT related knowledge management projects appropriate for diplomatic services. Diplomacy is a "human-intensive" activity; it is conducted largely through personal communication and individual actions, evaluations and decisions. Therefore, diplomacy cannot easily be represented through structural logical representation. It evades codification and rigid formulations. Diplomacy is based on intensive human communication at various layers of interaction. Day-to-day conveying of information and exchanging of messages is the first and obvious level of communication, and this is already often performed through IT communication tools. But communication has aspects other than the technical means of message conveyance. One of these aspects is intentionality: our ability to think about the perception another person has of us, or to go further, our ability to consider what other people think that we think about them, etc. Our social communication depends to a large extent on the level of intentionality that we can achieve: usually four to five levels. ${ }^{15}$ In traditional diplomacy the ability to envisage the reaction of the other side is crucial.

The requirements of diplomacy for spontaneous human involvement is usually presented as one of the key arguments for the limited possibilities of the use of IT in diplomacy. Without arguing that IT based communication is better or worse than face-to-face communication, we can think of certain situations where it may be a benefit if the "noise" of normal human communication is replaced with dry electronic communication. Last year, negotiation exercises conducted via the Internet demonstrated that in certain situations the simple conveyance of messages without the trappings of body-language, tacit communication, intentionality, etc. can be very effective in the process of achieving diplomatic breakthroughs. 


\section{Application of knowledge and information to the decision making process}

Diplomatic services operate through a constant process of decision making. Every day, a variety of decisions, from the routine to those which could determine the future of the country and decide questions of war or peace, are made. How can the wealth of information, preserved knowledge, and institutional memory accumulated by the diplomatic service be applied in the decision making process?

This is a key question, because practice in diplomatic services shows that often decisions are not a product of textbook style rational rules applied by rational decision-makers based on available facts, past decisions and expertise. On the contrary, decisions are often made through the specific interplay of rational elements, institutional memory, political influences, trade-offs on the international, national and institutional level, and last but not least, the influence of individuals.

The key for the success of knowledge management projects in diplomatic services will be the establishment of this link between recorded information and knowledge and the decisionmaking process.

The first step in making this link is to make information and knowledge readily available. The expertise is usually available in the services, but not accessible or acknowledged: often diplomatic services do not know what they know.

The second step is to make information and knowledge accessible not only in the technological sense (access to the computers, libraries), but also in the logical sense (possibility of pinpointing and selecting the most relevant information, i.e. data-mining).

The third, and likely most difficult, step is to base decisions on information and available knowledge. This is a very complex task, the success of which has serious limitations not only organizationally, but also in human nature. Knowledge management can make a difference by making information easily available to decision-makers. Ignoring knowledge and information is a decision in itself.

\section{PRACTICAL TECHNIQUES OF KNOWLEDGE MANAGEMENT IN DIPLOMACY}

\section{Information management}

One of the key arguments of the early "techno-optimists" was that diplomats would become obsolete because information would be easily accessible via the Internet. However, information gathering, one of diplomatic functions listed in the Vienna Convention, is not simply the collection of information, via the Internet or from any other source. Information gathering would be better referred to as information management: a broad process which starts with gathering data and ends by providing relevant information for decision-making processes. The changing context of information management in diplomacy was nicely summarised by Newt Gingrich in a speech at Georgetown University: "Now (there)'s a level of proliferation of data, of information unlike anything that the human race has ever known. And in that context, to suggest that we're going to have traditional ambassadors in traditional embassies reporting to a traditional desk at the State Department, funnelling information up through a traditional assistant secretary who will meet with a traditional secretary strikes me as unimaginable. And of course, in the real world, it no longer works that way." ${ }^{16}$

After data is gathered it must be transformed into relevant information, usually through one of the following three essential techniques: contextualisation, data-mining and condensing. These techniques are not new but they have taken on a completely new life with new technology. 
a. The first technique of information management is contextualisation. The enormous amounts of data available on the Internet have to be put into the proper context in order to be useful. This is the process of transforming data into relevant information. For example, the data that two ambassadors met does not mean much if this data is not put into the proper context. Context building involves answering questions such as: Why did they meet? Was it a regular meeting? Did they agree about something? How often do they meet? What could be the consequence of this meeting? Contextualisation requires special skills and knowledge which go beyond simple technological proficiency. Contextualisation has to be performed both on the spot (i.e. in the place and at the time of the event in questions) and in the ministry. Nothing can replace a diplomat on the spot who knows the complex social and cultural web and local circumstances that can help in interpreting particular data. After contextualisation on the local level is performed (in the particular country, mission or region) that information must be put into the broader context of the overall activities of the diplomatic service. A diplomat on the spot can provide proper local context but may not have the broader perspective of the overall diplomatic service. Therefore, contextualisation must also be applied on the level of the diplomatic service. For this activity, horizontal communication in diplomatic services needs to be enhanced, enabling easy access to data from various departments, missions abroad, etc.

What can knowledge management contribute in this respect? First, organisationally speaking, certain techniques and methods can help overcome the limitations of hierarchical organisation and enhance horizontal exchange whenever it is necessary. While preserving positive elements of hierarchy for stability of the institution, dynamics should be provided through various forms of problem-centred structures. Problem-centred structures provide smooth shifts in the perspectives from which particular problems are addressed. Nowadays, in our inter-connected world, any diplomatic event can be approached from a number of perspectives. Essentially bilateral data can have multilateral consequences and a wide variety of cultural, political and economic aspects. Thus, in a proper analysis, data should be evaluated from as many angles as possible.

Second, technically speaking, certain IT tools can ease the process of contextualisation. Besides databases which provide access to structural information, hypertext is a key tool for access to unstructured information. Contextualisation usually involves the management of unstructured information. For example, through hypertext tools, context could be built by linking a paragraph of text about the meeting between two ambassadors to another paragraph with a report about their previous meetings or cultural activities between the two countries. Sometimes a diplomat may want to add comments or annotations to a text. Hypertext allows the same information to be positioned in different contexts. Moreover, hypertext enables management of advanced interpretation features such as "reading between lines" or "small print": meaning that cannot be detected at first glance. The "DiploWizard" system developed by DiploProjects at the Mediterranean Academy of Diplomatic Studies includes practical tools which could be considered a first step towards the creation of intelligent hypertext tools for the contextualisation of diplomatic information.

b. A second important technique in information management for diplomats is datamining. Data-mining involves deriving useful information from vast amount of data using the processing power of computers. An example of data-mining techniques in diplomacy is the use of "voting patterns" in bilateral relations between the USA and other countries. The American diplomatic services gather and process voting data from the United Nations in order to learn about the voting patterns of particular countries which are of concern to the United States. The isolated data that a particular country voted for a proposed UN Security Council resolution gains new significance when it is seen as part of a series of similar data including the way that country voted in the past and the way various other countries voted. Thus, data- 
mining can derive very interesting information of possible use as the basis for further diplomatic activities out of otherwise unconnected data.

Although theoretically speaking it was possible to perform data-mining in the past (through manual searches of all records), data-mining is made easy with the increase of processing power and storage capacity of computers.

c. The third important technique for information management is condensation. We are currently inundated with enormous quantities of information. Thus, simply finding information is no longer the question, but now the key technique is to select relevant information, put it into context and present it in a concise form. Faced with proliferation of documents and materials, participants in international diplomatic life, both diplomatic services and international organisations, often find themselves concentrating on the means (documents) rather than on the real problems that should be addressed through those documents. The information glut is becoming unmanageable.

One organisational solution that could be introduced is to impose a limit that any problem or issue should be presented on a maximum of one or two pages. This solution could work in a paper-based world, but has a few serious limitations. First, reduction of complexity without reduction of meaning is one of the most demanding intellectual tasks. It requires a particular mixture of skills that may be difficult to find, such as logical thinking, ability to make abstract constructions, high literacy, etc. Moreover, even if one has those skills, reduction of a complex issue to a few pages may reduce the richness of information and deprive the user of one of the advantages that the Internet provides-access to vast amounts of information. The solution is to change the paradigm, though the use of hypertext, which provides an excellent advantage-the presentation of information in layers. A paper-based version of the presentation of information in layers is already in use in business reports which present first an executive summary, and after that more detailed considerations of the particular problems. With the hypertext approach, one can start with the first layer containing an "executive summary". The second layer would contain more detailed explanation. The next layer could contain academic perspectives on a particular problem. Following that, one could deal with the economic perspective, and so on. Even more importantly, the document itself could have annotated hypertext links to resources other than text. (Annotated hypertext links provide pointers to other documents with explanations of why those documents are relevant to the discussion.)

Parallel to the proliferation of information, one often hears nowadays that modern problems are too complex. This is not just an incidental observation by overwhelmed diplomats but a real development based on the fact that the modern world is becoming increasingly inter-connected. Many problems have perspectives and aspects that go far beyond traditional classifications of politics, economy, or society. How can diplomats deal with this? Often the first idea is to reduce complexity by simplifying things-an appealing solution, especially in politics. People like simple answers. Unfortunately, the historical track record of providing simple answers to complex questions is not very favourable. Generally speaking, simplification carries the potential difficulty of undermining elements that look unimportant at the time but which may, with the intensive developments in modern society, become more important later on. Hypertext provides another solution: it allows us to present an simple and short story while at the same time preserving complex data-structures necessary for a complete understanding of an issue or problem. 


\section{Diplomatic processes and knowledge management}

The functioning of diplomatic services can be explained in terms of processes. Any diplomatic service is involved in a variety of processes. Beside the type of processes which are themselves the object of diplomatic work (Northern Ireland Peace Process, Middle East Peace Process, etc.), numerous processes take place within diplomatic services. The key resource in these processes is information, which is contextualised through the process. But the value-added element that makes a process successful or not is the knowledge which is used to evaluate and make decisions. As already discussed, diplomatic processes are much broader than those in the business sector. In the business sector companies can customise processes to fit their stable and predictable interaction with an environment (selling, providing consultancy). In diplomacy, on the other hand, the operational environment both within a country and internationally fluctuates.

This fluctuation of environment limits the level of automation that can be applied and the type of knowledge management tools that can be used. A more detailed exploration of diplomatic processes shows that processes fit into three main groups:

a. Highly repetitive and routine processes are those which follow a clear sequence; each step is predictable. Most of these processes are related to consular activities such as issuing visas or passports. The steps involve filling out forms, asking other departments for recommendations, checking criminal records, issuing visas or passports, etc. These procedures could easily be translated into computer algorithms and facilitated through specially developed computer applications with limited need for human intervention.

b. The majority of diplomatic activities fall into the category of semi-repetitive tasks. Globalisation has intensified the process of development of international regimes in the field of environment, trade, human rights, etc. Based on international conventions, these regimes consist of machinery that organises regular meetings, processes documents, provides opinions, controls implementation of conventions, etc. These activities are carried out through more-or-less regular processes. Reports are prepared for specific periods of time; meetings of various committees are organised repeatedly in a more or less routine manner. The form is repetitive, while the content fluctuates, depending on developments in the field. Some areas such as traderegimes in the field of WTO have recently been more dynamic than others. Also in bilateral relations, activities are increasingly following certain patterns. Bilateral cooperation regimes established by bilateral conventions, for example, consist of regular meetings of mixed committees. Moreover, technical conventions in the field of double taxation, air-service transport, and investment are also established according to clear patterns. The repetitive aspects of these activities are ideal for automation. In addition, advanced knowledge management techniques can be designed to retain expertise developed in the framework of these activities, especially in the areas of high technical expertise (environment, trade, etc.).

c. The last group of activities associated with diplomacy are non-repetitive activities. These are the cream of diplomatic activities, consisting mainly of negotiation both on multilateral and bilateral levels aimed at solving international crises or bilateral problems, establishing new bilateral and multilateral regimes, etc. These processes require a lot of information and knowledge which cannot be codified into consistent logical structures. Advanced knowledge management tools can play a key role in non-repetitive activities, assisting in creative decision making, and even more importantly, in capturing knowledge and expertise developed through the process of making creative decisions. 


\section{KNOWLEDGE MANAGEMENT AND HUMAN RESOURCES}

Knowledge requires a specific type management. It cannot be managed in the same way as other resources, and it cannot be managed "separately from the people in whose heads it resides". ${ }^{17}$ The key for the success of knowledge management projects is their acceptance by the people who use them. More than in any other area of the use of technology, the rule that "humans make or break" applies to knowledge management. Following are some important aspects of knowledge management relating to human resources.

\section{Creating a knowledge culture}

One of the biggest challenges of knowledge management is the creation of a knowledge culture. People often fear and resist change. Without the appropriate culture among users, tools will not be effective regardless of their potential.

An initial problem with the introduction of IT is the fear people have of computer technology. At first people thought that computers could replace humans in the workplace. As each new level of technology is introduced people move from the initial fear and gradually come to accept, use and trust new systems. While computers have certainly not replaced people, they have changed work patterns greatly.

Knowledge is a source of power. Thus, it is often difficult to persuade people to share their knowledge to the benefit of others, whether it is in the business sector, international organisations, or ministries of foreign affairs. Many knowledge management tools are designed to store and make available the knowledge acquired by individuals through years of experience. Unless individuals are willing to share their knowledge these tools cannot be effective.

\section{Training and transferring knowledge-a continuous process}

Knowledge management offers great potential in the areas of knowledge transfer and training. It is important to keep in mind that diplomacy both uses and produces knowledge. Diplomats use knowledge in order to perform their function; simultaneously they produce new knowledge. In this sense, diplomacy is "knowledge perpetum mobile".

Diplomatic training should be positioned within this circle. Training facilities should be built into diplomatic services and activities. This would allow, on the one hand, the transfer of continually generated knowledge and experience into training. On the other hand, knowledge provided through on-demand training should be easily integrated into diplomatic processes. Academic training institutions for diplomatic studies will have a more complex task in this respect.

\section{Establishing the function of Diplomatic Knowledge and Information Officer (DKIO)}

This position which has proved effective in the business sector could be introduced into diplomatic services. The DKIO should focus and coordinate knowledge management activities. The ideal DKIO would be a diplomat with a broad general culture, a talent for managing human resources, high technological awareness, and eagerness to challenge traditional views. The position of DKIO should be high in the traditional organisation of diplomatic services, and this should be reflected in all aspects of personal status (salary, promotions, postings, etc.). 


\section{Retirement and knowledge management}

The departure of a leading expert in a particular field without codification of his or her expertise could mean a major financial loss (you may have to pay for expensive consultancy). The traditional approach, for example, often leads to a paradoxical situation whereby many ministries deprive themselves of expertise with a diplomat's retirement. In many cases diplomats do not accept retirement with great enthusiasm since diplomacy is a very specific job which involves a lot of personal commitment. Once out of that circle many diplomats feel lost. Therefore, knowledge management offers a potential "win-win" formula. On the one hand ministries of foreign affairs can preserve a valuable resource-the information and knowledge possessed by diplomats. On the other hand, retired diplomats can remain somewhat connected to diplomatic professional circles. Of course we cannot keep people forever in the service, but one can think about making a smooth transition towards retirement with some scheme that would enable utilisation of this resource even after retirement, for mutual benefit. Our DiploWizard system should facilitate one of those schemes through Knowledge Management Centre. The centre links junior diplomats and others in need of knowledge with retired diplomats: those who have knowledge, and more importantly, those who have the time and readiness to share their knowledge.

\section{Integrated human resource management}

The traditional perception of the hierarchical organization of a diplomatic service, consisting of headquarters and missions, should be gradually transformed towards a perception of a diplomatic service as an integrated system. The role of any participant in such a system, in the missions or at headquarters, should be decided by his/her potential contribution to a particular activity of the service rather than his/her hierarchical position.

Personal promotions in diplomatic services are governed by a variety of elements (need for service, personal and family preferences, emergencies, coincidences, etc.). This often leads to situations where, for example, you may find an expert on some multilateral issue working in a bilateral diplomatic mission. An expert on copyright, law of the sea, trade issues, etc. may end up, due to various reasons, in an embassy dealing exclusively with bilateral issues. Confining that person to deal exclusively with bilateral issues would be a loss both for the service (expertise) and for that person (personal, academic and professional interests). While technology (Internet, communication tools, etc.) now provides the facilities to integrate diplomatic services, organizational changes are necessary to enable integration. One possibility is "diplomatic time-sharing": a diplomat will have time allocated for various activities, regardless of physical location. For example, a specialist on the law of the sea sent to a bilateral mission may dedicate $20 \%$ of his/her time to consultancy on law of the sea.

\section{CONCLUSIONS}

The emergence of the concept of knowledge management in the business sector re-opens the old question of the role of knowledge in diplomacy. Diplomats have been reflecting on their working methodologies and the importance of knowledge since the early days of diplomacy.

The key condition for the successful implementation of knowledge management in diplomacy is the acceptance of the new techniques by diplomats themselves. In the end, knowledge management is intended to capture the knowledge and expertise which is carried by diplomats themselves. Thus any unwelcome or artificial imposition of knowledge management is a recipe for failure. The introduction of knowledge management must be carefully planned and implemented, with continuous adaptation based on the responses of diplomats. In order to succeed, knowledge management projects must address the specific features of diplomatic 
professional culture in which the possession of knowledge and information is jealously guarded.

Most diplomatic services, like other institutions, are not aware of the knowledge and information they possess. The first step in introducing knowledge management should therefore be to activate this knowledge. Although this task is primarily organizational, technology can help. This is an example of how technology can assist in addressing an issue that would previously been solved by traditional methods.

While knowledge management should be needs driven rather than technology driven, it is still important to follow developments in the technological field. These developments can stimulate new ideas and provide tools for solutions to traditional problems. Most of these tools will be adapted from the business sector, with full awareness of the above mentioned differences between diplomacy and business.

Knowledge management in diplomatic services should welcome involvement and input from the academic field. Academics address the question of knowledge from a different perspective which may have limited applicability for diplomatic activities. However, a merger of the two perspectives and approaches to knowledge-that of practitioners and that of academics - can stimulate new ideas and directions for growth.

Knowledge management will require a gradual but profound restructuring of diplomatic services and the way diplomatic activities are performed. Any grand design in this respect is doomed to failure. The process itself will determine the shape and characteristics of new knowledge-based structures for diplomatic services.

\section{NOTES}

${ }^{1}$ For more about the use of the terms data and information in the field of knowledge management consult T. Davenport and L. Prusak, Working Knowledge (Boston: Harvard Business School Press, 1998), 2.

${ }^{2}$ The term information was used by the founding fathers of information theory, Claude Shannon and Warren Weaver, as a technical term which does not carry any meaning. Technically speaking, it does not make a difference if a piece of information is loaded with meaning or if it contains pure nonsense.

${ }^{3}$ T. Davenport and L. Prusak, Working Knowledge (Boston: Harvard Business School Press, 1998), 3.

${ }^{4}$ Attempts to automate the thinking process typify artificial intelligence research from the 1960s and 70s. Researchers naively believed that with more computer power they would be able to simulate human thinking. The research raised high hopes and consequently proved highly disappointing when it could not deliver a machine to replace the human mind. The faulty element in this reasoning was not related to computing power, which has increased enormously, but the conceptual inconsistency based on the idea that the thinking process could be transformed into a set of computer algorithms. In the case of chess strategy such a transformation was possible due to the limited, although enormous, number of possible combinations. However, computers cannot simulate human consciousness. For more about the limitations of Al see: Hubert L. Dreyfus, What Computers Still Can't Do: A Critique of Artificial Reason (Cambridge, Massachusetts: MIT Press, 1992).

${ }^{5}$ http://www.info-strategy.com

${ }^{6}$ Neil A. Stillings, Cognitive Science: An Introduction (Cambridge, Massachusetts: Bradford, 1991). 
${ }^{7}$ E.T. Penrose, The Theory of the Growth of the Firm (Oxford: Basil Blackwell, 1959$), 77$.

${ }^{8}$ A. Marshall, Principles of Economics (London: McMillan, 1965), 115.

${ }^{9}$ Interview with Paul Romer for Strategy \& Business: http://www.strategybusiness.com/thoughtleaders/97110/page1.html.

${ }^{10}$ P. Drucker, Post-Capitalist Society (Oxford: Butterworth Heinemann, 1993), 7.

${ }^{11}$ For more information, see P.M. Senge, The Fifth Discipline: The Age and Practice of the Learning Organization (London: Century Business, 1990).

${ }^{12}$ C.K. Prahalad, and G. Hamel, "The Core Competence of the Corporation," Harvard Business Review (May-June 1990): 79-91.

${ }^{13}$ For more information, see E.H. Schein, Organizational Culture and Leadership (San Francisco: Jossey-Bass, 1985).

${ }^{14}$ Areas of diplomatic activities where efficiency can be measured are administrative and consular activities. Numbers of passports or visas issued are quantitative elements that could provide useful guidance for measuring efficiency.

${ }^{15}$ For more information about intentionality see: Daniel C. Dennett, The Intentional Stance (Cambridge, Massachusetts: Bradford, 1989).

${ }^{16}$ Speech by Newt Gingrich at Georgetown University, October 7, 1997, quoted in: Equipped for the Future: Managing U.S. Foreign Affairs in the $21^{\text {st }}$ Century, (Washington, D.C.: Henry L. Stimson Center, 1998)

17 "Knowledge Management, Encyclopaedia of the New Economy," Wired 6.03 (March 1998): supplement. 


\title{
KNOWLEDGE MANAGEMENT AND INTERNATIONAL DEVELOPMENT: THE ROLE OF DIPLOMACY
}

\author{
Walter Fust
}

I was asked to speak to you about knowledge management, knowledge and development, and the role of diplomacy. Combining these words caused me some difficulty! Nevertheless, I decided to organise my presentation into the following three parts: first I will give you some thoughts about knowledge management in general, then I will go to knowledge for development, and in the third part I will address the role of diplomacy.

\section{KNOWLEDGE MANAGEMENT}

When we talk about development, we always talk about resources. Two types of resources are usually recognised: renewable resources and non-renewable resources. However, we are convinced that there is a third resource, a resource that grows the more you use it, and that is knowledge. The very essence of international development cooperation is access to knowledge, sharing of knowledge, transfer of knowledge and use of knowledge.

This is why, about 4 years ago, we initiated discussion about knowledge within the World Bank, and, in 1997, we strongly supported their World Knowledge Conference. The reports our delegation brought back from the conference showed that what many people believe is not true: the technical part of knowledge-the technologies-is not the most essential. The most essential part is knowledge management: management of knowledge and management for knowledge. Information and communication technologies (ICT) involve a lot of issues, both for development cooperation and for the world: tele-education, tele-trade, tele-medicine, telebanking, video-conferencing, etc. But all of these are technical means. You have to provide the information. And information is, let's say, like the bridge to knowledge-the input for knowledge. I distinguish between management of knowledge - the collection and validation of information, establishment of necessary databases, and so on; and management for knowledge - the use of knowledge for productive means. And at the World Knowledge Conference we were all convinced that you use ICTs to aggregate information, to carry information, to validate knowledge, to use that knowledge for productive knowledge, and that productive knowledge should serve sustainable development.

Nowadays we-some international fora and of course national groups-are discussing some new trends. As I said, one of the outcomes of this conference clearly stated that the technical aspects of knowledge accounted for about $20 \%$ of the total importance, but $80 \%$ of the importance lies in how you manage knowledge and how you manage for knowledge in order to make use of it. Recently, in companies both national and international, knowledge management has become a kind of a new management understanding or theory. They no longer concentrate solely on capital productivity or on working force issues, but also on managing structural capital.

Personally, I am convinced that not only private, profit making companies need to manage structural capital, but equally foreign ministries and development cooperation agencies need to do so. This involves accounting for strategy, organisation and institutional culture, structures and systems, organisational routine, the experience of previous years and all the procedures. These organisations need to contain and retain knowledge, thus making it the property of the institution. As Thomas Stewart writes in Intellectual Capital: The New Wealth of Organisations, rapid knowledge sharing, collective knowledge growth, shortened lead times and more productive people are all reasons for managing structural capital. 
In order to start managing structural capital, in order to recognise what is the structural capital of your organisation, in our experience you must start with simple things. For example, the creation of databases: the use of technology to pull scattered information and wisdom together to convert it into institutional knowledge. Collecting information-stocking the databases, involves a certain financial investment in knowledge management technologies.

What kind of knowledge should be stocked? We started with the creation of a "yellow pages" system. This is a registry of who in our organisation has what experience and expertise, allowing us to validate and gain the maximum benefit from the experience and knowledge of our people. Then, for example, if we need to offer relief services for a disaster in Central America, we can easily see who knows the region very well, who has served there, who has some special knowledge about the cultural environment and who has mastered the Spanish language.

A second method of knowledge management we began four years ago was to create a culture of "lessons learned". We should not work or continue to work without taking the time to examine lessons learned over a certain period of time. In fact, lessons learned are a precondition, let's say, for a kind of evaluation before starting the next working phase. Lessons learned provide a kind of guiding line for many other activities. For example, we now recognise that we have to integrate "best practices" into our operations. Best practices cannot be generalised: you cannot equate best practices in one country or regions with best practices in another. In this area you can make use of knowledge about methods, results, and intercultural communication to determine best practices for particular projects in particular areas.

Knowledge management needs knowledge managers. Someone needs to develop ways to stock knowledge and to identify what knowledge we want to stock. This person will be occupied full time with collecting and organising information, collecting knowledge, sharing it, using it and managing it. Breakthrough new ideas need to be sought out and publicised as well as processed; lessons learned need to be documented and an institutional memory needs to be organised. Someone needs to be responsible for managing the content of institutional memory as well as its technology.

A professor at Geneva University, Gilbert Probst, who has developed a working group of people involved in knowledge management, clearly states the structural elements and the key processes of knowledge management as follows. First, the organisation must define what knowledge it needs and produces, and what are the aims, goals and objectives of its knowledge management. This, I believe, may be the most difficult part. Then the organisation must identify the knowledge it needs, ensure the familiarity to develop this knowledge, share it, use it, store it, and evaluate it on a permanent basis. All these processes are in a way interrelated and interactive.

Knowledge management is an essential theme for development cooperation. I would say that the difference between diplomatic work and development cooperation is very often that diplomats tend to collect a lot of information but don't turn it into knowledge or don't use it later on in a productive way, as we do in development cooperation.

\section{KNOWLEDGE FOR DEVELOPMENT}

Through discussion with various colleagues, I came to realise that for an institution such as the Swiss Agency for Development and Cooperation, knowledge management is not enough. It needs a prerequisite, and that is value management. I am deeply convinced that all institutions, even foreign ministries, should know by what values they want to be guided in developing their futures. Even big international companies now recognise that they need value management. A value audit can lead to a set-up of personal values and ideal organisation values: the input for formation of guiding principles or guidelines. Vision, mission and values must be known and communicated as an integral part of an institution's identity. 
What is a value audit? A value audit, according to Richard Barrett and Associates, has the objective of measuring the following: strengths and weaknesses of the existing culture within an institution, degree of alignment between espoused values and actual values, degree of alignment between actual values and staff's ideal values, degree of alignment between personal and organisational values, and indication of direction and priorities for change.

The SDC carried out a value audit last year with the British consultant, Richard Barrett. Our audit included over 350 people at the headquarters and 150 in 31 countries. The result of that exercise have helped us form our guiding principles and the basic set of guidelines for our strategy development. We can look at where the SDC will stand in 2005 and where we will head for by 2010. But it also showed that we needed to develop a number of additional aspects in order to achieve a good balance. We needed to come forward with some strategic goals. For this we are now developing a "balanced needs scorecard". This defines strategic goals as related to the authorising environment (be it in parliament or politics, in order to get the financial support; who will provide support in our country in five and ten years time and how do we deal with them), the partner and beneficiaries relations, the organisational culture, society contribution, organisational evaluation over the next ten year, and organisational effectiveness.

Self-understanding is important in our work in development cooperation, and to conceptualise our self-understanding we developed a symbol which we call the "tree of sustainability". In the planning, evaluation, inspection and explanation of our work this tree of sustainability is the landmark each of our collaborators have to keep in mind. We do not in our work, and I also symbolise this with a plant or a tree, stand by that tree pulling the leaves and think the plant is growing fast. Rather, our work is an external contribution to what our partners want to do, and that external contribution starts in the ground, meaning that we foster the local resources and our partners' own will. We can motivate them, increase their self-esteem and self-confidence, bring in positive experience, support creativity and autonomy, but we will not get involved in programs or projects where no local resources are mobilised, be it as little as $5 \%$ or $10 \%$. If the partner is not willing to engage proper financial means to at some extent, he is not ready to share the risks, he is not ready to bring ownership into it, and he is not ready to make the project sustainable.

On these grounds we specify six basic requirements in order to make our programs and projects work. First, projects must be target oriented: we must be able to reach those groups who want and need to be involved in the project and are ready and willing to contribute. Second, effective organisation must be in place, and if not, we will spend time first on capacity building. Third, financial viability must be demonstrated. It is easy to invest in a project, but more difficult to finance the so-called current expenditure costs or the costs following certain programs. The follow-up costs are the most important ones to consider over the years. For example, if you build a school and the community is not ready to carry the costs for teachers or for maintaining the school, then why build the school? Fourth, the project must use appropriate technology. Fifth, all related decision makers must involved. For example, we found that three years after initiating some water supply schemes in West African, the projects were only $60 \%$ successful. We investigated the reasons the projects were not more successful, and found that women had not been involved in the decision making process, yet they were the ones carrying out the agricultural and water supply work. Of course we had to correct this situation. Frequently, especially in everyday life in industrialised countries, the gender approach is not adequately considered. I just returned from Bosnia where I had discussions with the people responsible for developing new laws in Bosnia. I asked, to their surprise, whether they had considered the gender approach, and they replied that they didn't have the financial means to start such a project. We provided the financial means, and are now waiting to see the results. The sixth requirement is realistic project conception.

Another important dimension of development cooperation and knowledge management is human resources development, which is related to knowledge transfer and capacity building. Poverty is linked to the lack of knowledge. Knowledge gives people greater control over their destinies. You all know the saying "knowledge is power": the more knowledge you have, the more power you have. Perhaps here lies the biggest role for international cooperation in the 
future, as financial means are not being substantially increased recently. Development cooperation should concentrate its efforts on creating a real partnership: information should not be a one way road, but should generate a dialogue between different partners on an equal level. We are not developing our partners. Our partners develop themselves and we support the process, although it is not our development. Our contribution is an external one; we do not create the development. Trust and confidence play an important role, allowing for the transfer of knowledge that corresponds to local needs. Knowledge for development is based on the concept of empowerment. International cooperation should strengthen the capacities of partners to create information, to transfer their knowledge, to adapt external knowledge to local needs, in short, to be responsible for themselves.

Training is therefore a key issue in knowledge transfer and management, and that is why we finance or contribute to quite a number of institutions, for example the institution here in Malta. The contribution is external, aiming to assist and support our partners in offering training. We no longer do the training on our own, through our institutions or even Swiss institutions, but prefer to do it regionally and locally. This is part of our general goal to invest in local resources development. For example, over the last ten years we have reduced the number of Swiss experts in our cooperation programs from 370 to 61 . We now are involving more locals or nationals from each country where we have coordination offices.

Knowledge transfer is, of course, not the only answer to poverty alleviation. Access to other resources, in order to implement the acquired knowledge, remains of utmost importance. Furthermore, knowledge transfer and use needs to be adapted to needs of specific groups. There is no magical recipe.

I would like to provide a few considerations about the focus for development agencies such as ours. We want to avoid discrimination in the access and the transfer of knowledge, ensuring that our partners are involved in the discussion regarding knowledge transfer and the use of new information technologies. We would like to avoid gaps widening between various groups: for example, rich and poor, men and women. We want to ensure that the needs of our partners rather than our wishes are forwarded and taken into account in the international arena. We would like, through training, to ensure that our partners can participate in the creation of international knowledge and information and that they can adapt information to local needs and resources. We would like to provide our partners with the knowledge to use technologies and to ensure them access to international networks, use of the Internet, tele-medicine, etc. We would also like to create an enabling environment in these countries to allow them to decide what is in their best interests. And I think we especially have to put emphasis on strengthening institutions, be it in academia, on vocational training levels or in government, in order to implement various issues related to good governance, for example, to fight or combat corruption.

We focus on a number of other areas. We have also to consider that we cannot do our work without taking the interest of our country into consideration. However, safeguard of national interests cannot easily be linked with development cooperation when you really mean development cooperation in the sense I just explained. You must safeguard national interests on another level, bilaterally. But in development cooperation we are involved in the internal politics of a country and that should not be linked to the safeguard of national interests. This is why we operate without a hidden political agenda-this is a prerequisite of trust and mutual understanding. We also have to take into consideration that the ethics of development cooperation have changed and it is not just a question of charity but a question of mutual interests.

\section{THE ROLE OF DIPLOMACY}

Development policy-making takes place in international forums. And that's where the role of multilateral diplomacy in our range of activities is very important. The global dimensions of problems call for global solutions. Development policies have to be discussed on a multilateral level. Only in this way can globally relevant codes and standards be established. 
Furthermore, national policies need to reflect international policies. So far, especially in industrialised countries, the reflection of international policies on internal politics is rather low, due to a perception that these international policies refer specifically to developing countries. Sustainable development in an issue for all of the countries in the world, industrialised and non-industrialised. We also believe that each nation must give away part of its sovereignty in the shift to global solutions and global governance. However, cultural diversity should not become a victim of economic globalisation. Finally, mass media is gaining an increased importance in international agenda setting.

I think the Carlson Report on Global Governance of 1994 came out perhaps a few years too early, and that so far traditional diplomacy has not taken its findings enough into consideration. This is not a criticism, but I think traditional diplomacy could learn much from development cooperation. I know that many diplomats have a kind of psychological hindrance about the methods of international cooperation, and this is unfortunate because these skills could prove valuable in many situations. Often the diplomats sent to deal with a situation do not take into consideration intercultural exchanges or the real experiences and the knowledge you can get on the ground while working in another country.

The role of bilateral diplomacy is shrinking but it is concentrated on the safeguard of national interests. Bilateral diplomacy can be used especially for building up alliances in order to work out better solutions to common concerns before entering the multilateral forums.

As you are all aware, the working environment of the diplomat is changing, primarily through the use of technology. Dimensions of information are changing: the collecting and sending of information will become less necessary, while the ability to identify items of real interest in the mass of information available becomes vital. A related issue is how to prepare young diplomats to deal with this rich mass of information, to make use of the information that really serves their needs.

The mechanisms of consultation are also changing, due in part to the informal nature of email exchanges at the working level, which can take place regardless of distance. Two years ago I proposed that Switzerland should open a "virtual embassy". I explained that as 500 million people around the world have access to the Internet, why not open a website allowing visitors to ask questions, for example about economics, or to apply for visas. Why should it still be necessary for a man in Tajikistan to go to Moscow to apply for a visa to enter Switzerland? Why can't he get the visa through the Internet and collect it at the airport in Zurich or Geneva? But the virtual embassy has still not been opened-I am still trying. I suggested giving the project to young diplomats, as they would respond immediately. The project would require four or five people engaged 24 hours a day, interactively answering questions for the world public.

Another project I proposed, which has not yet been carried out, relates to image promotion. I suggested that we look into several important data banks in the US and in other countries, to see what information they contain about Switzerland. There was practically nothing, just some historical information. This problem should be addressed.

We are, of course, aware that for knowledge use in development cooperation you need a set of guidelines to make your approach understood. And that is my last message: approaches are a part of knowledge and are very important-they can become as important sometimes as information. And in that respect, when you work with a lot of partners you have to be aware that you need a basic set of rules and principles to follow in your work. We developed these for our organisation, and we are still working on it. We even have a set of seven simple management principles for everybody in our organisation, to ensure they know the basics of the philosophy we follow. I conclude with these remarks knowing that I could not fulfil all your expectations, but I hope I have given you some food for thought for your further undertakings in this seminar. 


\title{
THE ROLE OF KNOWLEDGE IN THE CYBER-AGE OF GLOBALISATION
}

\begin{abstract}
Richard Falk
Malta exemplifies a country whose diplomacy enables it to play a far greater role in international life than its power and capabilities would suggest. It exemplifies, in other words, the creative use of diplomacy to exert influence, especially on the formulation of normative ideas. Malta contributed to the world such inspirational ideas as the common heritage of mankind, as the foundation for the distribution of ocean wealth. A plea for respecting the rights of future generations is also associated internationally with Malta's leadership. Perhaps the most significant of these initiatives is the pioneering work on the application of information technology to diplomacy that has been going forward at the Mediterranean Academy of Diplomatic Studies under the leadership of Jovan Kurbalija.
\end{abstract}

My university in the United States has a well-known School of Public and International Affairs - the Woodrow Wilson School-and yet it is at least one epoch behind the work being done at the Mediterranean Academy on the organic relevance of information technology to the conduct of effective and informed diplomacy. Princeton has no one on its faculty that even approaches Jovan Kurbalija in terms of commitment and insight into the potentialities and relevance of IT. So in a genuine sense, Malta is making a very significant contribution to the enormous challenges of adaptation that are hidden beneath this banner idea that we are all now living in an era of globalisation. In these remarks I will try to give some historical context for what this adaptation is likely to mean for diplomacy.

I think it is fair to say that diplomacy and diplomats are embedded in a world of sovereign territorial states, probably to a greater extent than any other single profession. What we call diplomacy is primarily an invention of the state system. The ritual and formality of diplomacy expresses the central idea that representatives of geographically separated territorial, political entities, were needed to maintain contact among these political communities. Over the decades and centuries, many changes in transportation and communication have frequently altered the traditional nature of diplomacy, especially diminishing the relevance of distance. Yet nothing comparable to computer-driven IT has previously arisen. Nothing previously produced such a potentially transformative impact on the nature of diplomacy, even upon what we mean by diplomacy, and upon the very identity of diplomats. These fundamental questions-what is diplomacy?-are necessarily being raised anew during the dawn of globalization. Such questions arise, above all, because it is everywhere evident that we are no longer living in a world that can be adequately defined in terms of territorial sovereign units that are spatial in character. The global maps that educate us about the world convey only one dimension of globalisation. Among many other shortcomings, these maps fail to take account of the degree to which we are now living in temporal communities as well as spatial communities. In other words, the pace of change has become so rapid that we are constantly trying to identify links to the past and future that will enable us to interpret successfully the kind of world we are inhabiting and the problems that it presents.

And it is this challenge posed to diplomacy that seems to me to be best contextualised by referring to our time period as the "cyber-age"; by using such a phraseology, thereby recognising the centrality of IT and the connected hardware/software features of this technology that is generating, without any deliberate plan, a new world order. It is a new world order that cannot be understood just by reference to these technological potentialities. There is an interesting statement that was recently made by the managing director of the World Economic Forum, Claude Smadga, just prior to the annual meeting at Davos. Mr. Smadga said "governments will be judged more and more on their ability to address the social repercussions of the globalisation process and finding ways to balance its destabilising impact." In other words, the technological miracle that is embedded in information technology needs to be connected with these fundamental challenges of a more ethnical and social character. How can we be sure in this process of transition that is going on in the world that this new technology is genuinely being devoted to making this world a better place for the 
peoples living on the planet who are the ultimate justification of politics and particularly democratic politics?

It seems useful to clarify somewhat what we mean by the domain of knowledge in relation to diplomacy, and with respect to interpreting the world. I think it is helpful to conceive of the knowledge that we are concerned about as "valuable information". Such an emphasis is intended to distinguish the focus of inquiry from the kind of unspecified, massive overload of information that has become accessible to us through information technology. In other words, one of the challenges in this age is to convert information into knowledge. Or putting the same idea somewhat differently, how do we gain efficient access to valuable information? This kind of distinction between knowledge and information, which I think is very important, also should be contrasted with what one might call wisdom, which can be defined as knowledge that is devoted to the goals of human well-being, and includes in that sense, as core concerns, matters of values, ethics, human rights and the religious foundations of our identity.

I think the preliminary challenge that we face at this point in history is how to convert information technology into "knowledge technology". The even deeper, related challenge is how to convert "knowledge technology" into "wisdom technology", moving from KT to WT.

I think that among the things being done creatively here in Malta is to address one important dimension of this challenge, that is, to devote the main effort of training diplomats to ensure that those from the global south have an adequate access to this technology.

A concealed danger associated with this rapid acquisition of a revolutionary new technology is to create a new antagonistic class structure in the world. Part of the necessary implication of IT is that it almost inevitably exploits those that don't have the appropriate computer literacy to take advantage of this technology. Without appropriate literature whole parts of the world are left further and further behind in this phase of history. There is an exclusionary element to it that needs to be acknowledged.

The collapse of the Soviet Union might be interpreted partly by its failure to master reliance on IT. It is plausible to interpret the immense historical transition that we are experiencing by reference to two underlying developments in this era-IT and the end of the cold war.

I would contend that these two seemingly disparate developments are really quite closely interrelated - the end of the cold war was partly and I think necessarily occasioned by the inability of the rigid state structures of the Soviet Union to adapt to the economic opportunities and challenges of the information age. The Soviet Union was unwilling to expose itself to these new technologies. The rigidity of their system contributed to their collapse.

It is a lesson that China, interestingly, has partially learned. This revolutionary technological cluster of developments has already transformed the politics of the world. It condemns those parts of international society that cannot cope with information technology to a marginalised status. Those parts of even the most modern sectors of world society in the richest countries that cannot cope are also being denied the benefits of economic growth. I am praising the Mediterranean Academy for this attempt to build a bridge between these innovative technologies and the struggles of the global south to participate positively in this emerging new world order.

I wanted to frame some of my remarks by reference to a quotation taken from Manual Castells, who is the author of a three volume study called The Information Age: Economy, Society and Culture. This work of scholarship has had a big influence. It is referred to as "the bible of Silicon Valley". Castells has made the most comprehensive effort to grasp and evaluate the multi-dimensional changes and trends associated with IT. His overall assessment of the revolutionary impact of IT is expressed in the following words:

In the last quarter of this fading century a technological revolution, centred around information, has transformed the way we think, we produce, we consume, we trade, we 
manage, we communicate, we live, we die, we make war, and we make love. A dynamic global economy has been constituted around the planet linking up valuable people and activities all around the world while switching off from the network of power and wealth people and territories dubbed as irrelevant from the perspective of dominant interests: a fundamental transformation of the macro-political and macro-social contexts that shape and condition social actors and experiences around the world.

In a sense, what Castells and others are really telling us is that we are in this transition from a familiar world to one in which our whole experience, our basis, is being reconstituted.

Another recent book by Ray Kurzweil, a computer specialist, entitled The Age of Spiritual Machines, has suggested that we are approaching a dramatic evolutionary frontier in which machines are increasingly able to exceed human capabilities. You probably are familiar with the IBM machine Big Blue, that defeated the best chess player in the world, Gary Kasparov, a few years ago. The argument of Kurzweil's book is that this chess prowess is just the opening gambit of an expanding machine assault on the experience and the claim of the human beings to be mentally superior, and so to be the chosen species. Kurzweil argues that even when it comes to poetry, by the middle of the next century, the "spiritual machine" that will then exist will be producing poems that are comparable to that of the best work of poet laureates in our most cultured societies.

Such a projection represents a breathtaking kind of re-understanding of the place of human beings in the universe, and this is true even if it is appreciated that computers are conceived and sustained by human ingenuity. This prospect of creative and spiritual computers is accompanied by a variety of unrecognised challenges that will undoubtedly provide the context, or at least deeply influence the underlying context, within which diplomacy will be conducted in the future.

Can government bureaucracies assimilate this transformative technology in a manner that is consistent with human well-being? Such a response depends on managing other aspects of the global setting. The nature of these tasks is in dispute. Some have suggested that only by stabilising the world population can we keep the planet sustainable over the period of the next century or so. Others suggest that only by eliminating or greatly mitigating the institution of war as the decisive mode of conflict resolution can we cope with such an interconnected planet that has such extraordinary capabilities to inflict destruction with precision. Still others suggest that this kind of globalisation can only remain stable if it addresses the gross inequalities and disparities that exist among the distinct peoples of the world. And others contend that it is only by rediscovering our spiritual roots can we hope to avoid what amounts to a collective mental breakdown in the face of a technology that transcends human capabilities. In effect, society is confronted by a spiritual challenge as much as it is with political and economic challenges arising from this new dimension of human experience.

And so, when we think about knowledge and knowledge deployment in relation to diplomacy we should not treat these inquiries as being merely technical matters of learning how to master the appropriate skills. Every form of knowledge needs to be interrogated and evaluated in terms of its social, economic, political, and cultural effects. At this stage it is especially important to understand who is controlling these new forms of knowledge and for what purposes. Without this deeper interrogation of IT we are likely to become subject to some very regressive forces of control during this transition.

In this spirit of critical inquiry it is important to recognise that there are at least three dark sides to the advent of this era of globalisation. The first, which I have already referred to in passing, is the emergence of what is being called the "fourth world", that is, the societal domain constituted by those individuals, peoples and societies that are being excluded from participation in the positive benefits of globalisation as a consequence of their marginalisation by the operation of market-driven logic. In other words, globalisation as we now understand it, as it functions, is reshaping the social structure of the world as a result of "the discipline of global capital". A major component of this discipline of global capital is to make profitable use of information technology. Those that are not able to make this profitable use find themselves 
situated in the fourth world. Much of Sub-Saharan Africa and the Caribbean, many of those who do unskilled work around the world, find themselves belonging, generally unwillingly, to this new classificatory zone of a fourth world. So we must ensure that what the World Economic Forum director described as the social repercussions of globalisation are being addressed as seriously as are the technical potentialities of IT.

Secondly, it is important to consider the implications of information technology for new forms of warfare, especially for those that have a one-sided character that has in my view some extremely disturbing features. The Gulf War was the first expression of this hyper-modern one-sided kind of warfare where those that control IT can choose the means by which they inflict suffering on others, pain and devastation, without exposing themselves to retaliation, or without at least risking retaliation in a comparable form. The leaders of the American military establishment are now planning for wars in the future that are described as "zero casualty" wars: that is, zero casualties for the high tech side, but unlimited vulnerability to devastation by a low tech adversary. There is another expression that is now emerging in this domain among war planners, which is "asymmetric warfare". The extraordinary inequality among states with differential access to IT that is emerging and is well depicted by James Adams in his book The Next World War. Computers are the core of these new weapons systems and the battlefield can be anywhere. One of the implications of one-sided warfare is that it begets violence that resembles the structure of torture carried out on a large scale. If you reflect on the nature of torture you realize, that above all, it involves inflicting one-sided pain on the victim with the perpetrator deciding what form of pain and at what level, what intensity, and acting without any anxiety that the victim can strike back. It is a non-reciprocal relationship in the context of life and death situations. In this new type of warfare that we are entering by way of IT, we are adapting warfare to the structure of torture. This is very bad not only for the victim, but also for the perpetrator. It creates a very dubious moral relationship to the use of force, which is always, to begin with, dubious, but it seems to me that prior doubts are greatly intensified. The NATO war of 1999 in response to the troubles in Kosovo provides grim confirmation for these concerns.

But there is a further element that is also disturbing in its impact. The very structure of this technological asymmetry invites violent retaliation in a different modality, but also devastating. It is no accident that international terrorism has emerged as such a threat at the same moment historically as IT. Or that anxieties about biological weaponry and chemical weaponry are rising in an unprecedented manner in the United States and elsewhere, suddenly creating a societal feeling of acute vulnerability that has rarely existed during the cold war except during crises when the real danger of a catastrophic nuclear war became apparent. President Clinton, perhaps to divert attention from his impeachment turmoil, has also been involved in what might be described as a hysterical preparation for meeting these challenges of terrorism and biological warfare. It needs to be realized that such preparation poses a serious threat to democratic society. To protect against these alleged challenges it is contended that extensive control needs to be maintained over hostile social forces. Such a requirement provides justification for continuous and pervasive intelligence operations against your own society and in relation to those who might be seeking to penetrate it. So there is a new rationale for what might be called total intelligence. The US military establishment is now proposing for the first time in American history the creation of a US military command to operate in country. In the past the role of the military has always been conceived as confined to conflict external to the country. To address this internal dimension of national security becomes natural if the main challenges are no longer to be spatially identified as external. It is evident that hidden within the wonders of this information technology are some very menacing nightmares associated with its misappropriation and with anticipated backlash behaviour by those with the unequal access to its capabilities.

There is also a fairly widely shared sense that a market-driven globalisation is not necessarily providing the path to human betterment, especially for economically disadvantaged societies. One danger is the link between government and IT, but another danger is the link between the market and IT in a political climate that lacks social equilibrium. If you think historically, the Industrial Revolution ushered in an era of cruelty to the relations between the market and society, fictionalised by Charles Dickens in the early nineteenth century: child labour, long hours, no safety, capitalist greed. It was only with the emergence of labour movement that it 
became possible to achieve some social equilibrium, allowing capitalism to acquire a human face in the industrialised era. In other words, capitalism needed the threat of socialism as an alternative political project in order to avoid many of its cruel potentialities.

We have to ask the question now, can we imagine this kind of social equilibrium in relation to a globalising capitalist economy? Organised labour can no longer play such a role. It is too weak relative to business and finance. In addition, socialism has effectively collapsed as an alternative ideology. What, then, now challenges the cruel side of capitalism and encourages moves toward a new compassionate capitalism? Or as the World Economic Forum director put it in 1999, "globalisation with a human face". The fact that people are even talking in this way in business arenas expresses some recognition of the underlying problem. I doubt, however, that voluntary adjustment will be effective. Some degree of social pressure is needed. Can it be mounted by the activist side of global civil society? Greenpeace has been effective in organizing consumer boycotts against even the largest multinational corporations. Consumer power seems to be hurting companies such as Nike that are alleged to be running sweatshops in unregulated Third World settings. Can such initiatives be organized in such a way as to provide a counterweight to business and finance?

Let me end these remarks with a few comments about some of the brighter sides of this revolutionary development. Aside from the obvious reality that for the first time in human history the entire planet has the potential access to the entire corpus of valuable information, that is, virtually, all that exists, there is a decentralising and democratising potentiality present. So far the Internet has avoided being fully appropriated by the market. Its knowledgegenerating propensities have remained a free resource. This is an amazing dimension of our world. The struggle to keep this resource, this emancipating knowledge, from being appropriated by the market is, I think, of extraordinary importance. How do we keep IT free? How do we keep IT in the public domain? And unless I am very wrong about the acquisitive disposition of the market, it will not be kept in the public domain without a very vigorous social struggle. There is too much rent-seeking wealth at stake. But if we do succeed, and if projects such as the project of the Mediterranean Academy do succeed, then one has a levelling of the playing field of diplomacy throughout the world which will open exciting potentialities for intercultural and intercivilisational collaboration of a much more meaningful sort than has ever existed in the past.

A second very, I think, hopeful development is that the Asian crisis and its reverberations in Japan, Latin America and Russia has removed the false euphoria from globalisation. It has led individuals such as Smadga, the World Economic Forum architect and manager, to talk in a new way about something other than a market logic. I think there is now emerging, as knowledge, the sense that the social dimensions of globalisation cannot be left entirely to the market, that the invisible hand is a deformed part of the body politic that moves to correct distortions far too slowly, if at all. We cannot responsibly rely on the automatic effects of economic growth to provide human well-being and to maintain stability and progress for the planet. We require a form of global governance that also is concerned with how to deal with poverty, with economic deprivation, joblessness, with fluctuations in the world financial markets, in other words, that tries to incorporate the lessons of the Asian Financial Crisis into a new structure of authority for the world.

And finally, in terms of hopeful developments and trends, are these series of elections in Europe and elsewhere that have moved against a neo-liberal orientation towards political leadership. The last wave of social democratic victories in a series of European countries are partly a backlash against the economistic approach to globalisation. It is not clear that these new social democratic leaderships will be able to cope with the discipline of global capitalism, or whether their policies will be much different than the governments they have replaced. Indeed, the forced resignation of Oskar Lafontaine raises doubts on these scores. But such electoral outcomes do send a message to the leadership of the world that citizens in democracies are expecting more than capital-driven politics at the level of the state, that adjustments by the state to globalisation need to do more than facilitating business and finance. In effect, these elections are a call to establish a new equilibrium between the needs of peoples and the aspirations of citizens and the logic of capital and growth. Whether or not 
this equilibrium can be found in the coming years, will, I think, determine whether the future of globalisation will be stable or will give rise to very deep new patterns of social and political conflict that are certain to have far-reaching implications.

I want to close by saying that it seems to me that we are genuinely, not just as a cliché, but genuinely, at a crossroads in human experience that will establish the crucial context for the diplomacy of the next century. The question is whether we have the imagination, as well as the skill to cope with this revolutionary technology, and can realize the promise that it contains while coping with the dangers that it brings to our world. Whether we can manage such a transition is a challenge of great magnitude that very few generations have faced. It is a challenge that we are only beginning to depict and understand. Surely we are living in "interesting times" but whether such an experience will prove a curse rather than a blessing remains to be seen! 


\section{WILTON PARK: SUI GENERIS KNOWLEDGE ORGANISATION Colin Jennings}

I propose to make some fairly heretical comments about knowledge management. In doing so I take comfort from the fact that the instigator of Wilton Park, Sir Winston Churchill, believed in breaking the rules when necessary. I like, in particular, his comment that "a preposition is something you should never end a sentence with."

When I saw the programme for this conference I couldn't work out what the title of my talk meant. But the organisers kindly explained that I should simply explain the way in which the particular institution I lead, Wilton Park, operates. So I will:

- explain what Wilton Park does;

- highlight some of the key reasons for its success;

- identify some specific outcomes of the conferences; and

- offer a few reflections on the theme of knowledge management.

\section{WILTON PARK}

Wilton Park organises over 40 residential conferences a year on a wide range of key policy challenges, and produces reports on each one. Most last three and a half days, some are shorter. The conferences are mainly on international issues but there are also some on domestic policies of interest to a range of countries. Wilton Park is an Executive Agency of the British Foreign and Commonwealth Office but is academically independent (an unusual and highly productive mix). Because of this status, $60 \%$ of the participants are government officials and politicians working on the issues, and the remaining $40 \%$ are from a range of non-government professions. Only a fifth are British. A few come to learn for the first time about an issue, but most are already highly knowledgeable. Wilton Park's website at www.wiltonpark.org.uk provides more background.

\section{Why does it succeed?}

I was impressed that one of the things Al Berg, an IT expert speaking at the February 1999 conference on Knowledge and Diplomacy in Malta, mentioned was exactly our sort of method: bringing people together for conferences as one way of exchanging knowledge and information. It is important to hear that statement from an IT expert. One can easily argue, in our fast-moving world, with e-mails and the internet, that bringing people together, as we do, in a $16^{\text {th }}$ century, rural location is out of date. Is it really worth it? Doesn't it take a long time?

I would argue that it is definitely worth it, and that data alone will always be insufficient: personal contact between individuals has a very important part to play in exchanging views and information on complex subjects. Part of this is human nature. What do we remember most? What we have read, or what people have told us? For most of us it's the latter, and the laptop won't change that.

There are four basic reasons why the way we bring people together at Wilton Park is not only still necessary but is, in fact, on the increase.

First, despite all the conferences and other meetings that take place on so many different issues, and among so many different nationalities, there are very few occasions when policy makers and non-government people get together and really examine the underlying problems. What are the root causes of the dispute between the protagonists? Are their aims and needs really so different, or is that a failure of perception? What can all concerned do to bridge gaps and work to mutual advantage? What are their current plans, what are the real 
prospects of making progress? This may sound basic, but all of us who have experience of working on international issues know that this sort of discussion is vital yet doesn't happen very often in a productive way. So that's the first reason: those coming find the exchanges useful and, because so many work for governments, there is a very direct impact on policy formulation.

The second reason is that the unattributable nature of the discussions encourages frank but informed debate. The collective experience is always vast, but it's not an international negotiation and you won't be quoted. Those are real benefits. There are lots of meetings where you represent your institution or your government, but very few where you can talk off the record. Wilton Park's confidential and residential environment encourages participants to say what they think. They may be a bit constrained on the first day, but once they've got to know their fellow participants they relax and talk frankly. That can lead to some quite stormy exchanges, but there's no harm in that if it's reasonably controlled.

The third reason it works is that by bringing in top people in their field, the updating of knowledge is always considerable. Everyone gains new insights and new information. However much you know, there is always more to learn.

The fourth is the fact that it's residential nature helps develop personal contacts. I know cases where they have lasted a lifetime and been really valuable.

\section{The outcome?}

But does all this make any difference? Does it produce a real outcome? If I were in the British Treasury, I would be saying: that's all very well, but it costs money. Not much taxpayer's money, but nonetheless, some. And what's the result?

It is certainly true that increasing knowledge in itself doesn't solve problems. Wilton Park conferences over the last year or so have highlighted that there was going to be a major crisis in Kosovo, an escalation of overt nuclear proliferation between India and Pakistan and a serious crisis in Asia because of the social and political tensions. None of these were prevented. But nonetheless, better informed policy makers can at least be better prepared to deal with such crises when they happen, and do their best to prevent them if they can. And in addition to the obvious benefits of the cross-fertilisation of ideas and information, and the creation of new personal links with people of real influence, there are concrete outcomes. A few examples.

We held last year a conference on the Common Agricultural Policy and a planner from the German Foreign Ministry told us that it had been invaluable for him in preparing the German government's policy for their Presidency on this very important policy area.

We held a conference two years ago on the Greek-Turkish relationship, with just Greeks and Turks and a few other observers, which produced Greek-Turkish talks led by another institution on media coverage, military links and other contentious areas. I am not aware of any other forum that's doing that. The influential people involved on both sides find it very useful, I am told.

Smaller foreign ministries that come to our events tell us they use the reports we produce on each conference as a working tool to update knowledge and think through policies.

We had a conference last year on the forthcoming Lome aid and trade renegotiation. Several of the ACP people there told us they found it very useful in preparing their negotiating position.

The BBC used one of our conferences as a basis for briefing their journalists for coverage of the German elections last year, and interviewed quite a few of the people who came to the conference. 
We held a conference on the future of the UN last year, out of which we think there may well come a new set of principles for rejuvenating the UN in various ways, not least its Agencies.

And we held a conference on welfare reform last year which undoubtedly fed directly into the 13 January article on the front page of the London "Times" about the introduction of new welfare policies in the UK, in this case a modified form of American style workfare. I know for a fact that this in part came out of our conference.

\section{KNOWLEDGE MANAGEMENT}

Perhaps I could conclude by offering a few personal reflections on the theme of knowledge management in diplomacy based on 22 years of working for the British government in the Ministry of Defence, the Foreign Office and now Wilton Park. None of this may be revolutionary but I hope its worth hearing.

First point. Diplomatic services have very high quality staff, with exceptional commitment, and in the British case a global heritage which produces an enormous number of networks through the Commonwealth and other institutions, a virtually incorruptible civil service, and a stable and transparent democracy. Despite this, we manage information badly.

In my experience, the life of a civil servant in Britain is almost constant crisis management. Cutbacks in staff and resources have led to real overstretch. There is precious little time to think. I'm sure this will be familiar to lots of you, it's not just a British problem. But in our case, there is little time to read carefully and to think, and even less to organise your information. The interaction with non-government thinkers is greatly restrained by the pressure of work. That lack of interaction can be damaging. It leads to perpetuation of policies which are well past their shelf life because civil servants are only talking to each other.

Job turnover is far too high, which means that experience, certainly in capitals, is far too slim. That applies in virtually every area.

Key information and recent documents are often very hard to find. A lot of time is wasted looking for them. IT is not used nearly enough to overcome this. As mentioned by other speakers, the introduction of IT in our organisations in the last ten or so years hasn't saved work. It's created vast amounts of extra work. Of course it has benefits. E-mailing and so on is enormously useful and time saving, but in other respects we're a long way off. When it comes to design and use of IT, it's like the motor car in the early stages of the century. We have an awful lot further to go, in terms of having systems that are easy to use, where you don't have to click on 25 different things to obtain what you want, which don't crash twice a day or remove useful tools every time a programmer touches them , etc.

I am not suggesting that everything we do is ineffective. The qualities of the people we have make our organisations work. But it's despite rather than because of good management and use of knowledge. This may be a heretical thought, but it is certainly my own experience as a practitioner.

\section{CONCLUSION}

There is an obvious conclusion: we should have more meetings like this. This one is excellently timed. There needs to be more such opportunities to exchange views, and have training on the management and use of knowledge. Many of the things other speakers mentioned are new and directly relevant to my organisation and probably are to yours.

For our own part, in Wilton Park we are doing our best to increase the dissemination of our knowledge, for instance, through our website. We're also going to be introducing a new 
publication which will bring together all our reports and papers, to be launched by the Stationary Office in April, entitled Current issues in International Diplomacy and Foreign Policy.

Last but not least, we are going to do our best to manage knowledge better by holding a conference with the Mediterranean Academy of Diplomatic Studies in Malta in November on the social impact of free trade in the Euro-Med area.

To conclude, I would suggest that the key to knowledge is giving greater priority to making the time to learn from others, not least at meetings like this. We should learn from Henry

Kissinger's shrewd observation: "There can't be a crisis next week, my schedule is already full." 


\section{HISTORICAL DIPLOMACY: FOREIGN MINISTRIES AND THE MANAGEMENT OF THE PAST ${ }^{1}$ Keith Hamilton}

In the spring of 1986, a little over three years before the demolition of the Berlin Wall, Professor Alfred Grosser contributed to Politique Etrangère a brief survey of fifty years of Franco-German relations. The article came to no very startling conclusions. Grosser noted that, although West Germany was superior to France in an economic and monetary sense, France was the superior of the two in three other respects: as one of the four powers responsible for the governance of Berlin, France was a co-possessor of German sovereignty; unlike West Germany, France, was a nuclear power; and "l'Allemagne a eu Hitler dans son passé et la France pas." ${ }^{2}$ Few political scientists have been quite so explicit in citing history per se as a component in the balance of power. Yet, in referring to Hitler, Grosser was making an obvious point. West Germany in the 1980s was constrained by Germany's recent past, and the same has, perhaps to a lesser extent, remained true of a reunited Germany in the 1990s. Not only have military defeat, occupation and the limitations imposed by the Federal Republic's Constitution restricted its capacity to exercise its power abroad, but the memory of National Socialism has stamped a hideous stereotype upon Germany's past and cast a long shadow over its present and future conduct. Bonn's foreign-policy initiatives, even when taken in the contexts of the European Union and the North Atlantic Alliance, have been susceptible to claims, often from critics who should have known better, that Germany was reverting to expansionist ambitions attributed to Hitler. The epithet the "Fourth Reich" has acquired sinister connotations which have only a tenuous connection with the First and Second Reichs and virtually nothing to do with contemporary German politics.

Germany has not, however, been alone in finding its diplomacy hampered by its history. Countries, like people, are judged in terms of their past actions or, at any rate, according to how such actions are interpreted by historians and translated into popular culture. This has become only too evident in an era in which charges of collective guilt and demands for diplomatic apologies, redress and recompense have become such a significant feature of global politics. It is therefore hardly surprising that since their emergence at the end of the seventeenth century foreign ministries have found it necessary and, where not necessary, prudent, to manage that particular branch of knowledge labelled the historical past, They, along with other government departments, have sought to use archives and historians to promote a more favourable national image abroad, to reinforce territorial claims, and to achieve other political goals-a process which might be conveniently described as historical diplomacy. It has involved controlling access to records, the sponsoring of official or semiofficial histories, and the publication of diplomatic documents. Foreign ministries have always been well placed to fulfil this last function. After all, few human activities generate more documents than does diplomacy, and few others are so dependent for their success upon the efficient administration and utilisation of archives. Full and accurate records provide enlightenment on past developments and precedents for current and future negotiations and, in consequence, some of the oldest divisions of modern foreign ministries are those responsible for records management. Diplomacy may still be regarded as a secret craft, separated by protocol and its own peculiar rites and rituals from the public at large. Yet diplomatic archives remain one of the most extensive and potent sources for the public's understanding of the past, and the publication by foreign ministries of selections of their correspondence, memoranda and other papers, has been a powerful stimulus to the study of international relations.

Not all such publications can be characterised as historical diplomacy. Foreign ministries share with other government agencies and departments a duty to keep members of the public informed with regard to enactments, legislation and political and economic changes likely to affect their lives and livelihoods. The provision of such information is an obvious requirement of good government. Individuals travelling abroad and companies engaged in international commerce and investment need to be kept abreast of developments which might impinge upon their enterprise. And the British, with their world-wide trading interests, were amongst the first to engage in the regular publication of documentation relating to frontier changes, international treaties and negotiations. Lewis Hertslet, the Foreign Office Librarian from 1810 
to 1857 , and his son and successor, Edward, were pioneers in this work. Of Swiss/Lombard origin, the Hertslets made the management of Foreign Office records virtually a family business. Brothers, nephews and sons were employed, and the Librarian's Department, which had custody of correspondence and treaties, became the Office's collective memory, providing detailed information and guidance on the major international issues of the day. It was also a paying concern. In 1820 Lewis Hertslet published as a private undertaking, but with a guaranteed order from the Office, two volumes of Commercial and Slave Trade Treaties. Six years later there appeared the first volume of Hertslet's classic reference work, British and Foreign State Papers. ${ }^{3}$ Originally intended only for distribution to government ministers and British missions abroad, this collection of treaties and other political and commercial documents went on sale in 1831 and continued in annual production until 1968. Edward Hertslet continued the family tradition. He too published documents, and he too made sure he received adequate remuneration for the work. After having succeeded his uncle, James Hertslet, as sub-Librarian in 1855, and his father as Librarian in 1857, he began work on his four-volume Map of Europe by Treaty, a collection of maps and papers recording political and territorial changes in Europe since 1814. He also undertook the editing of a parallel series, The Map of Africa by Treaty, the third and final volume of which appeared in 1909. ${ }^{4}$

Meanwhile, the British Foreign Office, along with other foreign ministries, had become actively involved in the editing and publication of works which were intended not simply to inform, but to persuade. This was in many respects a diplomatic response to the emergence of public opinion, that is to say the increasing political importance of all those non-governmental opinions which found public expression in the press, national and provincial assemblies, the universities, and the great houses, salons and societies of Europe's expanding intellectual and political élite. The impact of such opinions varied according to the political and social institutions of different countries. But even in autocratic Russia the Tsar's ministers had to take account of a slavophile intelligentsia when handling relations with the Austrian and Ottoman empires. Elsewhere, the growth of literacy and the establishment of popularly elected parliaments led to the greater involvement of chancelleries, ministries and diplomats in attempting to defend their decisions at home and in seeking to influence governments abroad. Already, in the aftermath of the Seven Years' War, the British government had released for publication documents relating to the negotiation of the Peace of Paris of 1763. Then, in the aftermath of the Napoleonic Wars, the Foreign Office began the more or less regular publication of selections of diplomatic correspondence in the form of parliamentary papers or Blue Books. ${ }^{5}$ Other countries followed the British example. Thus, after the British reoccupation of the Falkland islands in 1833 the government in Buenos Aires published papers dating from the crisis over the islands of $1770-71,{ }^{6}$ and more than fifty years later Anglo-German friction over colonial claims caused Bismarck to lay the first of his White Books before the Reichstag. The Emperor Napoleon III had by then sanctioned the annual publication of a selection of the Quai d'Orsay's correspondence and, in 1861, the State Department launched a similar but more enduring series, the Foreign Relations of the United States (FRUS). The French experiment with an annual series did not survive the FrancoPrussian war. Nevertheless, French governments continued to publish Yellow Books which, like their British counterparts, dealt with specific negotiations and particular developments.

Documents released in this fashion were sometimes emasculated and occasionally falsified. There were also instances when despatches were deliberately drafted with subsequent publication in mind. Such collections were meant to influence parliamentarians and a wider public, and documents were often selected for essentially propagandistic ends. Foreign ministers thereby sought to justify their conduct and win support against domestic and foreign rivals. But during the last quarter of the nineteenth century governments were also increasingly engaged in sponsoring the publication of volumes of diplomatic documents which were intended not so much to persuade or defend, as to enlighten and educate the public in the principles of foreign policy. This work was closely linked to that process of state-forming and nation-building which was so characteristic of the period, and it was often accomplished by diplomats working in association with academics who would not have blushed at being called patriotic historians. Some of its most enthusiastic disciples were to be found in the German empire. Nineteenth-century Germany was, in the words of the French historian Gabriel Monod, nothing less than a "vast laboratory of history", ${ }^{7}$ and the writing of history 
became a social integrating factor in the new Reich. North German historians were especially anxious to stress the political virtues of Prussia, and prominent among their number was Heinrich von Sybel, the founder of the Historische Zeitschrift and director of the Prussian state archives. Under his auspices, and with the financial backing of the Prussian Landtag, there began in 1873 the publication of the monumental collection of historical documents, Publicationen aus der königlichen Preussischen Staatsarchiven. These covered both domestic and foreign politics. Long before the Fritz Fischer debate of the 1960s German historians understood the importance, if not the Primat, of Innenpolitik, and the first foreign relations volume of this series did not appear until 1882, when Paul Bailleu edited a collection of documents dealing with Franco-Prussian relations during the revolutionary and Napoleonic eras.

Sybel captured the spirit of the series in his preface to the first volume which appeared in 1878. "A people", he announced, "which knows not from whence it comes, also knows not whither it goes. Its political education will only be effected in a sound manner if it is tied to a living consciousness of its historical development, and this is not imaginable so long as original documents remain inaccessible." ${ }^{8}$ These words were readily endorsed in France where the foreign ministry was already considering the possibility of publishing its own diplomatic records. ${ }^{9}$ French historians had been deeply affected by the events of 1870-71. They attributed France's involvement in the war with Prussia and its defeat in part to the failure of the French educational system. As the director of the newly-established Ecole libre des sciences politiques declared in 1873, the French public had been all too easily led astray in the summer of 1870 by a frivolous and nationalistic press. It was the duty of France's historians to equip the French nation with a proper understanding of international affairs so that in future such calamities would be avoided. ${ }^{10}$ There was also a profound sense of disillusionment with Bonapartism. A rising generation of republican intellectuals believed that France must separate itself from its immediate past in order to rebuild its strength. Gabriel Hanotaux, a diplomat, historian and sometime foreign minister, proclaimed that the new era demanded a new history. ${ }^{11}$ But a new history required new documents or, at any rate, better access to old ones; and it was largely with a view to meeting this need that in 1874 a Commission des Archives Diplomatiques was established in the Quai d'Orsay. ${ }^{12}$

Composed of archivists, librarians, distinguished historians and former and serving diplomats, and inspired by the Prussian enterprise, the Commission decided in 1880 to begin the editing and publication of the instructions given to French envoys in the period 1648-1789. These were the Recueil des Instructions données aux Ambassadeurs et Ministres de France depuis les traités de Westphalie jusqu'à la Révolution française, the first volume of which was edited by Albert Sorel and covered relations with Austria. A series of this nature, even though it dealt with events of previous centuries, was almost bound to raise sensitive issues, particularly when editorial comment conflicted, as it sometimes did, with current policy concerns. Bertrand Auerbach, who edited a volume containing the instructions to France's representatives to the Imperial Diet at Ratisbon thus found himself in trouble when he supplemented his documents with a narrative in which he suggested that German nationalism had developed in reaction to France's persistent interference in Germany's internal affairs. This was not what French diplomats wanted to read when the manuscript of the volume was submitted to the Commission in 1911, and it was only after protracted discussion and radical amendment of the text that the work was cleared for publication. There were, as this and other similar cases were to demonstrate, obvious limits to popular enlightenment in the Third Republic. ${ }^{13}$

Those responsible for another and in many ways far more important series of French diplomatic documents, Les Origines diplomatiques de la Guerre de 1870-1871, seem, perhaps surprisingly, to have experienced fewer such editorial problems. Their volumes were, like the Instructions, aimed essentially at revealing to Frenchmen the recent history of their country and at drawing their attention to the shortcomings of Bonapartism. The decision to proceed with the publication of this series was taken in 1907, shortly after the formation of Georges Clemenceau's first administration, and appears to have been linked to the triumph of radical republicanism. It was also in part a reaction to the attempt made by Napoleon III's last prime minister, Emile Ollivier, to use his voluminous memoirs to rehabilitate the Second Empire. French radicals wanted to show how imperial undiplomacy had contributed to bringing about the war of 1870-71 and France's humiliation by Prussia. As Stephen Pichon, 
Clemenceau's foreign minister, claimed in the preface to the first volume of the Origines, a democracy had the right to be truthfully instructed so that it might judge the men who had so profoundly affected its destiny. ${ }^{14}$ So likewise was it necessary to provide a democracy's representatives with an education in diplomacy. Indeed, in initiating the publication of French diplomatic documents in the 1870s French ministers and officials had assumed that these would assist in providing French diplomats with a proper understanding of their craft. Elie Decazes, the foreign minister who established the Commission des Archives Diplomatique, had asked its members to recommend documents for publication which would provide a true diplomatic education. He wanted to give to France's envoys the means to penetrate the details and procedures of past policies which had given France its grandeur. In other words, he was looking for models which French diplomats could follow in seeking to restore France to its proper position in Europe. ${ }^{15}$

Members of the Commission were also to claim the volumes they published were intended to be manuals for the instruction of diplomats. The correspondence of France's ambassadors and ministers of the seventeenth and eighteenth centuries was meant to serve as a practical guide to dealing with contemporary issues. Whether aspiring young French diplomats ever did dip into any of the volumes of the Recueil des Instructions is another matter. It would be interesting to know whether Camille Barrère and the brothers Paul and Jules Cambon, the ambassadorial triumvirate which did so much to enhance France's international stature in the years before 1914, found inspiration in the despatches of Hugues de Lionne or Nicholas de la Motte Goulas. But the idea that diplomats could learn from history, indeed that there were lessons to be learned, was a constant theme in French thinking about the publication of diplomatic documents before the First World War. Moreover, those French historians who participated in the meetings of the Commission seemed ready to believe that through the publishing of diplomatic documents they had altered the course of history. They readily praised themselves for that revival of French nationalism which helped bring about the elevation of Raymond Poincaré, himself a Commission member, to the presidency of the republic in 1913. And in the aftermath of the war Hanotaux applauded his colleagues for having given to the French people a spirit of continuity which satisfied the deepest interest of the country, and for having made Frenchmen aware of the opportunities which lay before them. A thorough grasp of history had, it would seem, helped France regain its preeminence over Germany. ${ }^{. "}$

The First World War was of course in itself a great stimulant to the publication of diplomatic documents. No sooner had it begun than foreign ministries hurried to print and publish selections of their prewar correspondence, not as an act of enlightenment, instruction or education, but rather as an attempt to justify stances taken during the war crisis of 1914 . Governments were anxious to rally popular support at home and abroad and sought to demonstrate that they were not responsible for the conflagration. In time the British published their Blue Book, the French their Yellow Book, the Germans their White Book, the Russians their Orange Book, and the Austro-Hungarians their Red Book. But these publications were often little more than sophisticated propaganda, prepared in great haste and without too much attention being paid to accuracy and detail. Of more significance for the future publishing of diplomatic archives were the new demands for more open diplomacy which grew in intensity as the conflict edged towards total war. In Britain, for example, the Union of Democratic Control, an organisation which counted amongst its leading members a future Labour prime minister, Ramsay MacDonald, was particularly critical of the secret diplomacy of the past which it held in large part responsible for the war. If such conflicts were to be avoided in the future then, its advocates maintained, diplomacy must be conducted more openly and be subject to democratic control. It was the need to respond to such criticisms that led the British Foreign Office to consider a more comprehensive publication of documents than that originally contained in the Blue Book of $1914 .{ }^{17}$

Prior to the outbreak of the war the British had seemed to lag behind their continental neighbours in publishing comprehensive volumes of relatively modern diplomatic documents. The Public Record Office received a government subvention to publish its series, Calendars of State Papers, catalogues of public papers with introductions and notes. These were valuable collections, but such diplomatic correspondence as they contained hardly went beyond the end of the sixteenth century. Indeed, in the early years of the twentieth century 
British historians began to show increasing concern over the apparent failure of the British government to assist historical research by funding the publication of Foreign Office records in anything other than Blue Book form. There was a feeling that modern European history, which usually meant the history of the revolutionary and Napoleonic period, was being written on the basis of foreign documents. Yet the Foreign Office, despite its reputation for secrecy, was not unsympathetic to such complaints. Eyre Crowe, a senior Foreign Office official well versed in German history, was particularly concerned about how little original historical research was being done in Britain. In 1908 he went so far as to propose that some historians should be given privileged access to Foreign Office records of a recent date. He also recommended the establishment of a Historical Section or Research Department in the Office with the specific object of engaging in such work. ${ }^{18}$ "We have," he noted, "nothing to lose as a nation and a good deal to gain by the widest possible publicity being given to our transaction with foreign countries." ${ }^{19}$

Nevertheless, any shift towards the Foreign Office taking a more active role in sponsoring the publication of documents, other than Blue Books and the British and Foreign State Papers, had to await the outbreak of war. Then, in addition to the desire to respond to public criticism of British diplomacy, it is possible to discern five factors which encouraged the Office to show more enthusiasm for such work. First, the personal doubts of Lord Grey, the foreign secretary in 1914, and his desire to ensure that the record was set right by a thorough publication of documents relating to his tenure of office; secondly, the acquisition by the Office during the latter stages of the war of a Political Intelligence Department and a Historical Section, in which historians were employed on propaganda and research work; thirdly, the belief shared by several of these that in a more democratic world the Foreign Office would have to educate its new masters and engage in fostering what Professor Charles Webster called "enlightened patriotism"; fourthly, the challenge posed by the Bolshevik revolution and the decision of the Soviet leadership to publish the secret treaties of imperial Russia; and finally, the concern felt by many British diplomats that the exigencies of war and the growth of prime ministerial diplomacy had eroded the Foreign Office's role in the formulation and implementation of policy, and that the Office required a popular constituency to support its cause. ${ }^{20}$ Professor James Headlam-Morley, who was assistant director of the Political Intelligence Department and, from 1919, the Office's first Historical Advisor, made much of this point. He argued in 1918 that the Office had become too aloof and that in modern times that aloofness "must tend to diminish the weight and authority of the office." It was, he insisted, necessary to provide the educated and interested members of the public with information, "not inspired guidance", but the kind of information governments had before them when they took decisions. ${ }^{21}$

Headlam-Morley was, however, no match for the Treasury. In the early postwar years no money was available for the kind of publishing projects he had in mind, and for the time being public parsimony triumphed over patriotic enlightenment. British governments, nonetheless, found it increasingly difficult to ignore the very public campaign which the German authorities waged against the treaty of Versailles. Indeed, few diplomatic instruments have had a greater impact upon the writing of international history. The victorious allies had, in order to provide a legal basis for their claims for reparation payments, all too confidently asserted in article 231 of the treaty that the war had been "imposed" on the allied and associated powers by the "aggression of Germany and its allies." This, the so-called "war-guilt" article, meant that diplomatic historians in general, and German historians in particular, would for much of the following decade continue to focus their attention not on the historical question of how did the war originate, but on the moral and legal question of who was responsible for it. If it could be demonstrated that Germany and its allies were not guilty, or at any rate not alone in their guilt, then the entire legal basis of reparations could be destroyed, and the moral basis of much else in the treaty would be undermined. The result was a diplomacy which was open, public and retrospective, in which the writing of history became tightly entwined with current international issues. The inter-war years became the golden age of historical diplomacy in which an ongoing debate about the recent past imposed itself upon current decision-making.

The German foreign office played a major role in initiating this debate, and German diplomats became masters in the art of what one historian has called "preemptive historiography". A war-guilt section, the Kriegschuldreferat, was established in the Wilhelmstrasse with the object of sponsoring the publication of documents and other material specifically aimed at 
countering the implications of article 231. This involved not only the use of German documents, but also those of other countries when available. In one instance a whole collection of Russian documents, the correspondence of Alexandre Isvolsky, was purchased secretly for publication by the section. But the collection of diplomatic documents for which the Wilhelmstrasse will always be remembered was Die Grosse Politik der Europäische Kabinette, a magnificent series of documents published in fifty-four volumes between 1922 and 1927 and spanning the years 1871-1914. The collection remains an indispensable source for anyone studying late nineteenth and early twentieth-century international history. Yet its purpose was very obviously to persuade rather than to enlighten or instruct. The volumes were intended both to defend Germany against its accusers and to mount an offensive against the legal and moral basis of the Versailles settlement. They were partial and obviously intended to give support to a particular interpretation of the past. Their editors, a lawyer, a theologian and a librarian, relied wholly upon foreign office documents, thereby omitting important material from other agencies and departments, such as the war ministry, which exercised a powerful influence on the decision for war in 1914, and they seemed ready to suppress or shorten other potentially damaging documents. ${ }^{22}$

There can, however, be little doubt about the success of the Grosse Politik as an exercise in historical diplomacy. It was the first major series of diplomatic documents to be published on the origins of the war, and it formed the basis of much of the early historical writing about the prewar period. Moreover, it had a considerable influence upon historical writing in the United States and upon opinion in former neutral countries. Indeed, the British and French governments soon found it necessary to mount an archival counter-offensive. The Foreign Office in London was particularly concerned about the impact of the Grosse Politik upon popular perceptions of the war and about the doubt that had been cast upon the validity of the British Blue Book of 1914. Nevertheless, it was not until 1924, when Ramsay MacDonald became prime minister in the first Labour government, that Headlam-Morley and other officials were at last able to secure political backing for the publication of a British equivalent to the Grosse Politik. Even then, the Treasury, worried by the cost of the exercise, tried to delay the appointment of editors. The latter, George Peabody Gooch and Harold Temperley, were deliberately selected as independently-minded historians whose past readiness to criticise British foreign policy would, it was assumed, help inspire public trust in the new series. And the eleven volumes of British Documents on the Origins of the War, which appeared between 1926 and 1938 responded almost as much to a longstanding desire on the part of officials and historians to be able to educate the public in the principles and traditions of British diplomacy, as they did to the immediate wish to combat German interpretations of the recent past. ${ }^{23}$

Gooch and Temperley had many difficulties to overcome in the selection of material for their volumes, most of them relating to the Foreign Office's decision that former allies should be consulted before the publication of communications originating with them. Other government departments were also sometimes less than generous in allowing access to their records. But the British editors have generally been regarded as more impartial and objective than their German analogues, and most of their volumes have stood the test of time. The greatest weakness of the series probably lies in its Eurocentric orientation-a tendency which doubtless owes much to the then prevailing view that the war's origins were essentially continental and to the fact that the editors' remit did not extend to the records of the India Office. The series also extends over a much shorter period than the Grosse Politik, beginning in 1898, and then only with a very brief volume whose contents seem sometimes to betray a desire on the part of the editors' to explain the rise of Anglo-German antagonism, rather than British policy towards the issues it purports to cover.

The one former wartime ally which raised the most objections to the work of the British editors was France. Protests from the Quai d'Orsay delayed the publication of the first volume of the British Documents, that dealing with the war crisis of 1914, and provoked Gooch and Temperley's first, but certainly not last, threat to resign. French politicians and diplomats were reluctant to admit that there could even be a debate on the origins of the war. After all, if Germany's war guilt were questionable then so also were French claims to reparation payments and France's military presence in the Rhineland. Only slowly did the French foreign ministry begin to appreciate that the historical debate could not be halted by France assuming 
a purely negative stance. And even after the decision had been taken in 1928 to proceed with the publication of the Documents Diplomatiques Français (DDF) the project was beset by financial difficulties. Indeed, in 1934 the ministry of finance came close to halting all work on the volumes, and the series was not completed until $1957 .{ }^{24}$ Like the British Documents, the $D D F$ were, in the first instance, intended to counterbalance the influence of the German volumes. Yet, also like the British, the French never truly succeeded in regaining the historical initiative in the inter-war years. The volumes of the DDF covering the period 1871-1914 are almost certainly the most extensive and comprehensive of those published by foreign ministries after the First World War. But their production was too long delayed to allow them to serve as effective instruments in the pursuit of historical diplomacy.

The feeling that the Wihelmstrasse had won a considerable propaganda victory, especially in North America, through the publication of the Grosse Politik and other documentary series helped carry the historical diplomacy of the inter-war years into the 1940s. In 1939 a British historian, Llewellyn Woodward, who had served in the Foreign Office's Historical Section during the First World War, reflected that the Germans had, in acting so quickly to present their case to the world, done much to influence American opinion in a sense unfavourable to Britain. And in order to prevent this happening again, Woodward began to press during the early stages of the Second World War for the publication of a set of British documents on Anglo-German relations in the 1930s. There was some resistance to the proposal, especially from politicians who were perturbed about what might be the effect of publishing documents relating to such controversial events as the Munich conference of 1938. Yet the prospect of the Americans publishing their own diplomatic records of the inter-war years encouraged ministers to take a more sympathetic attitude towards Woodward's plea, and in 1944 the decision was taken to proceed with the publication of another collection of British documents, the Documents on British Foreign Policy (DBFP), covering the period 1919-39. ${ }^{25}$ Meanwhile, it was decided that an allied commission would take on the responsibility for publishing captured German documents on foreign policy for the 1930s and 1940s-a case perhaps of archival or historical disarmament.

Since the 1940s the DBFP series has been completed by historians working on contract and full-time for the Foreign Office and its successor department, the Foreign and Commonwealth Office (FCO). But a series which at its inception was underpinned by a fairly clear diplomatic purpose, that of ensuring that in any debate on the origins of the Second World War the fullest account should be taken of British records, had by the 1960s become essentially a work of public enlightenment. The adoption in 1968 of the thirty-year rule for the release of British government records meant in any case the opening to researchers of almost all the Foreign Office correspondence for the years covered by the series. Likewise, the majority of the published volumes of the latest collection of British diplomatic documents, Documents on British Policy Overseas (DBPO), have been edited largely on the basis of records available to scholars at the Public Record Office. ${ }^{26}$ The two latest volumes of the collection, those published early in 1998, and covering the years 1968-75, have however broken new ground. They contain documents entirely from the closed period. In some respects this project was facilitated by the end of the Cold War: the volumes contain material that in the late 1980s might still have been regarded as too sensitive to publish. The recent past is, after all, for most governments too important to be left solely to historians. Yet the decision to embark on the volumes was inspired primarily by a desire to reinvigorate $D B P O$ and to ensure that the series continued to sustain, as well as supplement, research into the history of Britain's foreign relations. A more liberal records policy offered opportunities which could not be ignored; and renewed public interest in the final decades of the Cold War suggested a market that could not be neglected. ${ }^{27}$

Other foreign ministries are also committed to the publication of major series of diplomatic documents. In addition to FRUS, whose numerous volumes have become the basis for so much research into the Cold War, editors in Austria, Australia, Canada, the Czech Republic, France, Germany, Israel, the Irish Republic, Italy, Mexico, the Netherlands, Russia and Switzerland are all engaged in documenting twentieth-century diplomacy. These developments have gone well beyond the bounds of the historical diplomacy of the inter-war years, and reflect an increased readiness on the part of governments to encourage and maintain informed public debate on international affairs. Moreover, the end of the Cold War 
has stimulated renewed interest in the recent and not-so-recent past. Ambitious schemes for the editing of diplomatic documents have been accompanied by the pursuit of archival accords governing access to, and the joint publication of, documents. A "new world order" appears to demand a new world history, and historical revelation has again become both a function and an instrument of political change.

The democratising process has itself led to a new openness with regard to state archives, but access to them continues to serve a political purpose. The debate which reopened in the late 1980s, and which attracted considerable interest in the Baltic states, Poland and Russia over the existence and significance of the secret additional protocols of the Nazi-Soviet pact of 1939, arrangements which in effect provided for the partition of eastern Europe, was in part the result of glasnost in the Soviet Union. But it was also intimately connected with the endeavours of the Estonian and Lithuanian national movements to assert their independence of Moscow. Soviet historians had to tread warily in handling such material. After all, Soviet suffering and losses during the Second World War had been used to justify Soviet predominance in central and eastern Europe, and yet the very magnitude of these sacrifices could be regarded as a by-product of Stalin's consorting with Hitler. ${ }^{28}$ There has not, however, so far been any indication of a new war of the archives on the scale of that waged in the 1920s. On the official level archival détente and cooperation appears to be the order of the day. Like the radical-republicans of early twentieth-century France, the leaders of the emerging democracies of the east seem more concerned with publicising the transgressions of their predecessors than with exploiting archives to take pieces on the international chess board. They thereby enhance their own status and inhibit any return to former practices. History not only reinterprets the past in the light of the present, it also reinforces and legitimises the present by exposing the past.

Archivists and historians have not been slow in claiming for themselves a role in reshaping the new order in eastern Europe. In June 1993 I.V. Lebedev, the then director of the History and Records Department of the Russian foreign ministry, described his ministry's archives as part of the "culture and spiritual heritage" of the people. "Now," he added, "our historians and archivists should have their say in regard to the development of the very delicate process of formation taking place in the new Russia's immediate geopolitical vicinity, by issuing warnings about past mistakes and suggesting historically sound and politically acceptable decisions." ${ }^{29}$ Few western historians could feel quite so confident about what they had to offer. Those engaged in editing the major national series of diplomatic documents tend to conceive of their task in less pedagogic terms. Their aim is to assist in providing the raw material of international history; and if there is any one broad political objective implicit in their work it is that of encouraging the writing of diplomatic history on the basis of their own as well as foreign archives. History will of course continue to be used in support of diplomatic ends, and this seems all the more likely as newly-emergent states seek to define themselves in terms of their real or supposed historical pasts. And, as in earlier periods of revolution and reform, facts may be adjusted and rearranged to satisfy the requirements of political change.

There is a story, apocryphal perhaps, that when on 28 June 1919 the delegates assembled in the Hall of Mirrors at Versailles for the treaty signing ceremony, one of the German representatives turned to the French premier, Clemenceau, and said: "I wonder what history will say about this." Clemenceau replied that he did not know what history would say, but he did know what it would not say. "History", he declared, "would not say that on 3 August 1914 Belgium invaded Germany." Yet who today, when counterfactual history is so much in vogue and when the Internet provides opportunities for virtual diplomacy, could be so sure? Advances in information technology have facilitated the more efficient management of knowledge by foreign ministries: they may also offer new, possibly Orwellian, perspectives for diplomacy's handling of the past.

\section{NOTES}

${ }^{1}$ The opinions expressed in this paper are the author's own and should not be taken as an expression of official government policy. 
${ }^{2}$ Alfred Grosser, "Franco-Allemagne: 1936-1986," Politique Etrangère (Spring 1986), 247255.

${ }^{3}$ E. Hertslet, Recollections of the Old Foreign Office (London: 1901), 145-7.

$1^{4}$ FCO Historical Branch, History Notes, No. 5, FCO Library: Print, Paper and Publications, 1782-1993 (London: 1993), 1-4.

${ }^{15}$ H.W.V. Temperley and L.M. Penson (eds.), A Century of Diplomatic Blue Books, 1814-1914 (London: 1938), 1-7.

$1^{6}$ Ibid., 58.

${ }^{17}$ G. Monod, "Du progress des etudes historiques en France depuis le XVleme siecle," Revue Historique, i (1876), 28.

$1^{8}$ Publicationen aus den königlichen Preussischen Staatsarchiven, vol.1, Preussen and die katholische Kirche seit 1640 (pt.i, 1640-1740), ed. M. Lehmann (Berlin: 1878), v-vi.

$1^{9}$ Ministère des Affaires Etrangères (MAE), Paris, Procès-verbaux de la Commission des Archives Diplomatique (CAD), vol. 1, Sous-Commision du Catalogue et de la Publication, 6 April 1880.

$1^{10}$ J.A. Sorel and V.C. Pichois, "Albert de Gobineau et Albert Sorel: Correspondance inédite (1872-1879), Revue d'histoire diplomatique (1977), 229.

${ }^{11}$ G. Hanataux, Mon Temps (4 vols., Paris: 1935-47), ii, 8.

${ }^{112}$ Keith Hamilton, "The Historical Diplomacy of the Third Republic," in Forging the Collective Memory, Government and Historians through Two World Wars, ed. Keith Wilson (Oxford: 1996), 29-62.

$1^{13} \mathrm{lbid}$

${ }^{114}$ Les Origines diplomatiques de la Guerre de 1870-1871, vol. i (Paris: 1910), i-iii.

$1^{15}$ MAE, CAD, i, 4 April 1874.

$1^{16}$ Hamilton, "Historical Diplomacy."

$11^{17}$ Keith Hamilton, "The Persuit of 'Enlightened Patriotism': The British Foreign Office and Historical Researchers during the Great War and its Aftermath," in Forging the Collective Memory:Government and Historians through Two World Wars, ed. Keith Wilson (Oxford: 1996), 192-229.

$1^{18}$ Public Records Office (PRO), Kew, FO 370/811, L50296/5026B, minute by Crowe, 23 March 1918.

${ }^{119}$ Ibid., FO 370/16, L40126/16761B, memo. by Crowe, 17 Nov. 1908.

$1^{20}$ Hamilton, "Enlightened Patriotism."

$1^{21}$ PRO, FO 371/4366, PID 263/263, memo. by Headlam-Morley, 26 June 1918. 
$1^{22}$ Holger H. Herwig, "Clio Deceived: Patriotic Self-Censorship in Germany after the Great War," in Forging the Collective Memory:Government and Historians through Two World Wars, ed. Keith Wilson (Oxford: 1996), 87-127.

$1^{23}$ Hamilton, "Enlightened Patriotism."

$1^{24}$ Hamilton, "Historical Diplomacy."

$1^{25}$ Uri Bialer, "Telling the Truth to the People: Britain's Decision to Publish the Diplomatic Papers of the Interwar Period," in Forging the Collective Memory: Government and Historians through Two World Wars, ed. Keith Wilson (Oxford: 1996), 264-88.

$1^{26}$ On the principles governing the selection and publication of doucments for $D B P O$ see: H.J. Yasamee, "Official History: Editing the DBPO," FCO Historical Branch Occasional Papers, No. 9, Documents on British Policy Overseas: Publishing, Policy and Practice (London: 1995), 24-26.

$1^{27}$ Gill Bennett and Keith Hamilton, "Document Détente: A New Series of Documents on British Policy Overseas," in Diplomatic Sources and International Crises, ed. Leopoldo Nuti (Rome: 1998), 95-9.

${ }^{28}$ I am grateful to Dr. Eleanor Breuning of the University of Wales, Swansea, for letting me read her unpublished paper, "The Nazi-Soviet Pact and its Present-Day Repercussions," which examines this subject in detail.

$1^{29}$ I.V. Lebedev, "Democratic Reforms in the Foreign Policy Archives of the New Russia," FCO Historical Branch Occasional Papers, No. 7, Changes in British and Russian Records Policy (London: 1993), pp. 10-16. 


\section{HOW DO YOU KNOW WHAT YOU THINK YOU KNOW?}

\section{J. Thomas Converse}

When preparing this presentation I initially found it somewhat difficult to decide what its focus would be. Archival and records management theory and practice, knowledge management, information technology and diplomacy at first glance seem to be a pretty disparate group of topics for a 30 minute presentation. It can, however, be done. I chose to focus on four records-related areas where these issues come together and provide the greatest challenges to archivists, diplomats, historians and technology providers. These areas are: (1) validation, (2) trustworthiness, (3) context and (4) longevity.

Having been intimately concerned with diplomatic records as a creator of them, a consumer of them and a custodian of them has given me a well-rounded view of their importance, their functions and their limitations. As a result of my background with the State Archives of Kentucky, the U.S. Department of State, the U.S. National Archives and my current position as head of the records section of the Inter-American Development Bank I have become more and more convinced that an organization which has a well conceived and fully functioning records management program will have a solid archives and that that archives can be an essential contributor to the information and knowledge needs of the organization. On the other hand, an organization which lacks a solid foundation regarding both its current and its non-current records will be building its information structures on sand and will pay a heavy price for such a state of affairs. So, with my biases exposed, let us turn to some definitions of archives and look at their implications for diplomacy, especially in light of the new technologies.

\section{DEFINITIONS OF ARCHIVES}

The archival Magna Carta is Sir Hilary Jenkinson's A Manual of Archive Administration, published in 1922. This manual is the departure point for discussions of archival theory and practice, at least in the English speaking world. Sir Hilary, in a later essay, defined archives as "the Documents accumulated by a natural process in the course of the Conduct of Affairs of any kind, Public or Private, at any date; and preserved thereafter for Reference, in their own Custody, by the persons responsible for the Affairs in question or their successors." In an article in the Spring, 1994 issue of the American Archivist, Luciana Duranti quotes this definition and further cites Jenkinson's Manual in which she notes that "because they [archival documents] are created as a means for, and a by-product of, action, not 'in the interest or for the information of Posterity,' and because they are 'free from the suspicion of prejudice in regard to the interests in which we now use them,' archival documents are impartial and "cannot tell...anything but the truth.'" Now this is a startling concept-that archives are inherently trustworthy and useful precisely because they were generated as a by-product of recording the daily business transactions of an organization (or individual) and without regard to how they might be used by other people for other reasons in other times.

\section{Laundry lists}

A couple of examples might be illustrative. Consider, for example, the laundry lists of a medieval monastery and why they might be a very useful research tool. Some monk, or succession of monks, created, over a period of time, lists of dirty linen and what happened to it. These records express no interest in anything else going on in their organization, much less in their society as a whole. Whatever went into the laundry lists was validated as having to do with that topic by the mere fact of inclusion. Those responsible for the laundry records did not intermix records dealing with other matters; if it didn't have to do with dirty linen, they didn't accept them. Once accepted as germane, the records were arranged in ways most useful to the laundry department-by name of monk, by type of material, by date, whatever 
was organically most useful to them. The fourth point to note is, of course, that they survived the vagaries of the centuries.

Exactly because of this specificity in why they were gathered together (validation); the fact of their being accepted by the organization as reliable (trustworthy); their internal groupings (context and arrangement) and their survival (longevity) it is possible to use such records with confidence in, for example: an analysis of administrative costs of religious institutions; the names and status of individual monks based on the numbers of articles to be washed or numbers of changes of clothing; studies of medieval textile trade patterns, perhaps even determining the names of individual weavers or cloth merchants; the internal hierarchy of the monastery; liturgical customs based on the use of various vestments; the dating of visits by passing royalty; seasonal changes in clothing; etc., etc. The very fact that the creators of the laundry lists were supremely indifferent to providing information on administrative costs, names and status of monks, the textile trade, weavers, hierarchies, liturgical issues, royal visits, seasonal changes, etc., etc.-makes the information which they provide about these areas so very valuable. They unconsciously provide the peripheral vision of history, without which history would suffer from tunnel vision.

As an aside, the examples I am using here illustrate that diplomatic (and indeed all) archives share certain common traits which offer particular challenges to the consumers of today's information technology. These challenges include the development of computer functionality for the creation and maintenance of true records. To do this, records produced electronically must: (1) be able to be validated as being relevant to the business transaction at hand, (2) provide an environment which will allow records created in the normal course of business to maintain their inherent trustworthiness, (3) provide some architecture for maintaining a meaningful relationship among records and, perhaps the most difficult, (4) ensure survival over time. Surely it is not too much to expect the latest technology to at least provide the functionalities available to medieval monks.

\section{Concentration camp records}

This continuity of traits could be illustrated in any number of other examples. The records of Hitler's Germany, for instance, captured by the U.S. Army after the fall of Berlin in 1945 were useful at the War Crimes trials in Nuremberg precisely because they were created without consideration of how they might be used outside the context of their creation. They did not have subject files arranged under the title "Atrocities" or "the Holocaust" but rather they were organic records of routine transactions relating to, for example, the administration of concentration camps. These routine transactional records might include orders of the day, receipts for supplies (such as poison gas), bills of lading for the shipment of personal effects (such as eye-glasses and gold teeth), personnel records which listed everyone from the camp commanders to the guards (including periods of service and position descriptions), routine periodic reports from the camp medical unit (which might include the results of experiments on human beings), mortality registers, incident reports of uprisings and how they were quelled; in short, all the usual, mundane records likely to be produced in the daily course of business in a well-ordered military installation. Only by reviewing such routine records does the full impact of what went on in these camps hit home. And these routine records were accepted without question by the War Crimes Tribunal because they were inherently trustworthy. As unalike as these records are from the monastery laundry lists, they share the common threads mentioned above-they are trustworthy because they had no interest in documenting anything other than the routine transaction at hand, the act of inclusion in the files served to validated the records, they were maintained in a meaningful order and they were preserved over time.

\section{State Department records}

Another body of records to consider might be those of the U.S. Department of State. Regular reports are submitted to Washington from all diplomatic and consular posts, and have been since the 1790s. Studies of U.S. foreign policy can be enhanced by going beyond the selected documents published in the "Foreign Relations of the United States" (the FRUS) and 
looking at these raw reports. Indeed, since the documents printed in the FRUS are selected after the fact, they are inherently less trustworthy than the original reports which must be, by definition, trustworthy. These reports were filed by name of diplomatic post and chronologically thereunder. The pre-1903 reports have been microfilmed and are available for use and purchase at the U.S. National Archives. An early $19^{\text {th }}$ century consul might never have mentioned the words "foreign policy" in a report, but his comments on the treatment of U.S. ships by the local harbour master, the relative status of the U.S. ex-patriot community, the progress of civil and criminal cases through the local courts, the treatment of U.S. prisoners, the status of negotiations over export licenses, local gossip, rumours of coups, complaints about the unhealthy climate, currency fluctuations, local customs, language issues, legal issues, etc., provide a rich soup of information which was used then in the conduct of U.S. foreign policy and which can be mined for a variety of purposes today. This body of records is still receiving accretions to this day.

Let's follow the path of how more recent diplomatic information becomes a part of these files by looking at the first foray of a junior foreign service officer into diplomatic reporting in the mid-1980s. To protect the innocent, let's call him, oh, Tom, for the sake of this discussion. Shortly after his arrival at post, where he had begun his first tour as third secretary working in the consular section on the visa line, Tom attended a large reception at the ambassador's residence. The food and liquor were excellent, the music and the lights were soft, all the movers and shakers were there. In other words, all the elements were in place for a hard night of diplomatic representational work. Now l'm not being sarcastic here-this is the setting in which much of the most important work of diplomacy is done. Here is where information (and misinformation) is exchanged, where friend and foe are sized up, where friendships are made and rivalries contested. What is of interest to the archivist, as well as to the historian and the diplomat, is how such environments produce meaningful records.

Well, back to Tom. During the course of the evening, he acquired some startling information. It could have been about currency fluctuations, or export restrictions, or the flow of illegal aliens, or the love-life of a prominent local figure or any one of a thousand topics. For the sake of this discussion, let us say that it related to a coup d'etat planned for the following month. As soon as he could find his consul general, Tom told her of his hot item and suggested that they notify Washington immediately. She, much wiser than Tom in the ways of diplomacy and how information was treated, listened and suggested that they follow the usual channels. (She certainly knew that awakening the Secretary of State at one in the morning to discuss coup rumours with a junior officer would not be a career-enhancing move.) Disappointed but undaunted, Tom began to navigate those channels which would lead his information into the safe waters of the diplomatic archives.

At Tom's earliest opportunity he wrote a standard "memcon", or memorandum of conversation, going on for pages about what an important piece of information he had and how it would change history. He took the time and trouble to set the scene, providing copious background information about the party, the ambiance, his reactions to it, how he thought the information he was sending should be used, whose side we should take in the imminent civil war, what he thought of all parties concerned, etc., etc. Little did he realize the process through which his multi-page opus would go before being transformed from information to record.

The first step was to transcribe it from hand-written notes into a customized word processing package and print it out onto a standard form, compatible with the communications equipment in use at the time which would convert it to a cable and transmit it to Washington. (Now this is an important part of the validation process - the physical format must be correct or the record will be summarily rejected.) Excitedly he sat down at the terminal and began to work. Certain information fields were required, such as drafter. That would be proud young Tom. Then the system asked for clearances. Young Tom put down his boss, the consul general. He put in certain codes which were attached to the cable-to-be, such as $\mathrm{CO}$ for consular matters, reflecting his assigned position. Proudly young Tom took the great document to his boss, sure it would be flashed to Washington at once, re-writing diplomatic history. Alas, illusions are grand but not always long-lived. The consul general took a heavy blue pen to the draft, 
pruning out much deathless prose, not even trying to be gentle as she pointed out that no one cared that Tom's favourite scotch had been served at the party, whether or not the minister of justice's wife had on the same dress as someone else, how the newly redecorated residence looked, and certainly no one wanted Tom's opinions about the past, present or future. The purpose of the memcon was to report facts. Analysis was outside its scope. She also pointed out that even the subject code was incorrect. It had nothing to do with consular affairs, even though Tom might have been a consular officer. The proper subject was PO for Political issues. She increased the number of clearances to include the Deputy Chief of Mission and several others who had been at the reception. Unconsciously, as an organic part of her function, she was deepening the validation process by making sure that this embryonic document conformed to the standards of the records system of which it would form a part, both in terms of format and content. Once she had finished pruning, it went through the clearance process. The DCM made a few additions to the message, such as the fact that the high-ranking officer who was the source of this report was involved in a simmering dispute with another high-ranking officer whose career he had often tried to damage. Another clearer mentioned that the source had been drinking heavily all evening and that he had been overheard saying that he was going to "get el Colonel" that night. Other clearers added other details. When all the clearances were signed off on, the much shorter cable was taken to communications where it was sent. Once received, it was copied, distributed and filed with two centuries of similar reports.

Diplomatic history was not, alas, re-written. No coup occurred. Luckily the "fact" had been vetted, placed in its context, recorded as a rumour and then properly filed away with all its brother and sister reports going back two hundred years. Young Tom could, however, take comfort in the knowledge that he had contributed to both diplomacy and history, albeit in a very small way, since his information had been converted into something worthy to be part of the archives of the U.S. Department of State. It had been (1) validated, making it (2) inherently trustworthy, (3) it had joined with many other accretions to the reporting files, putting it in its proper context and (4) it would be kept for further reference.

Other examples could include aerial photographs of Europe and Japan, Stasi files, secret correspondence of Louis XV, baggage lists from U.S. immigration, visa files, Czar's secret police, and so on and so on, but I think that I have made my point about what gives a record archival value. I would now like to turn again to the issue which I raised earlier about new information technologies and the challenges and opportunities they offer to the "traditional" archives and records keeping systems.

\section{CHANGES AND CHALLENGES OCCASIONED BY TECHNOLOGY}

Because of the very success of archives in storing knowledge, new types of researchers are clamouring at their doors, demanding information in new formats and with new expectations of what can and should be done with the information "locked away in dusty old boxes". These new demands hold great promise and create perils for archives and their users.

One of the results of this change of users and uses is the blurring of the distinctions between information and records. All records are information but certainly not all information is a record. Those who ignore this distinction do so at their peril. Let me give you a couple of instances to illustrate this distinction and how technology has been involved.

\section{TWA Flight 800}

This blurring of lines was brought home to me when Pierre Salinger, the former aide to John F. Kennedy, claimed to have proof that the U.S. Air Force shot down TWA flight 800 over Long Island a couple of years ago. I remember him standing before the TV cameras in Paris, waving a piece of paper and saying, "Here is proof that the Air Force did it." As near as I can figure it out, the following happened. Mr. Salinger knew someone who worked in a French intelligence service. This person had obtained a copy of something which reportedly had been acquired by someone with access to the ClA's computer system. What they found, and 
posted on the Internet, was a statement that the Air Force had been responsible. The mistake that Mr. Salinger made was to transfer the assumed trustworthiness of a properly "archived" document to a piece of free-floating information. The information which was obtained (or leaked or planted) was deracinated, it had no context. Where was it from? Was it indeed from the CIA? If so, how had it been identified? Was it from their "rumours" file? Or from their "usually reliable sources" file? Was it in their cables from the field or was it a photocopy of something from a tabloid which they had as part of their reference files of nonvalidated information? Had it been forged and put out as part of an attempt to exculpate the airlines or the manufacturers of the plane or by some conspiracy-obsessed individual or by someone who wanted to make a movie? Where is it now? It fails every test of "archivability", to coin an inelegant word. It was nonvalidated, untrustworthy, without context and impermanent. And yet, because it came from a computer a person used to handling important information accepted it at face value. Where is technology taking us?

In the interests of time, I will pass over the issue of subject files and reference files and how they relate to archives. This could be the topic of a paper in itself.

To avoid merely complaining about misapplied technology and get specific I offer the following as minimum requirements which must be in place before records in electronic format could be acceptable to archivists, historians, diplomats or anyone else who depends of records on a daily basis:

- A sine qua non is meaningful metadata. The capability exists to ensure that all relevant data about data being created and preserved electronically is present and accounted for. I would want to know that any system purporting to be an electronic records system is robust enough to carry the heavy burden of validating the information.

- If electronic information is being represented as an archives, the standards which make it inherently trustworthy should be clearly defined. This can be done, but is expensive and complicated. Already there are records-keeping standards being developed in Australia and by the U.S. Department of Defence which are widely available. All of us must be clear that the computer term "archives" means to make a back-up copy. It has nothing to do with the functions of an archive. To mention a pet peeve of mine, "archives" is a noun, never a verb.

- Provide context. A simple, direct-access, relational database is wonderful for quick answers, but as anyone who has done even a simple search on the Internet knows, the results of that search may provide you with every single one of the thirty references you may want for Marie, Princess of Battenberg of the House of Hesse, but if those references are buried within 250,000 hits covering Battenberg lace, the Hesse Oil Company, the Princess cruise line, every real estate company selling houses and Herman Hesse, what have you got? In the field of archival cataloguing some of the most fiendishly difficult challenges involve the linkages between related files, series, sub-series, documents, etc. It can be done, but is also expensive and complicated.

- Provide longevity. (This may be the biggest challenge of all.) The current lifeexpectancy of five years for a computer application is not enough to guarantee that records will survive for as long as they are needed. In a related area, I also expect clear distinctions between the use of computers for access and for preservation and I expect both issues to be addressed. Confusion between them may present the greatest threat to the continued value of archives. They are not the same. Indeed they are sometimes diametrically opposed. Increasing access may put records at risk. Preservation issues may limit access. Those who say "Let's use the power of the computers and scanners. Just put everything on the computer where we can search it and don't worry about that old-fashioned paper" make ice-cold chills run up my spine. It's not the paper I continue to long for, it's the overt context I want to see. Another related spine-chilling comment is, "I've got what I need from this database. Just dump 
it." We do not have to be Luddites to have concerns about any organization's commitment to keep data fresh, to migrate it every five years or so, to keep all the metadata intact and to keep all the archival relationships clear, especially when the original creator or user has finished with it. Archivists and historians may know that there are lots of secondary uses of information, many of which are more important (to us, anyway) than the original use was. We must make sure that the IT department understands this use. I wonder how many electronic records will not make it across the Y2K divide because someone will decide that what's on them is "just old stuff" or "we're through with that file" and throw out the diskettes rather than spend valuable time and money ensuring that the information is preserved?

\section{CONCLUSION}

So where are we? Right where we started as far as archival principles go but light-years ahead as far as the tools available are concerned. Archives (and archivists) have survived paradigm shifts before; we have gone from clay tablets to papyrus to moveable type to punch cards and, yes, even diskettes. We'll survive again. It's the attrition rate of information loss as we cross that technological boundary which I would hope to reduce to a minimum. So let us embrace the power of the computer to provide us with access speeds we never imagined even a few years ago; let us take advantage of data-mining technologies, of messaging possibilities, of the Internet and the Intranet and the Web, let us do all we can do using the technologies on offer, but let us also demand the validating and relational functions which give archives trustworthiness for as long as they need to be kept. It would be ironic if the $21^{\text {st }}$ century, instead of leading to a technological utopia were to lead us backward to an informational Dark Ages where institutions loose the ability to create and maintain trustworthy records which can stand as guardians of individual rights and as sources of information which can be used to unite us. Working together we can ensure that computers will bring us great benefits. Failure to articulate our mutual needs as information consumers and custodians might well mean that records-keeping concerns are not addressed when designing information systems and we will all inadvertently contribute to an epidemic of organizational Alzheimer's. 


\section{BEYOND DIPLOMATIC - THE UNRAVELLING OF HISTORY Robin Alston}

When I was asked to attend this conference the invitation was, of course, by e-mail. I thought deeply for a while: perhaps this "solemn conference" needed a little comic relief and perhaps I could provide it. I am known here in Malta because I was a visiting professor five years ago. In deciding what to say, I realized that actually my whole life has been devoted to knowledge management. I did not call it that-I called it bibliographical control. As director of the Library School at University College, which includes the training of international archivists and librarians, I realized that, perhaps, I might have a few things to say which will interest you whether you are diplomats or are involved in IT, which I have been involved in for 35 years.

I am going to drift-I hope not confusingly for you - between the 1850s and the 1990s, and I will start with the 1990s because most of you were around in the 1990s and not many of you were around in the 1850s.

The British Library, as you know, was founded by an Act of Parliament in 1753. It was the library, basically, of Sir Hans Sloane and it slumbered on in its early years, governed by partially occupied clerics. Radical change began to take place with an Italian revolutionary expatriot by the name of Antonio Panizzi. Panizzi had sought occupation as a teacher of Italian at University College, but as there were no takers (at one point he nearly got Robert Browning as a student; unfortunately Robert Browning went to someone else to teach him Italian) he daringly applied for a job as assistant keeper in the library of the British Museum, a post which with some patronage from very high sources he managed to get.

The Panizzi diaries have never been published. That is great pity, because it is clear that from about 1840 when Panizzi's career begun to take off, he worked to create a universal repository of knowledge in the British Museum. How he set about doing that is all, actually, in the diaries, and it is an extraordinary story of persistent achievement. By the time of the 1851 exhibition, which, as you know, put England on the world map, Panizzi was convinced that there was a way of somehow persuading the governments of the world, whether they were friendly or not friendly, to deposit their documents and their official publications and anything indeed which could be of value in assessing the material culture of that country in the library.

The astonishing success of this enterprise had one catastrophic result. There was no way Panizzi could employ enough cataloguers to cope with the influx. The diaries report daily: another wagonload of documents from Italy, two more wagonloads from France. The result was that by 1866, when he retired as the director of the British Museum and principal librarian, the library was in possession of documents of an extraordinarily varied nature covering the entire world. Arankoff, who was a librarian in Russia, was sent to the British Museum to examine the documents and the books relating to the early history of Russia, and he was astonished at the volume of material which existed in British Museum, which existed neither in Moscow nor St. Petersburg. There were several visits from German librarians who, again, went home utterly mystified at the sheer volume of material, both manuscript and printed, which the library had managed to acquire.

Now, I am going to come to the 1939-45 war. The records of the British Museum for that period exist in 64 cartons. They have never been catalogued, they have never been sorted, and there is a considerable degree of sensitivity about these records. Why should there be sensitivity about records in the British Museum from World War II? The answer is quite simple. The intelligence services, as you probably know, were based during the war in Oxford. The reason for siting them in Oxford was that it was quite credibly believed that Hitler might bomb London, he might bomb Manchester, he would certainly bomb Coventry; but that he would draw back from bombing Oxford. And, therefore, the presence of the intelligence services in Oxford was reasonably safe. 
Thus, every week on Tuesday and on Friday a limousine arrived from Oxford and was loaded up with documents from various departments of the library-printed books and, of course, maps - which were sent to Oxford, and which played a highly significant part, actually, in many of the operations of the war.

I have read the entire contents of those 64 files. Let me give you one illustration. The landings in Greece would have been a total disaster without the very special knowledge of a map curator called Constantine who actually understood the nature of Greek cartography. And we would have made serious mistakes had it not been for the wisdom of that map curator and, of course, the collection of maps in the library.

Closer to our present time, I would like to remind you-and I am sure you are aware of this fact-that many decisions during the planning of the Falklands war-to the consternation of those who had to carry this exercise out-depended on maps of the region, but the Ministry of Defence had no maps of the Falkland Islands and I assure you a campaign carried out without maps is a very dangerous thing. The keeper of the map library of the British Library was woken up at an early hour in the morning to open up the department and find maps of the Falkland Islands, which could be sent to Southampton for immediate reproduction by the Ordnance Survey, so that when the landing forces arrived they knew the difference between what was a bog and what was terra firma.

Now I am going to return to 1990, when I suggested to the British Library that it would be appropriate to launch a series of advanced research surgeries, available to the public and to anyone who wished them, to combine the power of the computer with specialist knowledge of the collections-uncatalogued as well as catalogued. And don't forget when you look at those 600 volumes of the British Museum catalogue, you are looking at a mere $40 \%$ of what is in the building.

So, on January the $3^{\text {rd }}, 1990$, the research surgeries were publicly announced, and I sat there waiting for people to turn up at prearranged times and present me with their problems. The surgeries had a simple rule: if you can find the information you need using ordinary printed reference sources don't come near me because I have nothing to do with it. You have to prove to me that you have exhausted all the possibilities provided by the reference facilities of the library. Then we will try the computer.

For three years I conducted the surgeries. They were attended by civil servants, they were attended by members of the security services-they always called themselves Smith. They wanted to know very strange bits of information. Salmon fishing, artificial salmon raising in Nova Scotia, a range of topics which, very challenging, could certainly not be solved by the conventional resources at my disposal. General catalogues are useless. However, the resources of the Online Computer Library Center (OCLC), which you may be familiar with, a database which by then already had 40 million books on it, the Research Libraries Information Network in California which had 36 million books on it, and the Internet itself, provided one with access to over 400 university library catalogues and a few archives. We did not have yet the National Register of Archives; in fact we did not have a lot what we now have.

The problem, you see, was that some of my attendants at the surgeries were well aware of these resources, but had absolutely no idea how to interrogate them. If I can remind you, in 1990 there were no less than 56 retrieval protocols in use on the Internet, and searching very large databases like OCLC and RLIN is fraught with difficulties-the same sort of difficulties you get when you search the Internet, and you search for DNA and you get a café, and you get a lace manufacturer: you get anything but Crick and Watson! But there are ways of navigating large bibliographical and even archival databases.

The series was so successful that I submitted a report to the British Library urging them, when they opened the new building, which, as you know, was completed last year on Euston Road, that this should be offered as a matter of course, as a service to the public. I said in my concluding statement: "Librarians are not arbiters, they are prophets. They collect from the detritus of printers and the scribes, and they do so with judgement. The precision of 
judgement has always distinguished the good from the mediocre." The British Library, like so many large bureaucratic institutions, thought that it was getting into deeper water than it cared to get into, so it abandoned the service.

To conclude, let me take you back to the mood of the 1850s. While Panizzi was planning the future of knowledge and its availability in the British Museum, there was an obscure civil servant whose name I will now tell you: Albert Symons, who worked for 25 years in various ministries. He had lived through all of the various crises from 1825 up to 1853 . He was asked by Gladstone, who was then Chancellor of the Exchequer, whether he could draw on his experience in working with various ministries to produce a sort of blueprint for the management of government departments. There had been in the 1790 s much concern expressed about the state of government departments and there had been many inquiries. They discovered that the Royal Navy had somehow mislaid a million pounds since the age of Pepys. A million pounds is a considerable sum of money to lose in the $18^{\text {th }}$ century. Well, Symons was, of course, just the man that Gladstone needed.

He had worked in various departments and he had also done some work-and this is very important-in the Indian Civil Service. The Indian Civil Service was, probably, the most highly organized administration in the world. And the East India Company was virtually its own government-it became a government in 1858. It was at that time simply the largest trading company the world has ever seen. Symons observed the methodical way in which every single operation of the East India Company was structured, modelled, and recorded. And so he took Gladstone's invitation and produced a remarkable work. You will be very lucky if you find more than two copies in America, there are two known in Great Britain, apart from Gladstone's own copy in St. Deniols, which is marked up with all his own annotations. It was not published-it was intended for private circulation. And it has, I promise you, the most unpromising of titles: Papers Relative to the Obstruction of Public Business and the Organization of the Civil Service. I will read you one passage:

The ultimate object is to bring back the condition of offices to the state of subordination to one scheme of organization, which at one time characterized our institutions, so that each part may have its own proper function and subserve the common purpose of the whole without delay or obstruction to any other part; and so that the Prime Minister may truly preside over the whole while each associate minister be encharged only with those duties that are truly special, may be able fully and promptly to discharge them; and that the total result may be unity of principle and unity of action with, as far as may be, unity of practice in the execution of detail.

He goes through every government department, and at the end provides a synopsis, which is extraordinarily interesting because he divides it into what he calls the body (those are the elevated people-the ones who get the good lunches) and the establishment. And just note who are to be included in the establishment; and this is across the board: this is every department of state, it is the Post Office, it is the Treasury, it is the Home Office, it is everyone.

- The chief officer-what is he responsible for?

- the receiver and examiner of papers and fees;

- the clerk of minutes and board;

- the clerk of orders and correspondence; and

- the clerk of acts and records.

Underneath the chief officers' department are the special registering and recording officers:

\footnotetext{
- enumerator;

- describer;

- definer;

- classifier;

- designator;

- librarian;
} 
- index maker;

- reader, i.e. proof reader;

- abstracter;

- extractor; and so the list proceeds.

Clearly, Symons understood that it is not enough in government simply to have an apparatus for making decisions, but that all those decisions should be made in concert with other related departments, and that there must be a record. A record, which, as J.T. Converse reminds us, should be trustworthy and which should be long lived.

That is why, ladies and gentlemen, when you visit the Public Record Office today to consider the historical details surrounding an event after 1853, chances are you will find the records you are looking for. If, on the other hand, for thoroughly misguided purposes, you want to find out not why we lost the American colonies but how we lost them, you will find nothing. There is not a single record which will explain why, when George Washington sought an audience with admiral Howe, who was anchored off the New York harbour, he was refused audience because Washington called himself General, and Admiral Howe said: "I have no such name in my register." One can follow this even further: the petition of the 13 Governors, which was sent to London and which, apparently, never arrived. Why it never arrived it is not clear. There is a copy of it in the Massachusetts' Historical Society in Boston. But the original exists nowhere in the government records of Great Britain. Lord Sandwich, who was the appropriate person to receive that petition at the time was away grouse shooting in Ireland. And that, of course, was far more important than worrying about these tempestuous colonials who were always grumbling. I think it would be fair to say, on the balance of the records I have seen and the diaries I have read, that we lost the colonies quite simply by default. There was no need to lose them, which raises another interesting question: why we were prepared to lose them by default?

Well, the date 1764 has been raised, during the course of the conference, by Keith Hamilton. It is the very first year in which the Court of Directors of the East India Company were prepared to bail the British government out of a deficit—and this astonished all. It astonished the king, it astonished everyone. "India?" Half of the members of the Cabinet didn't know where India was. "Where did all this money come from?" Well, remember the Boston Tea Party? This was all surplus tea that the East India Company wanted to dump somewhere. And they thought: dump it on the Americans, send it to Boston. Suddenly, after 1764, the first year in which the income of the East India Company appears in the Parliamentary Papers, I think Britain realized that the income which might have or might not have come from the 13 Colonies was peanuts compared with what was going to come from India. And they said: "Oh, let the colonies go!" Of course, I cannot prove that because there is no documentation in the record to substantiate it. But there is plenty in the record to substantiate the growing swell of revenue which the British government began to enjoy after 1764 from the East India Company.

And for that fortunately we have double records. This is the historian's dream-to find the documentation from two sources. Because we have India from the records of the departments of state, and we have the impeccably kept records of the East India Company, which are now part of the British Library. This is an interesting situation, in that $10 \%$ of the public records of Great Britain are actually in the custody of the British Library and not the Public Record Office.

I leave you with this interesting dilemma. Some things have changed since my foray with computers in the 1990s, but an awful lot has not changed. Libraries still catalogue their books in a pretty casual way. They are indexed in sometimes a very imperfect manner and the volume of print has increased in spite of all the things that the prophets have been telling us for the last 20 years. "The book is dead!" "We need not worry about books any more, everything you need is going to be available on the Internet." "Forget books, we'll digitize everything." 
What they overlooked is that when you transfer (archivists will know this principle very well) a document from one medium into another you have to re-catalogue it, because how you catalogue it in one medium is of precious little use in another. Are we seriously going to consider re-cataloguing the printed record of the world since Gutenberg in $1456 ?$

There is a role for the computer in all matters, whether these matters are English literature, which happens to be one of my interests, or English political history, or whether it is diplomacy, or whether it is the study of archives. There is a role for the computer-but do remember some of the strictures which J.T. Converse insists upon, because without proper safeguards your machine readable information is destined to be useless. 


\section{KNOWLEDGE MANAGEMENT: EXPERIENCE FROM INTERNATIONAL ORGANISATIONS John Pace}

Knowledge management in the United Nations human rights program is a relatively recent phenomenon. It may be said to be symptomatic of the evolution of human rights activities over the years since the adoption of the Universal Declaration of Human Rights in 1948. This evolution may be classified into three distinct phases. The first phase was the phase when the United Nations system was busy setting standards. The second phase is that when the system was seeking ways and means of obtaining the implementation of the standards, and the third phase is that when the system started to look at the ways in which it could apply its experience towards creating conditions that would enable governments to prevent negative situations of human rights from further deteriorating or from developing. The first phase takes us till roughly around the second half of the seventies, the second phase would take us to somewhere around the mid-eighties, and the third phase brings us to today.

In the first phase the characteristic of the flow of information was more or less outward: we had a core or nuclear idea which needed to be shared and developed into international standards of human rights. These standards would be universal standards and would apply to all persons. This first phase took about 25 years, and consisted very much of the process of defining where the sum total of the national values met around a common denominator, which was reflected in the standards of the Universal Declaration. So, this was a period of reflection, consultation, negotiation and formulation, and was dedicated to the immediate process of setting of standards. But it really never touched people; it really never touched the individual.

In the second phase we started to get close to realities. It was the time when we were first authorised by the Commission on Human Rights and later by the General Assembly to gather information; to go to countries to meet individuals. We were able to inform ourselves directly of realities in human rights situations and we started to bring that back and apply it to testing the standards that had been developed over the previous years. Of course, the situations that we tested were the very denial of the situations that were envisaged by those standards. So the gap was immediately apparent; seemingly impossible to bridge. This was the time when it was fashionable to call human rights situations, situations that were anything but human rights situations since, in fact, they were situations of violations of human rights. So we went around in a number of countries, all impossible human rights situations. This period taught us a lot in terms of the gap that we had to bridge between those realities and those standards and also it taught us the need to reflect on ways in which this gap could be bridged.

The second phase was interesting also because at this time we experienced a dramatic increase in information emanating from local groups, non-governmental organisations, both international and local. They were not all the most objective of sources, but the quality of the information was generally authentic, and in any event most useful in re-constructing the factual situation when direct access was denied us. To some governments, these were subversive or opposition groups, and hostile sources. We did not really let the terminology affect our work, because for all we knew, both sides were right. What interested us at this phase was trying to record and to get an idea of the experiences that were actually being made by people on the ground, and the reasons for those experiences.

This led us to the third phase, where we started to apply this knowledge that we were deriving from the information we were collecting, in order to try to find ways and means of addressing or redressing these phenomena. It should be understood that what was happening was an all around evolution and not an invention of the international bureaucracy. It was the international political consensus, if you like, the intergovernmental common denominator that was enabling us to move from the earlier stages of discussing theory to the testing of these standards against realities.

It is at this third phase, with the procedures that had developed over the years, that knowledge management became a necessity. These procedures all depend on the receipt 
and application of information. Since they had been developed over a number of years and through different processes, it was necessary to provide a common pool where this mass of information generated by these procedures could be located in order to facilitate its use.

What are these tools and where are these information sources? At the core is the human rights programme of activities and at the core of these activities are those necessitated by the six main international conventions. Of these conventions, we have the two covenants, the International Covenant on Civil and Political Rights and the International Covenant on Economic, Social and Cultural Rights.

The fact that there are two covenants-as distinct from one Universal Declaration is, of course, the result of an aberration that took place in the fifties, the division-artificial division-of civil and political rights from economic, social and cultural rights, a division that never reflected realities.

In addition to these two covenants, we have four conventions: the Convention on Rights of the Child, the Convention on the Elimination of All Forms of Discrimination Against Women, the Convention on the Elimination of All Forms of Racial Discrimination and the Convention Against Torture and Other Cruel, Inhuman and Degrading Treatment or Punishment.

The two covenants and the other four conventions each have their own treaty monitoring body, consisting of a group of experts elected by the States Parties. These treaty bodies review information contained in reports presented by States Parties and other sources; they are intended to conduct their work through dialogue with representatives of States submitting reports and in certain cases, with inter-governmental bodies and non-governmental organisations. They meet at regular intervals throughout the year and from time to time issue General Comments or make Observations intended to aid with the interpretation of provisions of the international instrument in question.

In addition, there are extra-conventional procedures, which are heavily dependent on information since they are fact-finding in nature. Today there are something like 50 such procedures, also known as ad-hoc mechanisms, that consist of Special Rapporteurs or Working Groups, some dealing with situations in specific countries, and others looking into certain phenomena. These have thematic mandates, so they look into such allegations as those of disappearances and arbitrary detentions, etc. They are intended to buttress the conventional implementation that I have just described.

The third procedure developed over the years, and most recently, is that of technical cooperation, under which the United Nations provides assistance to governments directly through the human rights programme, and less directly, through the rest of the United Nations system, to create conditions, build institutions, and strengthen institutions within their society for addressing potential negative human rights situations. Technical cooperation is, like the other procedures, heavily reliant on information and analysis.

It is relevant to mention here the developments that led to change in the support of these three principal procedures. These developments may be summarised by referring to four decisions, all of which were taken in the mid-eighties.

The first is the decision of 1986 to adopt the Declaration on the Right to Development-you would have heard a lot about it and some of you who are more familiar with human rights will wonder why on earth I am mentioning this one. Then there was, in 1987, the decision to set up a Voluntary Fund for Technical Cooperation, which permitted the possibility of applying extra-budgetary resources to institution building. In 1988 came the decision which authorised for the first time the undertaking of human rights education and training. This decision enabled us to develop the tools by which we could deliver the technical cooperation support. The fourth decision was in 1989, to convene the World Conference on Human Rights that took place in 1993, the second World Conference on Human Rights that had taken place in the history of the UN. 
The reason for the convocation of a World Conference was the need for agreement on the priorities to be set in the search for the realisation of international human rights norms. The international community, having finished with the formal Conventions, having more or less saturated the potential for extra-conventional mechanisms, having tried technical cooperation, found the need to see where the international system was going; and during the three years of my life between 1990 and 1993 when I had the doubtful honour of coordinating the World Conference, we saw emerging around various regions this energy, as it were, to do something about human rights standards. In Asia, for example, the regional meeting in preparing for the World Conference in 1993 was the first meeting ever of the Asian Governments around a human rights agenda. The African regional meeting spun off some of the richest non-governmental organisations in human rights that we had not seen before. The same may be said with regard to the Americas; the regional meeting in Costa-Rica.

The preparation of the World Conference was a process which took the shape of a pyramid, consisting not just of intergovernmental meetings, not mere statements and declarations, but which took place through a very hard fought blow by blow process around the world in various manifestations. By 1993, when the World Conference adopted its Declaration and Programme of Action, it had in it a number of elements that enabled us to turn to a wider, more meaningful implementation of human rights standards. This was essentially inspired by the fact that by that time the knowledge of the realities was such around the table that nobody anymore could deny that these issues could be seen as something that they were not. So you had a situation where, for instance, an inter-governmental body like the Commission on Human Rights took up issues which a few years earlier were unheard of. When I started as Secretary of the Commission on Human Rights in 1978, it was my duty to advise the Chairman to stop a speaker, to cut the microphone for any speaker who mentioned a country by name. Today, virtually any human rights situation, any situation that has a human rights aspect to it, one way or the other is taken up in the same body: it is not solved, but it is addressed and the governments concerned respond on the merits. Even though some issues may not lead to decisions of substance because of procedural preferences they are on the table and they are addressed in substance.

The World Conference produced a clear priority for democracy, development and human rights. Governments gave themselves an agenda-whereby they could now address human rights in a much wider, a much more total context. What was missing was the institution and that was taken care of a few months later when the Office of the High Commissioner for Human Rights was set up, in December 1993. This created the vehicle which would clear the way for this process to realise itself.

As soon as this institution was set up, it became necessary to re-structure the secretariat to enable it to support the High Commissioner's mandate in addition to carrying out its earlier functions. It was possible for us to start examining that information and that knowledge that we had acquired over the preceding years with a view to applying it in a constructive and forward looking manner.

In order to do that we devised this tool called "Huricane", which stands for Human Rights Computerised Analysis Environment. Huricane was set up in order to enable us to marshal the information that we had been accumulating over the years; to set up a system for receiving information in order to create a common pool to serve all the activities of the human rights program. Moreover, it is intended to serve as a tool for monitoring the status of realisation of the right to development.

Huricane consists of eight databases serving as baskets for storing information. These eight databases, once Huricane is complete, will be interrogated by a search engine that we are developing, that would enable us to re-construct the picture in regard to the situation of civil, cultural, economic, political or social rights. This would enable us to assist governments in their efforts to create the conditions to enable them to meet their international human rights obligations. 
(The order of the rights—alphabetical-that I have just used is, in itself, significant, since it underlines the integral nature of the five groups of rights. It is worth mentioning here, by way of parenthesis, that the resolution establishing the High Commissioner for Human Rights was the first in several decades that used this order. In the last decades it has become accepted to refer to human rights in two distinct groups: civil and political rights on one hand and economic, social and cultural rights on the other. The significance in the use of the alphabetical order is in the fact that this was symptomatic of the change of culture of human rights that was taking place —-the return to the "integrated" approach to human rights.)

Huricane is made up of two types of information. One is the information that exists on the public media, such as the World Wide Web and the other public sources, and the other one is the information on our Intranet, the internal web where we store our own information. The idea was to try to bring the information more or less on the same manageable level. So we had to identify the common attributes, such as the human rights subject, the mandate or legislative authority, and the country concerned. In order to obtain a first list of relevant subjects, we examined the work of the Commission on Human Rights over the preceding 20 years and drew up from the work of the Commission what we felt were the key-subjects that the Commission had taken up over that period. Hence you will find a wide range of subjects like asylum, internally displaced persons, fair trial, right to food, etc.

Having done that, we then identified its components. Component number one was our Treaty Body system. It should be kept in mind at all times that the raison d'être of the United Nations human rights programme is the international legal regime of the International Bill of Human Rights. Governments ratify conventions and undertake obligations under which they have to report, and it is our duty to make sure that we make this process fair and feasible for governments. Now, during the early years, when the treaties were still in their post-adoption stages, the focus was on ratification by governments. There was therefore a need to provide governments with the knowledge and means to meet the obligations that they undertake when they ratify an international human rights treaty. Thus, this first database in Huricane contains all the information relating to the status of these treaties, such as details on each of the ratifications, including reservations, reporting status, and so forth. The full text documents are then included whenever they make reservations etc.

The next database contains the second component. This is made up of documents prepared for the so-called charter-based bodies, viz. the Commission on Human Rights and the General Assembly. This one is designed in three languages and it has the possibility to incorporate internal documents such as reports that we get from our field offices (there are 22 such offices), reports from evaluation missions, and other such internal reports.

The third component is our digital registry. This contains incoming mail and copies, or evidence of the follow-up that is given to this mail. This is done by scanning in the hard-copy mail, which enables it to be accessible to everyone on his or her screen. So far this covers mail coming in through the mail-room. Correspondence coming in through fax lines will be integrated through the installation of a central electronic fax server that will receive messages and direct them into the registry system. This will also have the advantage of avoiding the diffusion of multiple copies of hard copy of the fax traffic. It ensures monitoring of correspondence for follow up and continuity. It also makes it possible to follow correspondence attributed to others; these views are organised by the date of the registry, by registry number (the date and number are entered electronically), by the date that it was sent, by sender, by country or by mandate (subject).

The fourth component is the News/Statements Database where we have selected certain news sources which are relevant to the subjects making up the menu that I referred to earlier. The other components are:

- Communications Database. This is the database where individual complaints received under the established procedures are stored. These are confidential procedures that governments have devised either in the Commission on Human Rights, or in a human rights treaty. 
- External Sources Database. This is a bibliographical source which we use in order to make sure that we also have outside material that is, in some cases, also retained in full text.

- Thematic Mandates Database. This database contains the material that comes in from the so-called Athematic mandates. These are procedures established by the Commission on Human Rights to look in to allegations of violations of certain rights, and include allegations of enforced and involuntary disappearance, arbitrary detention, summary or arbitrary execution.

The sum total of information stored in these databases embraces human rights standards across the board. The multiple database search engine makes it is possible to draw up a profile that enables a reconstruction of the sum total of the human rights picture.

The search engine enables two types of searches, one by country or human rights subject and the other one permits full text retrieval.

Now you see, in fact, what we are doing is simply organising and applying the experience that we had made over the years. I will wind up with one example. In developing our tools for training - we were only authorised to do so as of 1988-we had to start with those sectors of society that were more likely, by virtue of their office, to be in contact with larger groups of people. So we started with the Administration of Justice sector, and specifically, law enforcement. In this group, we also had to address the human rights training of the armed forces. This was in 1994. This represented a formidable task, knowing full well how difficult the military culture, the armed forces culture, had been for us traditionally to assimilate to the respect for human rights. Thus, in order to overcome this barrier, the first thing we did was to look at the experiences that had accumulated over the preceding twenty years, which would show what we considered as negative situations of human rights resulting from or attributable to, in one form or another, armed forces behaviour. Having done so, we brought together twenty or so military persons, of various ranks and backgrounds, for a week to Geneva and we shared these experiences with them. From these discussions there emerged three types of situations where military behaviour was directly related to human rights situations, and which could form the basis of a human rights training program for armed forces personnel. The first was the situation illustrated by the Chile case. Chile was a very good case history because you had a government that was taken over by the military and substituting the government structure. You had generals who were government department ministers. This was hypothesis number one. Hypothesis number two was when the armed forces were called in to perform what were normally considered as police duties, like crowd control, where, being trained as soldiers, they applied their training and caused loss of life and limb. And the third sector was the behaviour of armed forces in peace-keeping operations, where, even though the colour of the cap had changed, the training had not-and therefore the resulting behaviour was still not very different from what it would have been during normal service, at least in some instances.

This exercise consisted of-no more and no less-simply sharing with them what we knew from the preceding twenty years. And they did not like that, since their military training and culture was intended to prepare them for loftier goals. Since that time we started working on developing a module for training. What had seemed impossible became very likely, simply by the application of facts; letting the facts speak for themselves.

This is the philosophy behind Huricane. Its purpose is no other except to enable governments to ascertain for themselves the relationship between a given situation and the international standards to which they have adhered, not in an accusatory or punitive sense, but in the sense of prevention, of enabling the creation of conditions to address and redress negative situations of human rights. 


\title{
KNOWLEDGE MANAGEMENT AND CHANGE IN INTERNATIONAL ORGANISATIONS: LEARNING FROM THE PRIVATE SECTOR
}

\author{
John Harper and Jennifer Cassingena Harper
}

The emerging concept of "learning economies" (i.e. those where the ability to learn is critical to the success of individuals, firms, regions, and national economies) has sharpened the focus on knowledge as a vital strategic resource. Building competencies and establishing new skills-and not merely getting access to information-has thus become a fundamental activity for both macro- and micro-economies.

Traditionally, commercial organisations have instinctively protected their sources of competitive advantage and have used patent rights to insure their innovative actions. However, in the wake of the information revolution has come a new appraisal of the function of global knowledge as a corporate asset-hence the emergence of "knowledge management" as a key strategic function. What an organisation knows about itself, its market, its products, its technologies and its people is unique and has high value in the competitive mix. Forced by the need to survive, organisations have recourse to international fields of operation in order to expand, and thereby to increase their knowledge pool by multiples of factors. It is knowledge which helps them succeed in this broader competitive field.

But this knowledge must be "managed" as any other asset, and the function must be integrated with all other functions since much knowledge is generated by operations themselves - thus the adage of "learning-by-doing" comes to life in a very significant way. What is also very interesting is that the factors of knowledge management seem to be equally relevant to both private and public sector organisations alike, national and international. All organisations are today obliged to extend their realms of influence globally, and their opportunity to succeed internationally is heavily dependent on their acumen with knowledge.

This paper aims to bridge the link between the private and public sectors in knowledge management for effective organisational change, by tracing current developments in the private sector and the public international domain.

\section{KNOWLEDGE: THE RESOURCE}

Knowledge is not a homogenous resource, but a range of levels of capacity, including a prolific memory of facts, the ability to relate pieces of information, the creativity to develop theory, the skill to produce artifacts, and the social skills to identify and develop useful and sustainable relationships, among others.

The following categories of knowledge have been identified: ${ }^{1}$

- knowing what, knowing why and knowing how;

- formal and informal knowledge within the organisation and external to it;

- codified and tacit knowledge (and being able to identify the difference);

- knowledge embedded in systems, tools and technologies;

- knowledge embedded in organisational culture and routines; and

- hierarchies of knowledge.

Private sector organisations are increasingly involved in the following knowledge-related activities in order to strengthen their competitive advantage:

- monitoring of worldwide databases and other information sources;

- tracking developments in new knowledge through R\&D activity;

- cross-fertilisation and fusion of knowledge from different disciplines and sectors; 
- assessment of product performance in the field and the evaluation of competitor activity, among others.

All these knowledge-related activities are the responsibility of the Knowledge Manager/ Corporate Knowledge Officer, who today operates in an environment of "Innovate or Perish".

\section{The knowledge resource - intellectual capital}

The resource available to the Knowledge Manager and that which drives the learning/knowledge-based organisation is its Intellectual Capital; that which is today protected by Intellectual Property Right (IPR), just as in the past patents and copyright have been protected. To measure and evaluate intellectual capital (not yet an accounting item, although goodwill, for instance, is computed for corporate valuation purposes), it is helpful to the reader to review and point out some areas for such estimation:

- intangible assets, not limited to but including goodwill;

- intellectual property assets; e.g. patents, manufacturing rights, proprietary rights, research results, market research information;

- human capital (the cumulative experience and know-how/tacit knowledge [assets that can walk out of the door tomorrow!]);

- infrastructural capital; e.g. technology, processes, recipes, preparations, systems;

- customer/market capital; e.g. brands, customer loyalty, licences.

\section{Knowledge management in learning organisations}

Driving the learning economies are the learning organisations (public and private), their success typified by the following organisational philosophy:

- learning organisations consider human resource development as central to organisational strategy;

- their organisational culture empowers individuals to learn continuously as a means to expressing their full potential;

- their jobs are designed as total learning experiences; and

- they extend this culture to include customers, suppliers and key stakeholders.

Learning organisations have the key goal of continuous organisational transformation. This is not achieved solely within, but by extending the perimeter to include collaborative entitiesorganisations can no longer afford to be islands of privileged information. Examples of such collaboration can be seen in relationship marketing, franchising, and niche joint ventures.

This fundamental shift to knowledge-oriented activities currently underway in the private sector has major implications for organisations in the public and international domain. The strategic use of knowledge is no less important for international organisations, charged with important global responsibilities. The impact of the globalising learning economy is affecting the way that these organisations operate, driving them to stimulate their learning processes through greater focus on knowledge-related activities. In recent years, international organisations have come increasingly under attack for their poor performance in terms of fulfilling their mission, managing their resources and responding effectively to change. ${ }^{2}$ In this article, we are mainly concerned with this latter aspect, i.e. knowledge management in international organisations and their responsiveness to change.

\section{KNOWLEDGE MANAGEMENT IN INTERNATIONAL ORGANISATIONS: RESPONDING TO CHANGE}

As noted by Ernst B. Haas in his book entitled When Knowledge is Power: Three Models of Change in International Organisation, international organisations have a very mixed track 
record in terms of whether they have evolved as learners or adapters. Haas's key criteria for determining the extent of learning and knowledge generation taking place within an international organisation is the level of "change in the definition of the problem to be solved by a given organisation." ${ }^{3}$ Thus, the World Bank, which was set up in 1945 to re-build Europe, re-oriented its mission in 1955 to the emerging challenge of promoting industrial growth in developing countries, and by 1975 to the elimination of poverty. "Today, the World Bank has shifted much of its emphasis to the intangibles of knowledge, institutions, and culture in an attempt to forge a more comprehensive New Development framework" ${ }^{4}$ for its work. The World Bank is thus an example of an international organisation which did not revise its mission over time simply by adding new tasks to old ones, but generated internal learning processes allowing it to re-define a completely new set of problems based on new knowledge made available. As Haas notes, the definition of new priorities "came about as a result of a systematic pattern of subsuming new means under new ends, legitimated by a new theory of economic development." 5

Haas thus identifies three models of organisational change based on:

1. Adaptatation—he distinguishes between two types of adaptation:

i. "incremental growth" where the organisation takes on new tasks without changing the decision-making processes; and

ii. "turbulent nongrowth" where the organisation undergoes major changes in decisionmaking, and the consensus on ends and means collapses.

2. Learning - which Haas terms "managed interdependence", where the organisation's aims are redefined through "knowledge-mediated decision-making dynamics". The organisation's behaviour changes, as original implicit theories underlying the programmes and strategies are examined and their original values questioned.

Haas's comparative analysis of the historical profiles of change of key inter-governmental organisations highlights the fact that while these organisations share a number of characteristics in common, they have evolved along different paths, based on the extent to which internal processes of knowledge generation and learning could flourish. Thus, while inter-governmental organisations share certain constraints, e.g. heterogeneous membership, inequalities of power among their member states and so on, they differ in terms of the setting (level of ideological consensus, representation of the states, etc.), power (revenue base, monitoring of compliance etc.); and behaviour (voting and budgeting procedures, and leadership). These three factors-setting, power and behaviour-determine whether an organisation evolves as a learner or an adapter. Decisions in organisations depend on knowledge, or more appropriately, consensual knowledge, "the sum both of technical information and of theories about it that command sufficient agreement among interested actors at a given time to serve as a guide for public policy." In learning organisations, knowledge is consensual or becoming more consensual, whereas in organisations undergoing decline the reverse trends are in place. According to Haas, other factors distinguishing learning organisations, are:

1. political goals—-the ability to justify expanding and interconnecting goals;

2. decision-making style: pragmatic and analytical rather than eclectic; and

3. issue linkage: the ability to link issues in a fragmented manner whilst aiming for substantive linkage.

At the core of the distinction between learning and adapting organisations is the extent to which these organisations indulge in policy learning, based on a pragmatic and open-minded evaluation of past successes and failures. "When facing disappointment with the outcomes of earlier actions, actors rarely question the theory of causation that led them to the initial choices." 7 
Among the prime examples of organisational learning are the World Health Organisation, the World Bank, the United Nations Environment Programme (UNEP) and the International Monetary Fund (IMF). In contrast, intergovernmental organisations like the United Nations and UNESCO are cited as examples of unsuccessful organisational learning.

Figure 1: Historical Profiles of Change in International Organisations ${ }^{8}$

\begin{tabular}{|l|l|l|l|l|l|l|l|l|}
\hline & \multicolumn{3}{l}{ At founding } & \multicolumn{4}{|l|}{ Years after founding } \\
\hline Organisation & Learning present & Nested problems & $\mathbf{1 0}$ & $\mathbf{2 0}$ & $\mathbf{3 0}$ & $\mathbf{4 0}$ & $\mathbf{5 0}$ \\
\hline World Health Org. & yes & no & 1 & 1 & 3 & 3 & - \\
\hline World Bank & yes & yes & 1 & 3 & 3 & 3 & - \\
\hline UNEP & yes & yes & 3 & - & - & - & - \\
\hline IMF & yes & yes & 1 & 1 & 2 & 3 & - \\
\hline OECD & no & no & 3 & 3 & 2 & - & - \\
\hline Commonwealth & no & no & 1 & 0 & 0 & 1 & - \\
\hline United Nations & yes & no & $11^{*}$ & 1 & 2 & 4 & - \\
\hline UNESCO & yes & no & 2 & 2 & 2 & $4^{*}$ & - \\
\hline
\end{tabular}

Note: $0=$ no change; $1=$ incremental growth; $2=$ turbulent nongrowth; $3=$ managed interdependence; 4 = decline

${ }^{*}$ Attempted managed interdependence, but failed.

Haas notes that "UNESCO's entire history has been one of turbulent nongrowth because the organisation has never had a cohesive dominant ideology, or a commitment to an identifiable nested problem set." ${ }^{9}$ This has been backed up in a report by the Moillis Group, made up of former senior staff of UNESCO, entitled UNESCO Faces the $21^{\text {st }}$ Century. The report identifies two critical elements for effective management which UNESCO lacks, "a culture of innovation, permitting failure not to be regarded as a fault but as a normal risk inherent in undertaking action; even an organisation learns from making mistakes. The other is an internal system of communication."10

On a more positive note, there is evidence that in recent years intergovernmental organisations are beginning to recognise the vital importance of knowledge and learning. The World Bank is seeking to establish itself as a "Knowledge Bank, not just a bank for infrastructure finance. We now see economic development as less like the construction business and more like education in the broad and comprehensive sense that covers knowledge, institutions and culture...The shift in focus was motivated in part by the experience of the most successful countries...the accumulation of capital could explain only a fraction of the increases in per capita income in the countries in East Asia. Their miraculous growth is largely attributed to closing the knowledge gap."11

Similar knowledge-related efforts are being promoted by the Commonwealth Science Council (CSC) and the Commonwealth Partnership on Technology Management (CPTM). The CSC, on the basis of a 1998 review of activities carried out to date, reached the conclusion that its mission should be more knowledge-oriented and user-driven, i.e. its priorities should not be set in London but be more oriented to meeting the needs of the member countries. The CSC has thus launched an initiative to promote itself as an innovative, proactive organisation, leveraging science and technology (S\&T) capability in the public and private sectors through networking of knowledge and finance, based on information and communication technologies (ICT). At the core of this initiative is the establishment of a Commonwealth Knowledge Network, an Internet-based initiative to unleash the knowledge repositories of member countries and build on the networking capacity of the CSC.

An interesting example of a knowledge-oriented international organisation which has been designed specifically to benefit from private sector best practice and knowledge is the Commonwealth Partnership for Technology Management Limited (CPTM). CPTM, an 
independent government/private sector partnership, was set up in 1995 as a not-for-profit company, to provide advisory services to Commonwealth countries on technology management as a tool for macroeconomic development. CPTM functions as a networking organisation drawing on the expertise of its members, given voluntarily-a system of "cooperative resourcing". CPTM Ltd. "was formed principally to act as a catalyst and a clearing house for co-operative efforts between member governments, the private sector members and the growing body of CPTM Networkers-senior professional managers in everything from basic research, technology integration, and environmental management, to macro-economic planning, venture capital and marketing." ${ }^{12}$ CPTM's main mission is to enhance national capabilities for wealth creation through the sound management of technology and public/private sector partnerships.

These examples of innovating, learning organisations point the way ahead for international organisations aiming to manage the challenge of the globalising learning economy. Not only do international organisations have to emulate best practice in knowledge management in the private sector; the indications are that they will have to move increasingly closer to the private sector, by establishing smart public-private sector partnerships to tap strategic knowledge and learning in the private sector.

\section{Notes}

${ }^{1}$ Adapted from Paul Quintas, "Why Knowledge Management? Why Now?" (Presentation for Open University Business School, Management of Knowledge and Innovation Research Unit, 1999).

${ }^{2}$ G. M. Gallarotti, "The Limits of International Organisation: Systemic Failure in the Management of International Relations," International Organisation 45(2) (Spring 1991): 183220.

${ }^{3}$ Ernst B. Haas, When Knowledge is Power: Three Models of Change in International Organisation (Berkeley: University of California Press, 1990), 3.

${ }^{4}$ J. Stiglitz, "The World Bank Group: A World Free of Poverty, Public Policy for a Knowledge Economy (Remarks at the Department of Trade and Industry and Centre for Economic Policy Research in London, 1999).

${ }^{5}$ Haas, When Knowledge is Power, 4

${ }^{6}$ Ibid., 74.

${ }^{7}$ Ibid., 72.

${ }^{8}$ Ibid., 156-158.

${ }^{9}$ Ibid., 152.

${ }^{10}$ Association of Former UNESCO Staff Members, UNESCO Faces the $21^{\text {st }}$ Century: An Invitation to Dialogue (Paris: Association of Former UNESCO Staff Members, 1995).

${ }^{11}$ J. Stiglitz, "The World Bank Group: A World Free of Poverty, Public Policy for a Knowledge Economy" (Remarks at the Department of Trade and Industry and Centre for Economic Policy Research, London, 1999).

${ }^{12}$ Commonwealth Partnership for Technology Management, Commonwealth Partnership for Technology Management: The New Initiative on Public/Private Sector Partnerships for the Commonwealth (London: Commonwealth Partnership for Technology Management, 1995). 


\section{References}

Association of Former UNESCO Staff Members. UNESCO Faces the $21^{\text {st }}$ Century: An Invitation to Dialogue. Paris: Association of Former UNESCO Staff Members, 1995.

Commonwealth Partnership for Technology Management. Commonwealth Partnership for Technology Management: The New Initiative on Public/Private Sector Partnerships for the Commonwealth. London: Commonwealth Partnership for Technology Management, 1995.

Commonwealth Science Council. Knowledge Networking for Development: Science and Technology for the Millennium. London: Commonwealth Science Council, 1999.

Gallarotti, G.M. "The Limits of International Organization: Systemic Failure in the Management of International Relations." International Organization 45(2) (Spring, 1991): 183220.

Haas, Ernst B. When Knowledge is Power: Three Models of Change in International Organisation. Berkeley: University of California Press, 1990.

Quintas, Paul. "Why Knowledge Management? Why now?" Presentation for Management of Knowledge and Innovation Research Unit, Open University Business School, 1999.

Stiglitz, J. "The World Bank Group: A World Free of Poverty, Public Policy for a Knowledge Economy." Remarks at the Department of Trade and Industry and Centre for Economic Policy Research, London, 1999. 


\title{
KNOWLEDGE MANAGEMENT AND DIPLOMATIC TRAINING - NEW APPROACHES FOR TRAINING INSTITUTIONS
}

\author{
Dietrich Kappeler
}

For a long time it was held that a diplomat is born as such and that it is impossible to produce a diplomat by training. This view was based on a lack of distinction between personal characteristics and qualities of the diplomat on one hand, and the knowledge and skills he needs to do his job on the other. Whereas the first are indeed part of the physical and mental makeup a person is born with, the second can be and must be taught. The days when any well-born and well-bred dilettante of great personal charm could handle diplomatic business as a result of these in-born and in-bred qualities are long past, if they ever truly existed. However there are some characteristics and qualities a diplomat should possess if he is to perform at all well in his profession, however vast his acquired knowledge and skills may be. Thus, before going into the issue of training, we should spend a few moments to consider what these qualities and characteristics are or should be.

Diplomacy is not for the sickly, the weak, the neurotic and the introverts. A robust constitution and good health are needed to stand the physical and mental strain put on diplomats in many situations. Being able to sleep well in almost any circumstances is of great help. A wellbalanced personality, good self-control, a natural inquisitiveness, an interest in understanding others and their manner of thinking are also essential. This should be complemented by a friendly and outgoing nature, natural courtesy and good manners, a capacity to create empathy and develop friendships. A gift for languages is a great asset, because being able to communicate with opposite numbers in their own language is becoming increasingly important, especially in some less traditional forms of diplomacy.

\section{WHAT MUST A DIPLOMAT KNOW?}

For a long time diplomats studied history, languages and law, and this was seen as sufficient. Even today, lawyers are over-represented in foreign ministries. A quick look at the subjectmatters of present-day international relations should suffice to impress on anyone the importance of multi-disciplinary academic knowledge. To that extent the generalist-specialist controversy does not exist at all. All diplomats must have basic familiarity with history, law, economics and political science. And it is therefore not surprising that curricula of all respected training institutions includes these subjects.

But diplomats must also be able to acquire specialist knowledge in nearly any subject when needed. This may be in order to assume a certain position within the diplomatic establishment or in order to handle a temporary task like a specific mission or negotiation. It is therefore important when providing them with their initial training, or when completing such training undergone prior to the admission to the career, to promote the capacity for assimilating unfamiliar subjects at short notice. A diplomat who has this ability can look forward to a variegated career, whereas one who finds it difficult to assimilate new knowledge is likely to spend his life dealing with matters well within his range of competence, thus becoming some sort of specialist not to be considered for assignments handling other matters.

\section{HOW SHOULD A DIPLOMAT BE TRAINED?}

In many countries with an old diplomatic tradition, candidates for the diplomatic service are expected to come with a sufficient baggage of basic academic knowledge to make initial training in such fields unnecessary. They undergo tests and examinations to make sure that they possess such knowledge. Training after recruitment is restricted mainly to teaching professional skills and to adding to basic academic knowledge specialised subjects of particular importance for diplomatic activities. Language training often occupies a 
predominant place in such systems. Other countries prefer to recruit candidates to whom basic academic disciplines for diplomacy are taught during a training stage. This kind of basic training is also provided by regional institutions such as the Mediterranean Academy of Diplomatic Studies, as many countries cannot afford to provide basic training to the few diplomats they recruit every year or only from time to time.

For many years now the need for continuous training of diplomats has been recognised, but little headway has so far been made for its satisfaction. This is quite understandable as diplomats once recruited are supposed to spend their time working and not learning. Current budgetary constraints make it even more difficult to release a diplomat for any kind of continuous training. On the other hand, the rapidly changing content of diplomatic interaction and of methods used make in-career training an inescapable necessity. Fortunately, as we shall see, new training approaches and facilities make it easier to respond to this necessity without disrupting a diplomat's activity to an undue extent.

\section{THE EVOLUTION OF TRAINING APPROACHES AND METHODS}

Institutions training candidates for diplomacy or offering training for beginning diplomats were mostly offspring of universities or strongly influenced by academic teaching methods. When foreign ministries started to set up in-house training establishments, these again mostly relied on university lecturers for the teaching of academic subjects. Thus ex-cathedra lecturing was the dominant approach, sometimes complemented by seminars. Where practising diplomats were used to convey their experience to newly recruited colleagues, the lecture method was invariably used.

Only in the 1960s were simulations of imagined or real diplomatic situations introduced to a meaningful extent. Diplomat trainees were made to simulate pleadings before arbitral or judicial tribunals, negotiations or even complex international crises. A pioneer in these fields were the Stabex exercises conducted at the Graduate Institute of International Studies for the trainees of the Carnegie diplomatic training courses. In conformity with the reluctance in those days to upset any existing country or government, most exercises were between invented Ruritanias, any resemblance to actual countries being "entirely coincidental." These days simulations use much more concrete approaches. Participants are made to simulate a crisis or negotiations which already took place (with the intent to show that the historical outcome was not the only possible one), or they simulate oncoming negotiations or even simulate alongside an ongoing negotiation. Such exercises allow diplomat trainees to immerse themselves in the reality of past or ongoing events rather than to amuse themselves with imagined "games." For their conduct, the expertise of seasoned negotiators is needed, who are in the thick of ongoing activities. They are of course not always easy to get hold of and all of them do not have the ability to convey their expertise to participants.

As in other fields, information technology has introduced new possibilities and methods for the training of diplomats. Computer-assisted and computer-based training allows trainees to participate in their own formation. By breaking down subjects into relatively small teaching modules it has become possible to move from basics into any degree of detail. As a result, basic and continuous training become interlinked. A diplomat who has to assimilate specialised knowledge in a given field can start with going back to what he already knows or, if he is totally unfamiliar with the subject area, acquaint himself with the basics. Then he proceeds gradually in the direction of what he really needs and thus finds it relatively easy to achieve a considerable degree of mastery.

Information technology also allows training to become delocalised. Trainers and trainees can interact in cyberspace without having to be physically present in the same place. This enormously facilitates continuous training, as a diplomat can do a lot of learning by himself, on his computer, at the time and for the duration of his convenience. Interaction in real time then starts from this base and becomes much more intensive and lively. As indicated, a special branch of continuous learning is the preparation for a given mission or event. In the case of multilateral negotiations, chosen negotiators can do their basic learning together and 
even simulate their interaction before the real event. This should reduce the duration of actual meetings, a constant preoccupation of cash-strapped international institutions.

\section{CONSEQUENCES FOR TRAINING INSTITUTIONS}

Should such institutions abandon their present methods of teaching, send home their students and proceed to teach them over the Internet? This would certainly be an unwelcome and extreme approach. Every teacher and most students know how important physical interaction is. Spending together not only classroom hours but also working together, studying together and discussing matters not immediately related to the teaching programmes are essential elements of learning. Moreover, the fundamental task of the diplomat is interpersonal contact and interaction. All this can to some extent be at least simulated in cyberspace, but sometimes the real thing is needed, especially in more recent forms of diplomatic interaction, where the diplomat must meet people who are not diplomats, distrust diplomats, want to be physically present with their guns and do not believe in cyberinteraction.

The approach chosen by the Mediterranean Academy of Diplomatic Studies for its distance learning programmes should therefore be highly commended. Trainees and trainers spend an initial period together in Malta or some other location before repairing to their workplaces and resuming interaction from there. Preliminary trial runs have shown that in ten days of intense cohabitation and interaction participants of a programme become a family whose members henceforth feel at ease with each other also in cyberspace.

As we are at the outset of what may well be termed a revolution in teaching approaches and methods, individual training institutions should feel free to find their own approach, for which cultural characteristics of those involved may also play an important role. It will be interesting to meet again some years hence in Malta-and not in cyberspace-to compare notes on experience acquired. 


\title{
KNOWLEDGE AND DIPLOMACY
}

\author{
Alex Sceberras Trigona
}

Diplomatic knowledge consists of both information and other elements of knowledge. Perhaps it is true to say that diplomatic information can be distinguished from all the other elements of diplomatic knowledge by whether it is recordable. If this is so then the best recorded form of diplomatic knowledge is the diplomatic information contained in diplomatic documents.

Much greater emphasis needs to be placed on primary sources of diplomatic knowledge: on the diplomatic document. Because of the increasing glut of information, scholars, diplomats, international negotiators, international lawyers, international civil servants, journalists and other cognoscenti of international relations tend to rely on commentaries, which are, by definition, secondary. Moreover, they are known to find themselves at a greater loss on how to acquire wider unrecorded diplomatic knowledge - if they are lucky enough to realise that they do not have it!

Since only recorded diplomatic information is normally accessible, (and not always, or all of it!), it is proposed therefore to develop a method which re-integrates the primary importance of the diplomatic document. Starting from analysing the diplomatic document, diplomatic knowledge which is clearly more than the diplomatic information contained in the document itself can be gained. This method therefore not only re-asserts the primary importance of the diplomatic information in diplomatic documents but also leads to acquiring elements of unrecorded diplomatic knowledge.

First this can be done by dissecting or unpacking the diplomatic document itself, attributing clauses to their sponsors, be they domestic or international, and then drawing a balance of strategic, political and economic interests displayed. This is all carried out in a static timeframe. At a second level the time factor is introduced. In this dynamic dissection, the "diplomatic trail" of an international agreement is analysed. Diplomatic knowledge is thus undoubtedly enhanced.

Digitalisation and information technology make this method much more user-friendly, all the more imperative for a better understanding of international relations and diplomacy, as well as an essential teaching tool.

\section{KNOWLEDGE, INFORMATION AND DIPLOMACY}

Diplomats' knowledge differs from that of ordinary citizens. The diplomat's essential relationship to knowledge is access to other knowledge and to others' knowledge. It is about that other knowledge. The diplomat must not only know his country's agenda. He must also know the agenda of the other country. Most importantly, however, he must identify and get to know very well which factors at both ends can be reliably used for his (country's) purposes. It is this third exercise which reveals the interaction between knowledge and diplomacy par excellence.

Too much diplomacy without enough knowledge may prove fatal. Too much knowledge with too little diplomacy may be disastrous. Discovering a judicious mix amounts to a basic survival kit for diplomats.

The types of knowledge the diplomat might want to access might be oral or written, public or confidential, lay or technical, past or present. Since administrative matters became more complex, masses of technical material increasingly found their way into diplomatic documents. Technical appendices however, and the best knowledge of them, do not, have 
not, and cannot replace diplomacy. It is the skilful juxtaposition of these technical chunks of knowledge which demonstrates the art of diplomacy.

Thus the diplomat's real intentions, motives, and strategy would not necessarily be on file at the ministry! Moreover, the media coverage of diplomatic meetings might be even further from the diplomatic version of the truth contained in the official files. A wealth of knowledge about diplomacy and diplomats' handling of knowledge is also maintained by way of oral tradition binding generations of diplomats together. Knowledge of this tradition sharpens the young diplomat's critical sense of trial and error.

Elements of the old and the new can be confirmed in numerous diplomats' biographies. But autobiographies must be taken with a pinch of salt. Even official records may be glossed over. A particular permanent secretary's choice of which diplomatic documents to downgrade and which to highlight might not be totally disinterested. Peeling the gloss away from official documents is an essential preliminary to diplomatic analysis.

\section{KNOWLEDGE AS INFORMATION}

Knowledge is not only information. Information has the advantage of being recorded. Knowledge, in general, is not easily recorded. Knowledge as information enjoys another characteristic: it travels. However, even when recorded, knowledge as information does not flow unhindered in the real world. The free flow of information is much more of an ideal than a true picture of reality. A number of obstacles exist. Some are easily surmounted. Others are more difficult and costly, if not impossible to overcome. Many are the obstacles which still hinder the free flow of information universally.

This truth also applies to the free flow of information in the same nation state. Within the state this truth also applies to the governmental administrative apparatus itself. There is hardly a free flow of information within a bureaucracy: the mandarins know only too well that knowledge is power or influence at the very least; they do not part with any scrap of knowledge completely or all the time.

On an even more domestic level this truth is not unknown to apply within the same ministry including the foreign ministry. Perhaps this is where this truth is at its strongest: between the very members of the same cabinet or secretariat or desk. Most paradoxically these are the diplomats entrusted with the UNESCO task of enshrining the principle of the free flow of information into an International Convention!

The management of knowledge as information in diplomacy can be illustrated quite succinctly. A clear example is the case of handling relations with the United Nations organisation and its agencies. Since its foundation the UN and its Agencies have developed a veritable international bureaucracy. Their numerous initiatives in their 50-year history produced volumes of paperwork. This demands much more than what a medium sized multilateral section in a medium sized foreign ministry can manage.

However, some foreign ministries will insist on retaining total control of relations with all the branches of the UN. In these extreme cases, relations remain the foreign ministry's domain not only with the General Assembly and its committees but also with the World Health Organisation, the International Labour Organisation, the Food and Agriculture Organisation and the United Nations Education Science and Culture Organisation to name a few.

At the other extreme, a foreign ministry will have delegated or been slowly relieved of all these particular duties by the respective health, agriculture, labour, or education ministries.

In reality a "modus vivendi" between the foreign ministry and the other ministries will have evolved somewhere in between these two extremes. Generally the foreign ministry will have 
kept control of what is political, though that might prove difficult to define sometimes; the ministries controlling what is eminently theirs by subject matter and keeping the relevant files.

\section{DIPLOMATIC DOCUMENTS}

Diplomacy could be circuitously defined as the activity of the diplomat. The focus of diplomacy is usually an international agreement, past, present or future. It need not be a written agreement, although it usually is. The Vienna Convention on the Law of Treaties explicitly recognises this definition of international agreements. This realistic admission helps to define the domain of diplomacy. Diplomatic activity between one international written agreement and its successor is punctuated by a series of verbal agreements which, in turn, are built upon various exchanges contained in diplomatic documents.

Form has been known to pre-occupy some diplomats unduly. Form has also pre-occupied a number of scholars and writers about diplomacy. In Sir Ernest Satow's classic work, A Guide to Diplomatic Practice, diplomatic documents are categorised. Thus diplomatic documents could contain demands or offers as in a Memoir and in an Aide-mémoir, or in the more official Note verbale, signed or unsigned, or in other diplomatic Notes. Once agreement is reached in part or in toto this is either implicit or explicitly stated as in an exchange of Notes verbale constituting an international agreement.

The more manifest form of an agreement could be held to start with an agreement initialled between lower officials "ad referendum" to higher governmental authority. Diplomatic documents range in importance from the unofficial Procès-verbal of a meeting, to Protocols, to Treaties. Similarly, Sir Harold Nicholson's reference work Diplomacy also classifies diplomatic documents.

Is a hierarchical order of diplomatic documents useful or necessary? By giving more or most importance to fully fledged treaties and the least importance to the modern "non-paper" a diplomatic primer for students is at hand. But is this enough?

This traditional method of assessment of diplomatic documents does not really contribute much to knowledge. It does not amount to proper diplomatic analysis. It is superficial as it only treats diplomatic documents at face value. Students emerge all the poorer for it, obsessed with form for form's sake.

\section{DISSECTING DIPLOMATIC DOCUMENTS}

Instead, it is proposed to dissect diplomatic documents. This should enable students of diplomacy-as well as diplomats themselves-to sharpen their sense of diplomacy by developing analytical diplomatic talents. However greater the complexity of the data of their future cases these can be crunched better with these more mature analytical diplomatic talents. Dissection of diplomatic documents can take place on a number of different levels. Dissection results open up more fruitful dimensions of analysis.

First, the "balance of interests" approach: a diplomatic document concluded between two governments, say an international agreement of ten paragraphs, can be dissected by unpacking it into its substantive points. This unfolding can then be developed further by attributing paternity to each of the various inputs into the treaty. Inputs may be whole articles, paragraphs, clauses or sub-clauses of the agreement. They may also be side-letters, ancillary exchanges of Notes-verbale, Agreed Minutes of interpretation etc. Usually paternity corresponds to the interests of a particular government. Each input is thus tagged according to whose interest is best served by it. Which party secured, input by input, more plusses and least minuses, for its national interest? The balance of interests is thus the result of a rough quantification of each side's score. 
In trying to attribute points to the two sides then, not only will the number of clauses count. Further refinements of this diplomatic analysis are in order. Definitions and meanings of each input will have to be re-assessed. It will be necessary to assess, for example, whether a favourably tagged clause was seen in one country to count for more than one clause in the given circumstances. In other words, whether a degree of diplomatic ambiguity in meaning in a particular clause-or even a single word-gave it a different value in the two different countries.

See, for example, the concession of UN Secretary General Kofi Annan to Iraqi Deputy P.M. Tariq Aziz in paragraph 3 of the 23/2/98 Memorandum of Understanding that UNSCOM would respect the "dignity" of Iraq; a term which means much, much more in Arabic than in English.

This method of analysis might, at the limit, be totally irrelevant in, say, a treaty of unconditional surrender. There is hardly any "balance" of interests there. Without resorting to such far-fetched examples is this method of analysis useful in contemporary diplomacy?

There is hardly any balance of interests noticeable in a number of standard treaties. Take, for example, standard treaties on visa abolition, cultural and sports cooperation, and the like. When a standard treaty contains a clause or two bearing only one party's interest then there is a clear imbalance of interests. Indeed this provides the student with a starting point for this method of analysis.

\section{PURSUING A "DIPLOMATIC TRAIL"}

The second level of analysis of diplomatic documents is not static. It is a dynamic analysis generated by pursuing the "diplomatic trail" of an international agreement. The student will be asked to examine a national issue that overwhelmed his country's foreign policy agenda, for example, ten years ago. This could have been an international issue which festered for a number of years. It could even have reached a crisis point before a diplomatic agreement settled the issue. Students are invited to identify and follow the agreement's diplomatic trail. The diplomatic trail is tracked from the files and various related records kept internally in the foreign ministry.

As with a series of flashbacks in a film, this method starts from the diplomatic agreement and moves backwards in time. By studying file after file on how each paragraph was developed and bargained for, precious diplomatic knowledge is gleaned. Diplomatic levers are observed in action, at work, not in theory but as they were actually applied in this particular case-study. These observations will then constitute valid contributions to others' diplomatic knowledge too.

By going right back to the start of negotiations, the students' inside knowledge of their chosen national issue will be immensely improved. By encouraging students to refer to the actual sources in their own foreign ministry archives, gaps between folkloristic or media versions of the crisis and the real story and issues involved might be discerned much more clearly. More importantly, the student will be accessing a wealth of diplomatic knowledge otherwise buried in the archives. Actual exchanges of diplomatic notes, the various memoranda presented or not, the procès-verbales of numerous diplomatic meetings, together with the rubrics-the marginal notes in the archive files_-all leading up to the final international agreement are a hidden treasure of diplomatic knowledge for any student, but most particularly for that country's young diplomats.

The young diplomat will also be able to note whether parts of (and which parts of) that international agreement were developed properly or shoddily. This might be relevant to a corresponding exercise to discover whether parts of an agreement are more precarious than others, rendering perhaps the whole agreement unstable. 
This method is also appropriate for analysing international resolutions. See, for example, the notorious UN Security Council 242 adopted unanimously on the "withdrawal of Israeli armed forces from territories occupied" after the 1967 war. As the French version had "the" territories, this encouraged the optimistic Palestinian interpretation that it included the 1948 territories too. Whether this ambiguity defuses or kindles a time-bomb remains a moot point.

It might also be possible and useful to identify the original motivations and factors causing certain clauses to be inserted into an international agreement and whether these are now redundant and superseded by events. Conversely interesting would be an analysis of why certain terms are found to be inconvenient and removed from a diplomatic document.

This is of utmost importance in the founding document, the establishment of wide-ranging long-term international initiatives. The European Union's "Euro-Med initiative" is a case in point. Few if any analysts have been able to answer the fundamental question of why the security clauses in the preliminary editions of the Euro-Med terms of reference were dramatically downscaled. Contrast the 1994 debate realistically emphasising the security dimension which is then whittled down in the communication of the EC Commission COM (95) 72 and finally disappears in the Council of Ministers mandate (10/4/1995).

Similarly useful would be to study whether meanings originally attributed to particular sections of the agreement (if not to the whole agreement itself) have changed by force of circumstance; whether the old meanings had been revalued or devalued by the new meanings evolved.

Other nuggets of diplomatic knowledge could be found in unutilised drafts of treaties or parts of them. They might have been discarded as too hot or because of domestic political rivalries, though still appropriate. Or they could have been abandoned out of neglect just because of changes of personnel or changes of circumstances. Undoubtedly they remain invaluable if brought back into circulation as diplomatic knowledge for potential use. Similarly enlightening would be the commentaries or inputs received in correspondence from the ambassadors and embassies involved directly.

\section{DIGITALISED KNOWLEDGE, INFORMATION AND DIPLOMACY}

Digitalisation has changed a lot of this: not everything, but a substantial number of critical matters have altered, some for the better, others for worse. What has not changed is the need for diplomacy, for its style, its human factor.

In other words, digitalisation, like other historic advances in transport and communications, is yet another tool in the diplomat's arsenal, not his replacement.

A. In dissecting a diplomatic document in digitalised form at the ministry, the paternity exercise is made simpler through hyperlinks. The score of each side in the simple two party negotiating model where all inputs clear instantly into the final agreement is thus more easily arrived at.

Standard treaties. Databases have already been developed for them thus permitting diplomats to avoid the task of re-inventing the wheel. They only have to add the few relevant, if any, additions or amendments to make the particular treaty as tailor-made to their country at that particular moment in time as possible.

These "standard treaties" are unlike and in sharp contrast to totally customised treaties arising out of a particular crisis. (See the Exchange of Letters between Tariq Aziz and Kofi Annan 13/11/1998 and pursue its "diplomatic trail".) 
B. Following the "diplomatic trail" in digitalised form is also made easier, in the more complex model where the two parties take time, rack their adviser's brains and strain the general public's tolerance, disturb NGO's patience and wreck MNC's cash-flows. Here all these inputs are available, can be accessed quicker, if not immediately, and given their relative weighting much more precisely than before. This is a research luxury compared to the previous position where one would have had to compare different files kept in different ministries or libraries.

At the more textual level, the trade-offs occurring between clauses as the final agreement is developed can be recorded more easily and influencing factors noted. Also, compromise formulae can be shown to have been derived from their parent clauses, according to or even against given written advice as the case may be.

C. Organisation. Digitalisation with its networking possibilities has vastly helped to overcome the inter-ministerial, inter-departmental or inter-agency problem. Where is the file? Who has the file? are (should) no longer remain a problem. Modern foreign ministries supervise other ministries' conduct of foreign relations with, for example, UN Agencies, by dividing responsibilities on a regulator/operator basis.

D. The human factor. However it remains doubtful to what extent digitalisation will be a perfect substitute for the human factor. Style, to put it mildly, is rather cramped in digital form. On the other hand, can cyber-sex be too far from boudoir diplomacy? Influence, charm, bloody-mindedness, bluff, are factors not easily conveyed in full on the Internet, though approximations have been recorded already.

E. Rubrics. The internal preliminary diplomatic discussions by e-mail now recorded, and immediately available, are a further rich source of diplomatic knowledge. Their instant hyper-links replace the value of rubrics in old files. Moreover, the advantage of opening up a draft or final diplomatic document for comments and discussion between the diplomatic community (existing and retired) are a boon for distance learning via the Internet. They will be a further recorded source of diplomatic knowledge.

To conclude, the method sketched only in outline here demands further development to increase the opportunities for diplomatic solutions as alternatives to the use of force. 


\section{KNOWLEDGE MANAGEMENT IN THE MINISTRY OF FOREIGN AFFAIRS OF MALTA Gaetan Naudi}

This presentation will focus on how in the Ministry of Foreign Affairs (MFA) of Malta we have tried to apply the various changes which have been taking place all around us turning the end of the century into an informatics era. My presentation will be given from a viewpoint that is neither academic nor of diplomats, two camps presented at this conference, but one of business management. In it I will show how ICT (Information and Communications Technology) matters look like in the practice of one fairly large organization, as the MFA with its diplomatic network is, and also what has been done in computerized knowledge management at the MFA.

In my presentation I will be very conscious to follow that piece of sound advice: "A speech should be like a lady's dress. It should be long enough to cover the whole subject, but it should also be short enough to remain interesting."

The public service in Malta for the past decade has been trying to address several issues in order to try to make it more professional in its approach. There have been various sectors which have been addressed. Two of them are the upgrading of the infrastructure and radical public service reform, including an intensive development of human resources. Now, evidently we are all agreed that the value of knowledge is information and facts which have been brought together by human beings. Diplomacy can be perceived as the interaction of this information and we would also have to communicate it easily, quickly and efficiently.

\section{STRUCTURE OF THE MINISTRY WITH EMPHASIS ON ICT INVESTMENT}

The MFA has attempted to follow in the wake of the changes which are taking place on a national scale, and the country has invested very significantly in the development of human resources. And we also, in that, believe in the message of this particular saying, the author of which is unknown to me: "If you want one year's prosperity, grow grain. If you want ten year's prosperity, grow men and women." It is very significant and it also explains the importance that we give to the human person.

I intend to give an overview of the Ministry of Foreign Affairs, first of all. The MFA in Malta, the head office in Malta is presented in Table $1 .{ }^{1}$

Table 1: Structure of the Ministry

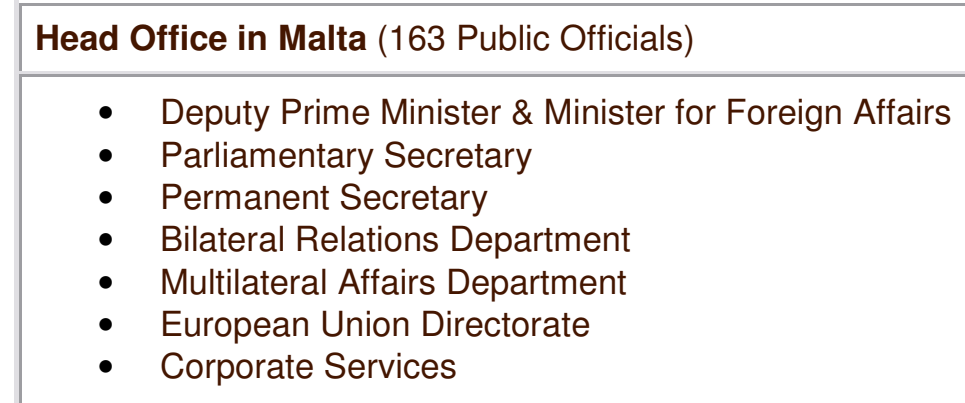

Overseas (51 Maltese Diplomats, 105 Locally Engaged Personnel)

- 19 Embassies/High Commissions

- 3 Consulates 
The Corporate Service Directorate provides the support services for all the Ministry. That is the department which I head at the time of this conference. We have 163 people staffing head office in Valletta. Table 1 also shows the diplomatic network abroad comprising 19 embassies/high commissions and 3 consulates, which are staffed by 51 Maltese diplomats and who are supported in their own way by 105 locally engaged personnel.

How this organization, the MFA head office and its diplomatic network-its human and material resources taken together-are financed is shown in Table 2.

Table 2: 1999 Budget

\begin{tabular}{|l|}
\hline Recurrent Expenditure: Lm 5,849,000 ( EURO 13.4m US\$ 15.3m) \\
\hline $\begin{array}{l}\text { - of which 56\% (Lm 3,285,000) is for Personal Emoluments } \\
\text { and 2\% (Lm 114,000) is for Training, both locally and abroad }\end{array}$ \\
\hline Capital Expenditure: Lm 331,000 ( EURO 760k US\$ 860k) \\
\hline - of which 52\% (Lm 171,000) is investment in Information and Communications \\
Technology \\
\hline
\end{tabular}

Special emphasis is given to the capital expenditure on ICT as a fast growing (52\%) component of overall capital expenditure, and also (see Table 3) the fast pace in investment in IT with the striking evidence of the growing ratio of number of PCs to clerical personnel.

Table 3: Investment in ICT

\begin{tabular}{|l|}
\hline - 1997 to 1999: Lm 728,000 ( EURO 1.7m US\$ 1.9m) \\
\hline - Pre 1997 - Directly out of Management Systems Unit Ltd's budget \\
\hline - Ratio of PCs to Clerical Personnel \\
- 7 officers in Malta \\
- 5 officers overseas \\
- 1 1999] 1 PC to: \\
\end{tabular}

\section{ORGANISATIONAL CHANGE AND REACTIONS TO THE INTRODUCTION OF IT}

Obviously nothing comes without its own frustration. In bringing organizational change we have, naturally, experienced various expressions of disgust and scepticism. Some of them were: "It will never work!" "It's too bureaucratic." Some people have tended to say: "It's not 
only that you are introducing a new system over here but the way you're introducing it is just another bureaucratic procedure." This other frustration I must admit that we still experience today even though it was voiced very loudly before we introduced IT in a big way. These, and others shown below were some of the comments which were made to us when we were trying to automate the processes in the Ministry.

- It'll never work!

- It's so very bureaucratic.

- What if it breaks down at the most inapporpriate moment?

- It's inflexible.

- It's slow.

- Adapt myself to a system, not have one tailored for my needs?

- It keeps me too desk-bound!

What fears did we experience with the introduction of IT?

- Change

- Feeling of insecurity

- Impersonal management

- Not knowing what is involved

- More paperwork

- Lack of visible improvements

\section{Change and feelings of insecurity}

Everyone knows that when computers were first introduced to the world, there was a talk about people being made redundant and that we'll only have machines working for us. This commonplace is perfectly illustrated with the following story:

The factory of tomorrow will have two employees: a man and a dog. The dog will be there to keep the man from touching the equipment, whereas the man will be employed in order to feed the dog.

So, people did tend to have this particular concern that once the PC was on their desk they will find themselves out of a job, the next day.

Worthwhile mentioning was fear of impersonal management. People say: "Yesterday I could go with a problem and discuss it with my boss, whereas today I have to send him an e-mail and he answers me when he decides to see my e-mail." That means that one loses direct communication.

We have tried to invest as much as possible in IT training, to dispel another fear, the one of "Not knowing what is involved."

In time people became accustomed to these new radical changes in the way they should be working and performing their duties, even though some of them may have recalled that saying of Georges Pompidou: "There are three ways where one can ruin oneself: gambling, women, and technology. Gambling is the fastest way, women are the most pleasant, but technology is the most certain way."

After some time they realized that unless they learned to ride the wave, they would be swamped down and round. So, they adopted a more professional approach. We actually have invested heavily in development of our people. Today in the MFA practically everybody has been to some sort of course on IT familiarization, at the very least, and the training programme is an ongoing one. 


\section{AN OVERVIEW OF ICT APPLICATIONS AND PROJECTS}

How did we apply the ICT revolution to our own needs, how could we analyse and disseminate information that was available at our end?

First of all, the government agency MSU (Management Systems Unit), later reorganized and renamed MITTS (Malta Information Technology and Training Services: ), helped and supported us to develop a number of applications.

We have a specialized library stocked with around five thousand titles and MITTS has developed a simple, stand-alone, DOS based (in FoxPro software) database application for that library.

Obviously, we have had a Large Area Network (LAN) installed in the ministry, which was unheard of until as recently as five years ago. We also developed a Country Profile application, whereby we have on file profiles of the various countries we deal with.

We are, at the moment, developing a scholarship system, which is a sort of an advertisement of what scholarships are being made available by overseas institutions or by foreign governments, and management of applications and selection process. A stand-alone database application in the scholarship section of the MFA is functional and it is planned to be linked to special information focal points in Malta and Gozo utilising the government's Wide Area Network. When this is eventually installed it will be possible for a person to apply directly from those information points. Currently, all scholarships available to the general public are advertised, besides the local media, via the Internet medium on the website of the Ministry.

It is possible for a person to download even the application form from home and send this in. It would be processed without him/her ever needing to catch the bus or drive into Valletta, even though the longest drive in Malta takes only 3/4 of an hour, but still, people think the fact they are staying at home and doing business is how the modern society should be.

Then this beginning in IT implementation brought the ministry close with the Mediterranean Academy of Diplomatic Studies. We realized that there was a need for the Academy to put into practice the various applications which it was developing over time for the diplomatic field, whereas the ministry itself had the professional resources and thus a partnership has been built between the two agencies.

We started off by developing the full-text International Treaties Database whereby the texts of various treaties, which were made, signed and ratified over years were put on file, and we could also access all reference information about a particular treaty, whether it had been acceded by Malta or whether the treaty had been acceded by other countries. Policy Statements followed the same scheme and both databases have been now included in the DiploWizard system.

We have also developed a website, a very informative website (). It is structured in a way which makes it very easy to go from one piece of information to the other.

Perhaps, our major achievement was the WAN (Wide Area Network) project which enables us to link up with our missions overseas. At the moment it includes two missions but eventually we should have more missions integrated in the system.

\section{DATA SHARING}

We have already said that diplomacy is the interaction of information and communication. The following list highlights some main points that can be deducted from this interaction with regards to sharing of data. 
- Encourages common utilisation of individual's potential.

- People have been put in synergy by the ICT technology and data sharing.

- Enhances collective effort.

- Creates standards and conventions.

When one talks about communication, one would have to be very cautious about how to communicate. Ambassador McDonald spoke during this conference on the need for nonvocal communication. This is something that we have to emphasize all along, that whatever system we adopt, whatever system we develop, we have to be sure that we have the means how to communicate the message in the proper way. This reminds to the following story.

The lord of a castle was standing on the rampart and he saw a knight coming in on a limping horse and the knight was all covered in blood and with bent armour. The lord of the castle asked the knight: "What has happened to you?"

The knight replied: "Well, sire, l've been looting, and l've been burning, and l've been killing your enemies up in the north of the country."

"But I have no enemy up in the north of the country," said the lord of the castle.

And the surprised knight said: "Well, I think you have now, sire!"

While still on the middle ages metaphor it is the right moment to switch to DiploWizard, which has another middle age mythological metaphor in its name although it is applied to modern diplomatic practice. DiploWizard is a knowledge management tool for diplomats that was given prominence during this conference and that is installed as an Intranet application on the LAN of the MFA (Internet version available at: ).

DiploWizard should be used in day-to-day working practice, and used in a way as to give results. DiploWizard is not a concept which should be taken in any other way. Key results and benefits of DiploWizard, thus are:

- $\quad$ easy access to information databases;

- fast, flexible, easy to operate, efficient programs;

- always and across the organization available (being Intranet application);

- expandable;

- up-to-date information.

\section{CONCLUDING REMARKS}

In concluding this review of a real system, that being the Ministry of Foreign Affairs of Malta, and of a transfer of technological achievements and theory into practice-into working practices of the institution over a number of years, I would like to stress again that nothing can be done without the human involvement, in other words, it is men and women who make things happen, for as Clarence Day said: "Information is pretty thin stuff unless mixed with experience."

Therefore, achieving the higher level of utilization of ICT, meaning knowledge management, in the institution will only be possible if the condition above is respected and fulfilled.

\section{NOTES}

1. All data in this paper is correct and accurate as of 31 January 1999, when this presentation was given. 


\title{
LEADERS' RHETORIC AND PREVENTIVE DIPLOMACY - ISSUES WE ARE IGNORANT ABOUT
}

\author{
Drazen Pehar
}

Analysis of the rhetoric that leaders use to explain, justify, and pre-program their foreign policies seems to offer a sound basis for diplomatic prevention of armed conflicts. There are two reasons for believing that this is the case. First, rhetoric, together with historical memories, cultural practices etc., belongs to the set of spiritual and psychological causes of war. Rhetoric usually precedes armed conflicts and hints at the important issues over which the upcoming war will eventually be fought. Thus, through leaders' rhetoric, one can witness a not yet fully materialized "war of minds". This may then, ideally speaking, prompt one to try to remove the spiritual incentive to fight a war; to cool down the "war of minds" before it turns into a "war of arms". Second, the rhetoric that leaders use is, as a matter of principle, extremely rich in imaginative projections, in fanciful descriptions of the international affairs of leaders' concern. The rhetoric is therefore always half a dream, and half a reality, which, from the perspective of critical and rational argumentation, makes it fragile and relatively easy to debate. More than one plausible rhetorical device has the potential of explaining away complexities of the international system, and the "king's" one may not be the best one. Leaders' rhetoric thus being principally fragile, debatable, and open to alternative readings, one again has a chance to prevent wars from erupting simply by showing the fragility of a leader's narrative and of the metaphors he or she chooses.

Such a tool for conflict prevention was tried during the public debate in the U.S. before the U.S.-led operation "Desert Storm" against Iraq was launched. A leading linguist and cognitive scientist, George Lakoff of the University of California at Berkeley, wrote a seminal paper "Metaphor and War", in which he tried to deconstruct the rhetoric U.S. president George Bush used to justify the war in the Gulf. Lakoff hoped to incite a public debate which would forestall the U.S. preparations to launch a war against Saddam, and he hoped his grassroots, Internet mediated diplomacy might save "tens of thousands of innocent lives".

Lakoff's idea was simply to show how the system of rhetorical schemes, the metaphorical system Bush applied in advance of the Gulf war, kept important aspects of international realities hidden, and did so in a very harmful way. Lakoff focused on several metaphors, but it will suffice to present the two most important ones: the metaphor of "Saddam as Hitler", and the metaphor of "Kuwait as innocent victim of a villain's aggression and rape". Bush, in comparing Saddam with Adolf Hitler, was, according to Lakoff, wrong on several counts. The predicament of the U.S. in 1991, after Iraq's excursion into Kuwait, did not resemble the predicament of the western powers at the Munich conference with Hitler. Iraq, for instance, was not comparable to Germany in the late 1940s. Besides that, there was no reason for anybody to believe in 1991 that Saddam was an irrational villain, like Hitler was, ready to take the riskiest action and to declare war against the entire world of liberal democracies. Lakoff thus rightly states that "the Hitler analogy also assumes that Saddam is a villainous madman. The analogy presupposes a Hitler myth, in which Hitler too was an irrational demon, rather than a rational self-serving brutal politician. In the myth, Munich was a mistake and Hitler could have been stopped early on had England entered the war then. Military historians disagree as to whether the myth is true. Be that as it may, the analogy does not hold. Whether or not Saddam is Hitler, Iraq isn't Germany. It has 17 million people, not 70 million. It is economically weak, not strong. It simply is not a threat to the world. Saddam is certainly immoral, ruthless, and brutal, but there is no evidence that he is anything but rational."

According to Lakoff, it was also incorrect for Bush to draw a comparison between "Kuwait" and an "innocent victim of a rape". Kuwait was an oppressive monarchy, resented by most Arab countries because of its discriminatory policy against the cheap labour it imported. Kuwait further committed a serious injustice against Iraq after the war between Iraq and Iran, by having refused to assist the war-exhausted economy of Iraq, which fought the war against Iran partly for the benefit of Kuwait itself. And finally, Kuwait launched a de facto economic 
war against Iraq by, as Lakoff points out, "overproducing its oil-quota to hold oil prices down" and thus lowering Iraq's chance to fight its post-war poverty.

Lakoff concluded his analysis with two important messages. First, the rhetoric Bush used to prepare the U.S. for a major war was fundamentally wrong since it presented America as a purely selfless hero, while America was a self-interested state eager, perhaps too eager, to protect the oil-pipelines on which its economy to some extent depends. According to Lakoff, the U.S. should not fight a war lacking clear rationale and an unambiguous enemy, following the rhetoric of a misleading leader. Second, he called upon the Internet browser community to spread his message for what seemed to be a very humanitarian purpose: to renounce the possibility of war and to try alternative means to find an overall solution benefiting Iraq, Kuwait, and the U.S. along with other western democracies. Lakoff's "Metaphor and War" was thus a critical analysis of a leader's rhetoric combined with an attempt to serve as an unofficial diplomat trying to prevent a conflict by putting into use the most democratic medium of today's communication to familiarize the public with his sophisticated expertise. Unfortunately, it did not work and America is still at war with "the dictator". I will not try to explain why an attempt to prevent a conflict through a sophisticated analysis of a leader's rhetoric failed: it may have failed for an infinite number of reasons. But I believe that Lakoff's attempt is worth probing more extensively, since it may tell us something important about many things we, as diplomats, humanitarian officers, members of an international team for crisis management, or public and elite opinion analysts, are deeply ignorant about.

\section{PREVENTION THROUGH RATIONAL ARGUMENTATION}

The first thing we can recognize in Lakoff's piece is his affiliation with the tradition of the Enlightenment. He at least implicitly believes that one is in a position to reach the population in a purely rational state of mind, and that the bad things happening in politics are due to the inclination of leaders to mislead and misinform people. In "Metaphor and War" Lakoff quite explicitly said that the Gulf War would serve the interests of only one particular establishment, the military-industrial one, and that Bush was simply trying to sell the interests of that particular establishment to the American people under the guise of "vital national interest". Bush thus offered a theory modelling the relations between a number of countries and made the rest of the country over which he presided re-shape its political preferences, i.e. desires, in accordance with the model. Had Bush not used the means of the above rhetoric to provide the U.S. action against Iraq with a deeper, or superior, meaning, American people would not have started considering Saddam their mortal enemy. In other words, Lakoff holds that the stream of causes leading from rhetoric through human mind to eruption of full-scale war, is approximately as in the chart below:

\section{/RHETORIC/ leads to /EXPLANATORY MODELS/ leads to /BELIEFS ABOUT THE OUTSIDE WORLD/ leads to /DESIRE TO CHANGE THE WORLD/ leads to /BELIEFS ABOUT THE ACTIONS LIKELY TO CHANGE THE WORLD/leads to /DECISION TO WAGE A WAR UPON LEGITIMAZION OF THE DECISION/.}

Notice here that Lakoff believes that the primary role of rhetoric is to provide knowledge about foreign affairs and to explain the mechanisms responsible for certain events. Notice further that Lakoff believes that the cognitive part of our brains has priority over the volitional, or emotional part of our brains, and that our beliefs give shape to our preferences and not viceversa. Lakoff's theory stipulates that the offer of alternative, metaphor-cleansing pieces of real knowledge should tear the war-causing desires apart and wake one up from the bizarre dreams in which "Saddam is Hitler", while "Kuwait is a small, unprotected and innocent country raped by the devil". Finally, notice that, along the lines Lakoff proposes, preventive diplomacy, based on deconstruction of leaders' rhetoric, should not lead to controversy at all but that once one presents both inductively and deductively valid arguments against the leaders' rhetoric, the temptation to wage a war should simply disappear. It is certainly under the conditions of a democratic environment and in the spirit of equality and tolerance that such an open presentation of arguments is likely to take place and deliver positive results. But do our minds really behave in the way Lakoff believes? Do we really focus primarily on the 
cognitive, information-processing aspect of metaphors? Do our minds really first form an image of their environment, upon which they then shape, construct, or reconstruct their preferences, their volitional parts? If we compare our minds with a colourful cuisine, does the descriptive dimension of our rhetoric really play the role of chief cook?

I am raising these questions because rhetoric performs several functions. It first, but not foremost, serves to create an image of whatever it refers to. If I compare Saddam with Hitler then my image of Saddam differs from the image I would have, had I compared Saddam with Martin Luther King. But rhetoric also serves to raise emotions. If I compare today's Bosnia with the triangle between China, U.S., and U.S.S.R from the early 1970s, my emotions concerning Bosnia would differ from the emotions I would have had I compared Bosnia with a patient dying in a coma. And, last but not least, rhetoric serves an outstandingly important function of defining and redefining one's identity. I say very different things about the identity of the people of a nation when I say that they always behave like an elephant in china shop, on the one hand, and when I say that they are only a "shooting star", on the other. The paradigms that nations adopt to forge or promote their own identity are always expressed through a number of historical analogies, and thus inevitably contain a rhetorical ingredient.

Rhetoric performs several functions, and this implies that several parts of the mind feel a need for rhetoric, and are equally operative in its creation. This further means that the origins of the rhetoric that leaders use to explain and prepare their foreign policies are multiple, and that what seemed to be a sound theory explaining the chain of causation of armed conflict, the theory George Lakoff proposed, may now encounter some complications. Lakoff also proposed a method of conflict prevention one could call "prevention through argumentation". It almost needs no mentioning that the method itself could now run into troubles. Why?

Imagine an individual with a strong in-built self-image or identity, who is getting involved in a situation he or she understands only partially. The basic question the individual will usually raise is not "What else do I need to learn to fully understand this situation?" but rather, "What can I do to reconfirm my identity under conditions not fully transparent to me?" The individual will probably try to adapt understanding of the conditions to his or her self-image, and not other way around, because, speaking psychologically, it is more dangerous to question one's identity than to question one's understanding of conditions which are not fully compatible with all relevant evidence. When one is forced to choose between leaving the self-image intact while the understanding of the environment remains incomplete, on the one hand, and deepening the understanding to fit relevant evidence, which would cast doubt on one's sense of identity, on the other, the individual is likely to choose the former. Otherwise he or she would have to suffer for a while, and to develop a new definition of his or her identity, which is a challenge few people are ready to accept.

Applied to Lakoff's critique of the rhetoric Bush used to justify the war in the Gulf, the above psychological pattern would imply the following explanation. America has a strong sense of identity, and like other states, it chose a particular historical moment of its extreme assertiveness to serve as its role-model, as the core of its self-image. That moment, that rolemodel meeting the need for identity, is the America which won the Second World War. Now, whenever a crisis occurs in international affairs, American leaders start with the assumption that the crisis is similar to the crisis preceding World War Two, because America's self-image leads them to choose the narrative and the rhetoric most suitable to the country's inner sense of identity. They therefore project the imagery of the past Word War Two experience into new crises and new challenges almost automatically, and cannot really change this process. The sense of identity cannot be challenged easily, and if America sees itself as a "selfless hero leading a coalition of the free world against dictators and rapists of this world", it will read empirical evidence accordingly, and, if necessary, neglect data not fitting the imagery of the Second World War. With regard to Lakoff's critique of the rhetoric President Bush used, a proponent of the theory of identity would say that it does not really matter whether Saddam is both an irrational and ruthless dictator, or just a ruthless dictator. America reacts to either ruthless or irrational leaders with the determination of the great World War Two victor, and will do anything to punish the leader who severely violates the principles of international law, as it did with Hitler. The rhetoric that Bush used to justify the Gulf War was thus not rhetoric he 
simply picked from a menu. He was actually not in a position to deliberate and choose the means for persuading the American people. He was just somewhat semi-consciously aware of the key layer of the American self-image, which implied that Saddam must be Hitler while Kuwait must be a victim of a brutal war machine. Bush's pre-Gulf War rhetoric came not from the cognitive, information processing part of his brain. It came from a deeper layer, from an inner sense of identity, from a drive to take an action for the sake of the actor's identity, from the need to confirm the self-image, the self-definition.

For that reason, Lakoff's interpretation of the chain of causation connecting leaders' rhetoric with eruption of war may be too simplified, too neat. A host of inner, mental processes compete for the role of the key cause of lethal aggression, and consequently, a number of alternative interpretations of the etiology of the Gulf War and the rhetoric that led to it have been offered. The famous psycho-historian, Lloyd deMause, proposed a reading of the Gulf War which is similar to the above theory of identity, which, as we see, significantly differs from Lakoff's theory.

\section{PREVENTION THROUGH RE-CHANNELLING}

DeMause believes that the decision to launch a war against Saddam was not motivated by considerations of political utility. According to him, it was launched to help America act out some of its 1990 and 1991 frustrations. In deMause's opinion, prior to the war with Iraq America had an intense need for inner, mental order, which one may compare with the sense of identity as described above. As anyone who needs to experience catharsis to recover a sense of inner identity also needs a symbolic stage on which to pull the basic role together, America needed such a symbolic stage too. DeMause argues, for reasons I will discuss below, that the stage America set to pull itself together was a stage with three characters: Terrifying Parent, Hurt Child, and Good Parent. Saddam's occupation of Kuwait offered America the first two characters, while Bush, in making the decision to wage war against Saddam, assigned to America the role of the third character. Thus, the war was inevitable. Good Parent had to punish Terrifying Parent to save Hurt Child. The rhetoric that was used to explain the policy towards Iraq was, according to deMause, a symptom rather than a cause of the Gulf War. It was, in actual fact, an expression of the fantasies that America had to cultivate for a while to restore its inner core. With that we come to deMause's explanation of the etiology of armed conflicts and the role that rhetoric plays in that etiology.

DeMause presented his theory of armed conflicts and the rhetoric that leaders use to prepare a nation for war in his paper "Historical Group-Fantasies". He first notes that a high percentage of the figures, metaphors, similes, and symbols that leaders use in advance of a war group around the image of a "body trying to set itself free", as well as around the image of a "mother-child relationship". In other words, he notices that the official discourse servicing war propaganda frequently refers to the "need to protect mother", the "need for mother to protect her children", a "state of pregnancy", a "birth-giving". One needs here to recall idiomatic expressions such as "the nation fought for survival", "the nation fought out its right to live", or the "birth of nation". Based on this observation, as well as on a number of additional ones, deMause draws the conclusion that before war actually breaks out a group-fantasy catches the minds of the people, who then simply have to experience the group-shock of war to live through the fantasy. DeMause believes that the group-fantasy is the fantasy of rebirth and that people put their lives at risk in times of war for one single purpose: to re-experience or re-enact the trauma of birth. This explains why the rhetoric is rich in the aforementioned imagery. He thus, in an elegant way, answers the question as to why people decide to wage war despite the fact that war brings more losses than gains. He says that people simply see in war something that war is not, and that one can understand this very easily by looking deeper into the rhetoric that precedes armed conflicts. The Gulf War was about a Hurt Child who needed protection from a Terrifying Parent, as we saw. It was not about soldiers, oil, and sovereignty. But notice here to what an extent deMause's theory differs from Lakoff's theory.

DeMause believes that war, or serious inter-group enmity, is a must-be. He further believes that the key cause of war is a group-fantasy, the fantasy of rebirth, something many people of 
similar background share. The trauma of birth is not restricted to a particular establishment. It concerns almost everyone, and it shapes almost everyone's identity. The trauma recurs time and again. Both incidence and abundance of wars, together with their eye-catching irrationality, prove that the cognitive part of our brains does not partake in their making. The rhetoric explaining, preparing, and inciting wars is not a conceptual tool for understanding international relations. The rhetoric is literal truth. It is a creation, not a description of the world. This means that for those who in 1933 said that their mother "Germany" needed to expand to embrace all her children, and to ultimately give birth to one gigantic nation, the land referred to had the meaning of a real mother experiencing real birth pangs. The rhetoric comes from our deepest memories, the memories of birth, and it does not follow the rhythm of our rational thoughts. Finally, its charm is overwhelming and irresistible. Since I presented a chart illustrating Lakoff's theory, I will do the same for deMause's theory.

\section{/BIRTH/ leads to /TRAUMA OF BIRTH/ + /INCIDENT, DISAGREEMENT, AND THE LIKE, BETWEEN GROUPS/leads to /RHETORIC OF STRANGULATION-A NEED TO RELEASE THE CHILD-PROJECTION OF THE BIRTH IMAGERY/ leads to /FANTASY OF REBIRTH/ leads to /CHILD'S LIFE AT RISK/leads to /WAR/.}

It may sound strange, but deMause does not believe that wars are quite inevitable. I deliberately exaggerated when I said that, according to deMause, war is a "must-be". DeMause himself holds that conflicts may be prevented. But his vision of preventive diplomacy differs from our official concept of prevention like heaven differs from hell, and, as one can easily predict, conflict prevention, in deMause's view, is not something that foreign ministries or diplomats should be doing. DeMause believes that there are actually three ways to prevent conflicts. The three represent what I like to call "prevention through re-channelling", which, of course, significantly differs from Lakoff's "prevention through rational argumentation", which certainly is something that foreign ministries and official diplomats are able, and more than welcome, to do. "Prevention through re-channelling" basically takes three forms: first, a leader may understand that his people have started to approach a very dangerous state of mind, the state of obsessive need to re-experience the trauma of birth. $\mathrm{He}$ may then offer his own sacrifice. He may enact the drama of birth himself, using himself as a scapegoat for the "hungry" masses. He may offer himself as a screen onto which his people will then project their inner drama of rebirth. DeMause holds that this is exactly what Nixon did through the Watergate affair. Second, a leader may simply simulate an action which will meet the need of the people to re-enact the trauma of birth. The leader should, according to deMause, use the opportunity of increased international tension to allow the people to let off steam by pretending he is ready to launch a war but really launching a very limited quasiaggressive action. The leader thus plays the role of a movie director, who, by taking only a half-complete, risky but not harmful or lethal action, satisfies the public's need to see and feel "blood and suffering". DeMause claims that Dwight Eisenhower was a mastermind of this type of "prevention through re-channelling". For instance, the actions Eisenhower took in late 1954 during the period of increased friction in relations between America and China was an example of the second means of conflict prevention. The third, and final, way deMause suggests to try decreasing the number of conflicts taking place in this world is through appropriate child-rearing. If one brings up a child in a safe environment, and is sensitive to the child's need to re-experience the trauma of birth, then the likelihood that people raised thus will need to act out the trauma through political means or lethal conflicts will decline. I like to call the third type of conflict prevention "prevention through the most timely re-channelling".

Notice here to what extent deMause's conflict prevention measures differ from all the wise things one learns in schools of diplomacy, international relations and law. Just imagine the consternation a junior diplomat would cause by proposing to his minister to propose to a head of state to initiate a mini-Watergate to calm the innate need of his people to re-experience the trauma of birth, which would definitely save "tens of thousands of lives", etc. Or imagine a diplomat deciding to resign from the ministry in order to rear a child in ways more sensitive to the child's experience of birth in order to aid in the prevention of future conflicts. Sounds silly, but if one believes that re-channelling is a better way to cope with the lethal and aggressive parts of our nature, then the ways of classical, formal diplomacy are definitely far less promising than those deMause proposes. 
DeMause is not the only theoretician who believes that rhetoric originates from deep and irrational layers. David Campbell, for instance, holds that the rhetoric of danger and of the alien is inherent to our making of foreign policy, and that without a rhetoric to describe the existence of a threatening other, neither states nor their foreign policy element would have an identity. There is no identity without an enemy. Campbell thus believes that rhetoric comes from a need for identity, that it is based on quasi-perception of a threat, and that without the sense of threat states would not have anything to do internationally. He writes that "the constant articulation of danger through foreign policy is thus not a threat to a state's identity or existence; it is its condition of possibility". Campbell in actual fact time and again voices his belief that the foreign policy element of the modern state is comparable to the role the church used to play in the age of pre-modernity. Like the church, which "relied heavily on discourses of danger to establish its authority", modern states rely on rhetoric and "evangelism of fear", to secure and maintain their identity, and finally, to maintain their authority through promising their "followers" salvation, immortality, and a role worth fighting for. Campbell's theory is very similar to deMause's, and can be summarized along the following lines.

Leaders' rhetoric comes from the deepest layers of our selves. It forms and maintains our political identity as it meets our most basic need to have all things threatening to us sharply defined and kept separate from ourselves. The concept of preventive diplomacy through "rechannelling" would be a clear implication of the tenets of Campbell's theory. Campbell himself would probably say that rational argumentation would do no harm to the discourses and the rhetoric of danger, and that one should find better ways to meet our needs for identity, protection, and salvation, in ways less harmful and less threatening to others.

\section{THE VEIL OF OUR IGNORANCE}

There seems little doubt that leaders' rhetoric plays some role in the etiology of armed conflict. There also seems little doubt that analysis and deconstruction of leaders' rhetoric offer an attractive method to prevent a "war of words" from sliding into a "war of arms". However, our key problem lies in the fact that we do not yet know where rhetoric and metaphors come from. What parts of our minds are responsible for the generation of metaphors in the context of international politics? Is it the part which strives for objective knowledge, for objective theories that retain their validity in all imaginable contexts of our action? Or is it the part which cares for maintenance of our self-image, our inner sense of identity? Or is it perhaps a deeper part, more irrational than the first two, the memories of prenatal stages, of our birth-fantasies?

There is another possibility. It is quite possible that the locus of origins of both rhetoric and metaphors changes from case to case, depending on complexity and severity of conditions. But we do not know this either. We may start with the assumption that some metaphors reflect our biological design (type A), some reflect our historical experience (type B), while others reflect our daily practices (type C). For instance, if I said "Malta is my mother", then the metaphor would reflect my biological design and have a deMausean flavour. If, on the other hand, I said "Kissinger is Prince Metternich reborn", then the metaphor would reflect our historical experience and have the flavour of an identity theory, so to speak. And finally, if I said "today's Bosnia resembles a victim of a traffic accident in which all drivers violated a number of traffic-regulations", then the metaphor would reflect my daily, practical experience and would have the flavour of the theory of rational argumentation. Now, the psychological theories in which we believe would predict that the more complex the conditions in which mental imagery and metaphors occur, the more likely our minds to regress. Thus, rhetoric of type $A$ is most likely to occur under the most complex conditions, rhetoric of type $B$ is most likely to occur under conditions of average complexity, and rhetoric of type $\mathrm{C}$ is most likely to occur under the least complex conditions. But, first, the complexity concerned is complexity relative to the mind which perceives it. Unfortunately, we are not yet in possession of a measure of that kind of complexity, although the sciences of complexity seem to accumulate more and more extremely interesting findings along the borderlines of math, physics, and molecular biology. Second, even if we come into possession of such a measure, no one will be able to isolate perception of complexity from arbitrary and randomly fluctuating factors. 
Leaders will probably continue enjoying the privilege to use rhetoric of type $A$ even under the least complex conditions of international politics, contrary to what the aforementioned theory predicts. Will they ever stop dramatizing non-dramatic events, a natural inclination because drama gives them an opportunity to portray their role as more important than it actually is? Will they ever learn that the line dividing drama from hostility is a thin one? We may only guess. Are they, and are we ourselves, capable of learning that? We do not know that either.

Finally, I would like to emphasize that as statecraft itself is highly dependent on the image of human nature it considers credible, the methods of preventive diplomacy debated here depend heavily on the theory of leaders' rhetoric one considers credible. Since we remain ignorant about the origins of rhetoric, about conditions of its appearance as well as about its effects, the measures of appropriate rhetoric-based conflict prevention remain unclear too. The issue as to whether one should conduct classical prevention through rational argumentation, as Lakoff proposes, or prevention through re-channelling, as deMause proposes, thus remains unresolved. Would it be better to opt for face-to-face prevention, with its immediate, short-term, and individually directed effects? Or to opt for prevention oriented towards the culture of an entire group, which, with its indirect, long-term, and slowly accumulating effects, can hardly be subsumed under the concept of preventive diplomacy as run by professional servicemen of foreign ministries? There also remains the third and safest way. Ignorant as we are, perhaps we should use both ways until we find which of the two, and under what conditions, is better. 


\section{IVO ANDRIC ON DIPLOMACY}

Ivo Andric was born in Travnic, Bosnia, in 1892. Before the First World War he studied Slavic languages and history in Zagreb, Vienna and Krakow. His university studies were interrupted by the outbreak of the war, during which he was sentenced to three years in prison for his involvement with a nationalist, anti-Austrian organisation. After the war Andric continued his studies in Graz, where he completed his doctorate in 1924.

From 1920 to 1941 Andric served as a diplomat representing the newly established Kingdom of Serbs, Croats and Slovenes (later to become Yugoslavia). He was posted to various European capitals, and prior to Germany's invasion of Yugoslavia, in 1941, as Yugoslav Ambassador to Berlin. In 1941 Andric returned to Belgrade.

Andric began writing poetry before the First World War and published several collections of short stories between the wars. His best known works of fiction were written in Belgrade during the Second World War and published in 1945: Na Drini Cuprija (The Bridge on the Drina), Travnicka Hronika (Bosnian Story) and Gospodjica (The Woman from Sarajevo). Most of Andric's works are set in Bosnia and describe the people and history of this multiethnic region where for centuries eastern and western influences have met. In 1961 Andric was awarded the Nobel Prize for Literature, "for the epic force with which he has traced themes and depicted human destinies drawn from the history of his country. ${ }^{1}$

This note on diplomacy, published here for the first time in English with the kind permission of the Andric Foundation, is taken from Andric's Notes. It was translated into English by Celia Hawkesworth.

\section{NOTES}

${ }^{1}$ http://nobelprizes.com/nobel/literature/1961a.html

\section{SOURCES}

http://nobelprizes.com/nobel/literature.1961a.html

http://www.kiriasto.sci.fi/andric.htm

http://www.nobel.se/laureates/literature-1961-1-bio.html

\section{WHO ARE DIPLOMATS?}

\section{Ivo Andric}

It seems to me that there are more "failed people" in the diplomatic service of every country, than in any other profession, people who have stumbled through the wrong door and now no one can escort them out and they themselves cannot find the exit and go back. In other walks of life such a "lost" person is unnoticed, he sings in the choir which he does not help but nor does he harm it, so his voice and his ear cannot be appraised. In the diplomatic service circumstances oblige the majority of people sooner or later to act independently, to show who they are and what they can do.

I have not read much that has been written about the diplomatic profession, but everything I have read has seemed to me superficial and inadequate. And I would find it very difficult to have to give a specific definition and describe the basic characteristics of this calling. I could only say something about it in a negative way. And only on the basis of experience. 
It is not only that diplomacy "is not for everyone", but one can say unreservedly that only a small number of people really have the gift and vocation for this work. It is, of course, far harder to say what those people are like and what they ought to be like. But, let us try.

They are people of sound but straightforward intelligence, people of simplified and limited sensitivity and a cool heart, but not without heart or any sensitivity; capable of deception, but not closed and mysterious, still less underhand; strong, but not rough; quick and decisive, but not hasty or impulsive; realistic, sober, but not dry and dull.

They need to know a certain amount, but there should be no trace of erudition or pedantry in what they know, and their knowledge should agreeably surprise and perhaps impress those with whom they are speaking, but never embarrass, offend or shame them.

It is the same with their courage: they need to have it, and it should be sound and reliable, but they should display it only in extreme circumstances and bear it as they bear arms which everyone knows they have, but are never seen.

They must also have imagination, but only in a certain degree, enough for a man to see every issue from every point of view and with all its possibilities and immediate consequences; anything more than that is both dangerous for them and damaging to the work they are doing.

Who could confirm and list everything that those who wish to devote themselves to this service ought to be?

They should be versatile and straightforward. Not arrogant, but naturally self-assured, even at times proud; they should not despise small details (never, in any circumstances!) but they should know how to stay somewhere on the borderline of pettiness and pedantry; they should be conscientious in everything, but without excessive zeal; value the moment and always make use of it, but also know how to leave time to have its effect; they should have many, varied interests in people, objects, art, games and entertainments, but not surrender themselves to passion or the intimacy in which a man completely forgets himself; they should be a bit human, and never inhuman; ready for everything and capable of anything, but not heartless or monsters.

That means, in effect: living constantly on two levels, the personal, human one and the official, inhuman one, but never in any way showing or betraying to anyone on which level you are at any given moment, or better still: not yourself being completely aware of it, which is the surest way of not betraying yourself.

In a word, you need to be a person of a particular kind without appearing to be, but always and in everything to give the impression of an ordinary, average man. You need to have a hundred abilities, but strictly controlled in many different ways. In general one could say of people of this kind that their ability lies more in a good and proper balance between different qualities than in the value of those qualities themselves. So that, roughly speaking, while each of those qualities is average, the whole that they constitute should be original and above average.

There is much else besides that one should be-and not be-in this profession. Everything that has been said about it and which could still be said may be more or less accurate, but it would be mistaken to think that this would be sufficient or that it is something that can be defined briefly and simply, once and for all, for everyone. But one thing is certain: if an individual does not have at least some of the main qualities listed even residually in his temperament, character and upbringing and is not capable of developing them and applying them in a practical way in the course of his work-it would be better for such a person never to enter the profession. 
However, it is just the kind of profession that has external, brilliant facets which both attract and deceive people. For this reason it contains, more than any other profession, people who have stumbled through the wrong door. That is a great misfortune both for the service and for themselves. A mistake in the choice of vocation is paid for in all professions, but nowhere so dearly as in the diplomatic service. Whoever does not pass the test demanded of him by the profession will become a comic and pathetic figure in a service for which he is not suited but from which he cannot free himself, a wreck which carries on floating for a long time. That poisons the life and undermines the soul and creates wretches of a particular kind. This unusual and unusually difficult profession, which, in the most auspicious circumstances, drains and deforms people, can turn them into misanthropic misfits and potential suicides.

That is how the matter looks schematically, but of course this scheme is somewhat artificial and even within it there are not many striking instances of either successful or unsuccessful diplomats, while there is a whole scale of those who move between those two extremes. Halfsuccessful, quarter-successful. Those who after their first failures had the strength or the skill or the luck not to sink, but to find their place. And the opposite, those who had a brilliant beginning, but did not manage to retain their place and now live from their previous glory and wait in the shadows of a humbler position for a better opportunity which fails to appear.

And all this seethes and shifts in a constant race and competition for success and recognition, in fear of professional misfortune, envy and accident which may lie round the corner. For in this service, which appears more uniform and rigid than any other, there is nothing constant or certain: a person moves as though through a mist in which the light which glimmers intermittently bewilders and deceives the eyes more than it shows the path and enables a person to find his way. 